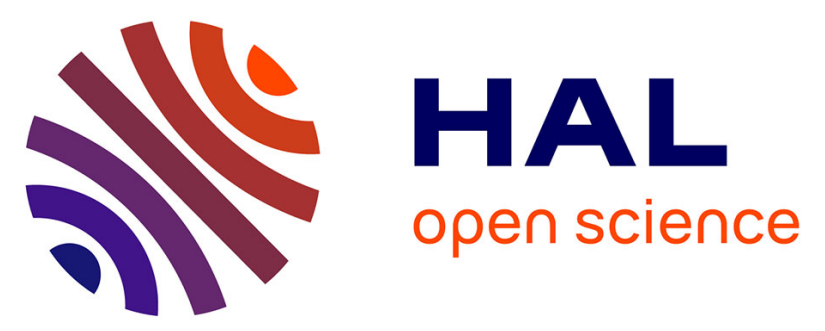

\title{
At the Interface of Isomorphous Behavior in a $3 \times 3$ Isomer Grid of Monochlorobenzamides: Analyses of the Interaction Landscapes via Contact Enrichment Studies
}

John Gallagher, Mark Farrell, Niall Hehir, Pavle Mocilac, Emmanuel Aubert, Enrique Espinosa, Benoît Guillot, Christian Jelsch

\section{To cite this version:}

John Gallagher, Mark Farrell, Niall Hehir, Pavle Mocilac, Emmanuel Aubert, et al.. At the Interface of Isomorphous Behavior in a 3 x 3 Isomer Grid of Monochlorobenzamides: Analyses of the Interaction Landscapes via Contact Enrichment Studies. Crystal Growth \& Design, 2019, 19 (11), pp.6141-6158. 10.1021/acs.cgd.9b00505 . hal-02365267

\section{HAL Id: hal-02365267 https://hal.science/hal-02365267}

Submitted on 6 Jan 2020

HAL is a multi-disciplinary open access archive for the deposit and dissemination of scientific research documents, whether they are published or not. The documents may come from teaching and research institutions in France or abroad, or from public or private research centers.
L'archive ouverte pluridisciplinaire HAL, est destinée au dépôt et à la diffusion de documents scientifiques de niveau recherche, publiés ou non, émanant des établissements d'enseignement et de recherche français ou étrangers, des laboratoires publics ou privés. 


\title{
At the interface of isomorphous behaviour in a $3 \times 3$ isomer grid of mono-chlorobenzamides: Analyses of the interaction landscapes via contact enrichment studies.
}

\author{
John F. Gallagher ${ }^{*}$, Mark Farrell, Niall Hehir, Pavle Mocilac, \\ School of Chemical Sciences, Dublin City University, Dublin 9, Ireland \\ and \\ Emmanuel Aubert, Enrique Espinosa, Benoît Guillot, Christian Jelsch* \\ $\mathrm{CRM}^{2}$, CNRS UMR 7036, Faculté des Sciences et Technologies, Université de Lorraine, \\ BP 70239, Boulevard des Aiguillettes, 54506 Vandoeuvre-lès-Nancy, France
}

\begin{abstract}
:
The physicochemical properties of a $3 \times 3$ isomer grid of mono-chlorobenzamides (Clxx) are reported with comprehensive studies of their crystal structures and interaction environments $(\mathbf{C l} \mathbf{x}=$ para-/meta-/ortho-chlorobenzoyl and $\mathbf{x}=$ para-/meta-/orthoaminopyridine substitutions). The nine compound Clxx series was synthesised from the three $\mathrm{p}$-/m-/o-chlorobenzoyl chlorides and three $\mathrm{p}$-/m-/o-aminopyridine isomers using standard synthetic procedures. Clxx exhibits some similarities to the related $\mathbf{F x x}$ and $\mathbf{B r x x}$ congeners e.g. the isomorphous behaviour of Clpp (para-Chloro-N'-(parapyridyl)benzamide) with several close relatives, and there are five isomorphous pairs of $\mathbf{C l x x}$ and Brxx crystal structures. Notably Clmp and Clpm both crystallise with $Z^{\prime}=4$ in space group $P \overline{\mathbf{1}}$ but show important differences. The overall lack of isomers crystallising with solvate molecules is noteworthy, except for $\mathrm{Clmm \bullet}\left(\mathrm{H}_{2} \mathrm{O}\right)$. In all Clxx crystal structures, strong $\mathrm{N}$ $\mathrm{H}$... N hydrogen bonds form, however, Clpo also crystallises as the unexpected Clpo_o polymorph with $\mathrm{N}-\mathrm{H} . . . \mathrm{O}=\mathrm{C}$ intermolecular hydrogen bonding. The Clxo triad (with orthopyridines) exhibits the expected cyclic $\mathrm{N}-\mathrm{H}$...N dimer formation with $R^{2}{ }_{2}(8)$ hydrogen bonded rings. The $\mathrm{H}_{\mathrm{C}}$ atom type, forming weak $\mathrm{C}-\mathrm{H} . . . \mathrm{Cl}$ hydrogen bonds, is the only favoured interaction partner of chlorine in Clxx. Conformational analyses (gas phase) together with crystal contact enrichment studies place $\mathbf{C l x x}$ in context and at the interface of hydrogen and halogen bonding interactions, though strong hydrogen bonding dominates. In Clxx the interaction energies with nearest neighbours are shown to contribute to most of the lattice electrostatic energies. The melting temperatures $T_{\mathrm{m}}$ show correlation with both molecular symmetry (Carnelley's rule) and total electrostatic energy of the weak interactions; in addition, these $T_{\mathrm{m}}$ values can be well predicted from a linear fit combining both descriptors. In Clxx, N-H...N hydrogen bonds dominate, largely in the absence of solvates, and with five Clxx forming isomorphous pairs with Brxx analogues; Clpp being isomorphous with several close benzamide relatives. Analysis of $T_{\mathrm{m}}$ reveals correlations involving both symmetry and electrostatic energies.
\end{abstract}

Keywords: Chlorine; Crystal structure; Conformational analysis; Contact Enrichments; Correlation; Electrostatic energy; Halogen; Melting Points; Pyridine.

Corresponding author:\# Dr. John F. Gallagher, e-mail: john.gallagher@dcu.ie School of Chemical Sciences, Dublin City University, Dublin 9, Ireland. 


\section{Introduction:}

In the natural world, bromine and chlorine derivatives are pre-eminent amongst the $>5000$ known and naturally produced organo-halogen $(\boldsymbol{R} \mathbf{X})$ compounds (where $\boldsymbol{R}=$ alkyl/aryl; $\mathbf{X}=$ halogen). ${ }^{1-6}$ As such, naturally occurring fluorine and iodine compounds are much less common (at ca. $5 \%$ of the total). However, the recent and substantial rise in the use of fluorine in pharmaceuticals ${ }^{7-8}$ and agrochemicals has been well documented. ${ }^{9-12}$ The role and application of halogen atoms (and especially fluorine) in organic materials and pharmaceuticals has attracted widespread scientific interest. ${ }^{13-19}$ The net effect of halogens on the chemical and physical properties of molecules and ultimately on research applications is an on-going scientific focus. ${ }^{1-19}$ The key differences between the $\mathrm{F}, \mathrm{Cl}, \mathrm{Br}$ and I halogens are best exemplified in their respective steric and electronic properties. How these impact on and modify steric properties and electronic molecular environments is important. While fluorine is usually classified separately to chlorine, the heavier halogens bromine and iodine are often classified together in terms of their general chemical behaviour. ${ }^{1-6,13-19}$ As such, organochlorine derivatives are generally studied as a distinct class and their behaviour and applications are readily contrasted with related organohalogens. ${ }^{1-19}$

The control and manipulation of intermolecular interactions lies at the heart of understanding molecular aggregation and therefore plays a central role in design and applications across supramolecular chemistry, crystal engineering and structural sciences. ${ }^{20-}$ ${ }^{24}$ Intra- and intermolecular interactions can play a role in influencing molecules towards the most favoured conformation(s) that are mostly retained in the crystal structure, ${ }^{25-30}$ but unusual geometries can be stabilised in the crystal state. The whole range of interactions typically observed in organic molecules ranges from strong hydrogen bonding e.g. N/O$\mathrm{H} . . . \mathrm{O} / \mathrm{N}$, through moderate hydrogen/halogen bonding ${ }^{31-39}$ through to $\mathrm{C}-\mathrm{H} . . . \pi$, aromatic donor-acceptor interactions to weaker contacts and van der Waals contacts. ${ }^{25-30}$

Halogen bonding, although recognised several decades ago has undergone an incredible surge in recent research activity. ${ }^{31-39}$ While fluorine is often treated as a distinct entity, it is usually convenient to evaluate all of the halogens $(\mathrm{F}, \mathrm{Cl}, \mathrm{Br} \mathrm{I})$ to determine their steric and electronic influences on molecular structure and aggregation. ${ }^{40-42}$ From a structural chemistry viewpoint, the role of chlorine in organic structures has not attracted the same attention as fluorine (fluoro-containing drugs) or the bromine/iodine pair (from a fundamental research perspective). ${ }^{7,8,13-19,31-42}$ Despite this and given the major role of chlorinated compounds in the agricultural industry as insecticides and herbicides, ${ }^{9-12}$ the present study serves as a template to examine the role of chlorine in a $3 \times 3$ chlorobenzamide isomer grid for direct comparisons with halogenated analogues. ${ }^{31-42}$ In previous work, the effects of methyl or fluorine were analysed for comparisons in series of benzamides and pyridinecarboxamides using extensive physicochemical measurements. ${ }^{43-46}$ Macrocycles derived from benzamides and devoid of strong hydrogen bond donors have been reported and the effect of halogen bonding on their $1 \mathrm{D}$ and $2 \mathrm{D}$ structures noted. ${ }^{47-49}$ Herein, a series of nine chlorobenzamide ( $\mathbf{C l x x}$ ) isomers as $\mathrm{ClC}_{6} \mathrm{H}_{4} \mathrm{CONHC}_{5} \mathrm{H}_{4} \mathrm{~N}$ (Scheme $\mathbf{1}$ ) is presented. The nine compound Clxx series is synthesised from three $\mathrm{p}-/ \mathrm{m}$-/o-chlorobenzoyl chlorides and three $\mathrm{p}-/ \mathrm{m}$-/o-aminopyridine isomers using standard synthetic procedures: these are analogues of the fluorobenzamide (Fxx) isomer grid. ${ }^{43}$ We present the structures, 
conformational analyses and physicochemical properties of $\mathbf{C l x x}$, together with highlighting correlations with crystal properties and molecular charge densities. 


\section{Materials, Methods and equipment}

All chemicals, materials, vendors, spectroscopic and crystallographic methods together with computational programs and equipment are as noted previously. ${ }^{43-46}$ Chemicals and silica (Davisil) were used as purchased from Sigma Aldrich, TLC alumina, silica plates from Fluka. Melting points were measured using a Stuart Scientific SMP40 automated melting point apparatus. IR spectroscopy was recorded using a Perkin Elmer Spectrum GX FTIR spectrometer by the ATR method: bands are quoted in $\mathrm{cm}^{-1}$. NMR spectroscopy was performed on a Bruker BioSpin UltraShield NMR spectrometer $(293 \pm 1 \mathrm{~K})$, at 400 or $600 \mathrm{MHz}$ for ${ }^{1} \mathrm{H}$ and $100.62 \mathrm{MHz}$ for the ${ }^{13} \mathrm{C}$ resonance. The ${ }^{1} \mathrm{H}$ spectra were recorded in $\mathrm{CDCl}_{3}$ with the ${ }^{13} \mathrm{C}$ spectra in $\mathrm{CDCl}_{3}$. The NMR chemical shift values $(\delta)$ are in ppm, referenced to TMS and coupling constants $(J)$ are quoted in $\mathrm{Hz}$.

The single crystal X-ray data collections for all nine Clxx isomers as ten crystal structures (Clpp, Clmp, Clop, Clpm, Clmm, Clom, Clpo_O, Clpo_N, Clmo, Cloo; Scheme 1) together with data reduction, structure solution and refinements are typically routine. ${ }^{43-46,50-52}$ Selected crystallographic and structural information are as detailed in the ESI (Tables S1, S2a-c, pgs $5-10)^{51,53}$ with pertinent structural details provided in the main manuscript in Tables 1, 2. Molecular and hydrogen bonding diagrams (Figures 1-9) are depicted with displacement ellipsoids drawn at the $30 \%$ probability level. ${ }^{43,53,54}$ The computational calculations $^{55-57}$ are routine, ${ }^{43-46}$ with optimisations and conformational analyses in gas phase as performed using the DFT method $[B 3 L Y P / 6-311++G(d, p)] \cdot{ }^{56,57}$ All calculations were performed using Gaussian0955 for Linux/Unix operating on a SGI Altix ICE 8200EX high performance computing system at the ICHEC (Galway, Ireland).

\section{Clx}<smiles>O=C(Nc1ccccc1)c1ccccc1</smiles>

Scheme 1: The Clxx molecular structures with Clx representing the $p-/ m-/ o-\mathrm{ClC}_{6} \mathrm{H}_{4} \mathrm{C}=\mathrm{O}$ and $\mathbf{x}$ the $p-/ m-/ o-\mathrm{HNC}_{5} \mathrm{H}_{4} \mathrm{~N}$ moieties ( $\mathbf{x}=$ para-/meta-/ortho-substitution).

Table 1: Selected crystallographic data for Clxx (full details available; Table S1 in ESI) ${ }^{50-54}$

\begin{tabular}{|c|c|c|c|c|}
\hline Structure & Crystal system; Space group & $Z^{\prime}$ & Unit cell volume $\left(\AA^{3}\right)$ & $R, \mathrm{wR}_{2}$ factors \\
\hline Clpp & Monoclinic; $P 21 / c$ & 1 & $1070.40(14)$ & $0.038,0.098$ \\
\hline Clmp & Triclinic; $P \overline{\mathbf{1}}$ & 4 & $2145.05(8)$ & $0.039,0.113$ \\
\hline Clop & Orthorhombic; Pbca & 1 & $2192.4(7)$ & $0.041,0.089$ \\
\hline Clpm & Triclinic; $P \overline{\mathbf{1}}$ & 4 & $2156.6(4)$ & $0.043,0.084$ \\
\hline Clmm & Monoclinic; $P 2_{1} / c$ & 1 & $1142.99(13)$ & $0.050,0.097$ \\
\hline Clom & Monoclinic; $C 2 / c$ & 1 & $2256.16(9)$ & $0.034,0.089$ \\
\hline Clpo_O & Monoclinic; $C 2 / c$ & 1 & $2134.8(3)$ & $0.031,0.089$ \\
\hline Clpo_N & Monoclinic; $C 2 / c$ & 1 & $2222.78(5)$ & $0.032,0.093$ \\
\hline Clmo & Triclinic; $P \overline{\mathbf{1}}$ & 1 & $530.27(6)$ & $0.034,0.100$ \\
\hline Cloo & Monoclinic; $C 2 / c$ & 1 & $2166.51(16)$ & $0.036,0.110$ \\
\hline
\end{tabular}




\section{Methods ${ }^{58-62}$}

Electrostatic energy calculations were performed with the MoProSuite software. ${ }^{58}$ The multipolar electron density of the molecules was modelled by transfer of the ELMAM2 charge density database without further refinement. ${ }^{59}$ The asymmetric unit content was rendered electrically neutral after charge density transfer by applying a uniform valence population shift to all atoms. The $\mathrm{N}-\mathrm{H}$ and $\mathrm{C}-\mathrm{H}$ bonds were elongated to standard distances obtained from neutron diffraction. ${ }^{60}$ The electrostatic energy is computed over pairs of atoms using the Hansen and Coppens multipolar atom model. The lattice electrostatic energy was computed with the VMoPro module in real space. The software can compute the energy in successive parallelepiped shells around the unit cell. Convergence was achieved over the $[-9 a, 9 a] \times[-9 b, 9 b] \times[-9 c, 9 c]$ space around the molecule containing $19^{3}$ unit cells.

The Hirshfeld surface and decomposition of intermolecular contacts in pairs of chemical species were computed around the different moieties of the asymmetric unit with the program MoProViewer. ${ }^{61}$ The polar $\mathrm{H}_{\mathrm{N}}$ and hydrophobic $\mathrm{H}_{\mathrm{C}}$ atoms were distinguished. Crystal contact enrichment ratios were averaged, as noted by Jelsch and Bisseyou: ${ }^{62}$ arithmetically and harmonically, for values smaller and larger than unity, respectively. ${ }^{62}$ Supplementary Figures and Tables are provided (ESI; Figures S4-S10; Tables S4-S7).

Table 2: Salient structural features (inter-planar angles, distances, packing; $\AA^{\circ},{ }^{\circ}$ ) of Clxx..$^{51}$

\begin{tabular}{|l|c|c|c|c|c|}
\hline Structure & $\mathbf{C}_{6} / \mathbf{C}_{5} \mathbf{N}\left({ }^{\circ}\right)$ & $\mathbf{C}_{6} /$ amide $\left.^{\circ}\right)$ & $\mathbf{C}_{5} \mathbf{N} /$ amide $\left(^{\circ}\right)$ & $\mathbf{N} . . . \mathbf{N} / \mathbf{O}(\AA)$ & Packing \\
\hline Clpp & $50.88(6)$ & $32.33(18)$ & $19.2(2)$ & $3.114(2)$ & 1D chains \\
\hline Clmp & $10.98(9)$ & $33.47(6)$ & $22.80(7)$ & $2.9431(16)$ & 1D chains \\
& $7.18(9)$ & $23.53(7)$ & $21.21(8)$ & $3.0120(16)$ & \\
& $5.19(4)$ & $1.11(5)$ & $4.54(5)$ & $3.1576(16)$ & \\
& $7.93(4)$ & $8.79(4)$ & $2.21(4)$ & $3.1913(16)$ & \\
\hline Clop & $73.27(5)$ & $64.64(6)$ & $12.36(11)$ & $3.010(3)$ & 1D chains \\
\hline Clpm & $11.79(17)$ & $5.97(18)$ & $6.21(16)$ & $3.184(4)$ & 1D chains \\
& $11.54(16)$ & $6.25(17)$ & $5.33(16)$ & $3.203(4)$ & \\
& $35.35(11)$ & $28.28(13)$ & $7.31(15)$ & $3.151(4)$ & \\
& $33.24(10)$ & $27.57(13)$ & $5.78(14)$ & $3.150(4)$ & \\
\hline Clmm & $3.67(12)$ & $21.71(8)$ & $23.49(8)$ & $2.892(4)^{*}$ & N-H/O-H...O \\
& & & & $2.858(4)^{*}$ & and O-H...O \\
& & & & $2.890(4)^{*}$ & composites \\
\hline Clom & $74.97(4)$ & $58.56(5)$ & $17.13(5)$ & $2.9058(17)$ & 1D chains \\
\hline Clpo_N & $36.75(7)$ & $35.80(7)$ & $1.07(8)$ & $3.0715(19)$ & Dimers \\
\hline Clpo_0 & $3.44(8)$ & $23.54(6)$ & $20.92(6)$ & $3.1296(14)$ & 1D chains \\
\hline Clmo & $47.05(4)$ & $36.25(4)$ & $15.77(6)$ & $3.1990(17)$ & Dimers \\
\hline Cloo & $66.72(4)$ & $68.95(5)$ & $2.90(3)$ & $3.0485(14)$ & Dimers \\
\hline
\end{tabular}

Footnotes: $\mathrm{C}_{6}$ is the $(\mathrm{C} 11, \ldots, \mathrm{C} 16)$ benzene ring and $\mathrm{C}_{5} \mathrm{~N}$ is the $(\mathrm{C} 21, \ldots, \mathrm{C} 26)$ pyridine ring defined for the least squares (LS) planes in Scheme 2; the bridging amide plane is defined as the 5 atom $\mathrm{C}_{\text {ipso }} \mathrm{C}(\mathrm{O}) \mathrm{NC}_{\text {ipso }}$ (or $\mathrm{C} 11, \mathrm{C} 1, \mathrm{O} 1, \mathrm{~N} 1, \mathrm{C} 21$ ) LS plane, with reference to Figures 1-9. The $\mathrm{Clmp}$ and $\mathrm{Clpm}$ structures have $Z^{\prime}=4$.

* = Clmm is a hydrate (hydrogen bonding distances all involve O1W). 


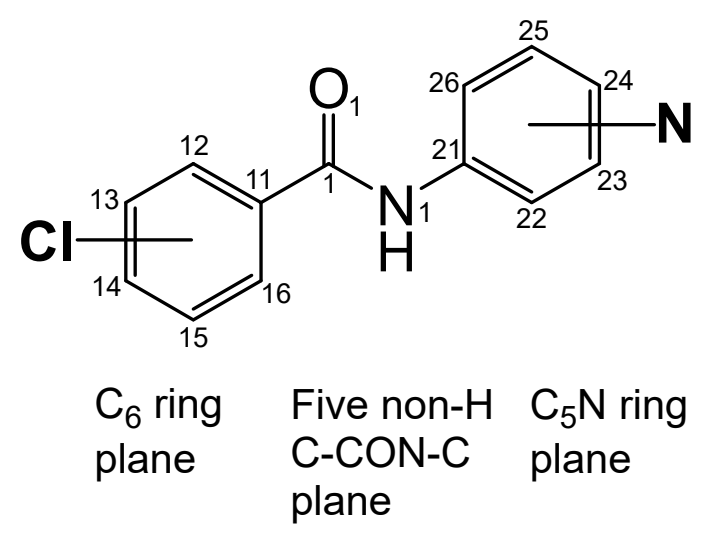

Scheme 2: A diagram of the three planes (with only non-hydrogen atoms used in the interplanar calculations of Tables $\mathbf{2}$ and $\mathbf{3}$. 


\section{Results and Discussion \\ Crystal structure results:}

Nine Clxx benzamide isomers are reported (as ten crystal structures), presenting a wide variety of molecular geometries and structures, with Clpo or para-Chloro- $N^{\prime}$-(orthopyridyl)benzamide crystallizing as the Clpo_N and $\mathbf{C l p o \_ 0}$ polymorphs ( $\mathbf{N}_{\text {pyridine }}$ or $\mathbf{O}_{\text {amide }}$ suffixes denote the primary intermolecular hydrogen bonding acceptor). There is isomorphous overlap between some Clxx structures with their $\mathbf{F x x},{ }^{43} \mathbf{N} \mathbf{x x F}{ }^{44} \mathbf{M x x}{ }^{45}$ or $\mathbf{N x x M}^{46}$ isomer grid relatives (ESI, Figures S1,S2) and there is also structural similarity with the CxxM and CxxOMe carbamates. ${ }^{63,64}$ Computational studies in gas phase are analysed for comparisons directly with the crystal structure results. ${ }^{43-46,55-57}$ Only salient features of each Clxx structure are presented, with further information in the ESI (Tables S1, S2a-c).

The Clpp, Clmp, Clop series: Isomorphism

Clpp (Figure 1) crystallises in the monoclinic system (space group $P 2_{1} / c$, with $Z=4$ ) and augments a series of seven isomorphous compounds that includes the parent Hpp, ${ }^{65}$ the Fpp, Fmp, Fop triad (Figure S2, ESI), ${ }^{43,66}$ 25p, ${ }^{67}$ Clpp and Brpp. ${ }^{68}$ These molecules display varied peripheral $\mathrm{H} / \mathrm{F} / \mathrm{Cl} / \mathrm{Br}$ atom-site positions and the resultant isomorphous series is unusual in that the structures have similar unit-cell parameters, packing and alignment but different interaction/contact geometries at the secondary level. ${ }^{43-46,69-72}$ Disparities are primarily due to the $0.3-0.7 \AA$ differences between typical organic $\mathrm{C}-\mathrm{H} / \mathrm{F} / \mathrm{Cl} / \mathrm{Br}$ bond lengths $(\AA)$ and resulting directional influence of the peripheral $\mathbf{X}$ atoms on weaker interactions and contacts in their respective crystal structures. With increasing numbers of structures available on the CSD, ${ }^{40-42}$ it is expected that progress will be made towards forming a continuum where isomorphous series of molecules overlap with series of isostructural compounds. In fact, Mpp (para-Methyl- $N^{\prime}$-(para-pyridyl)benzamide) bears a resemblance to Clpp and is considered as an isostructural relative. ${ }^{45}$ In the literature there is considerable on-going interest on groups of isomorphous structures that exhibit structural diversity. ${ }^{69-72}$

The Clpp structure contains an intramolecular C26-H26...O1 contact (C26...O1 = 2.891(2) $\AA$, $\left.\mathrm{C}-\mathrm{H} . . . \mathrm{O}=117^{\circ}\right)$. The classic $\mathrm{N}-\mathrm{H} . . . \mathrm{N}$ intermolecular interaction $\left[\mathrm{N} 1 . . . \mathrm{N} 24^{i}=3.114(2) \AA\right.$, $139.2(17)^{\circ}$; symmetry code $i=1-x, y+1 / 2,1 / 2-z$, ESI, Table S2a] with $C(6)$ motif is the principal hydrogen bond and the remaining intermolecular interactions comprise $\mathrm{C}-\mathrm{H}$...O [3.3482(2) $\left.\AA, 130^{\circ}\right]$ and $\mathrm{Cl} 14 \ldots \mathrm{C}(\pi)$ halogen bonding contacts [3.3269(18) $\AA, \mathrm{C} 14-\mathrm{Cl} 14 \ldots \mathrm{C} 21^{\mathrm{xix}}=$ $150.10(7)^{\circ}$; symmetry code $\left.x i x=x, 1 / 2-y, 1 / 2+z\right],{ }^{31-39}$ linking the non-planar molecules into a 3D structure (Figure 1), together with $\mathrm{C}-\mathrm{H} . . . \pi$ and aromatic stacking. ${ }^{25,27,30} \mathrm{Clpp}$ forms part of an isomorphous series that widens the structural scope of a group of similar structures. ${ }^{40}$
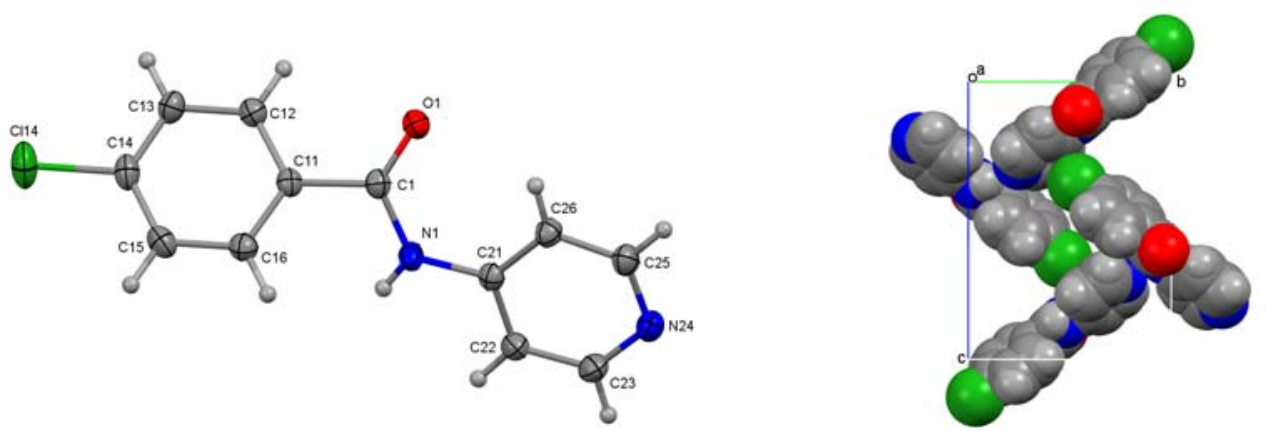

Figure 1: ORTEP of Clpp and CPK view of the N1-H1...N24 and C14-Cl14...C( $\pi)$ contacts. ${ }^{31-39}$ 
Clmp crystallises in the triclinic system (space group $P \overline{\mathbf{1}}$, with $Z=8$ ), containing four independent molecules in the asymmetric unit $\left(Z^{\prime}=4\right)^{73-75}$ (Figure 2). Trials in a subunit cell (with $c$-axis halved) in $P 2_{1} / n$ gives a result with $R=0.11$ having at least four non-H atoms with unusual displacement ellipsoids; this result was discarded. In Clmp the major differences between all four molecules (A, B, C, D) are exemplified by different $\mathrm{O}=\mathrm{CCC}$ torsion angles [with a range $>30^{\circ}$, from $144.06(14)^{\circ}$ to $177.91(13)^{\circ}$ ] and distinct N1-H1...N24 distances $[\sim 0.25 \AA$, from 2.9431(16) $\AA$ to 3.1913(16) $\AA$. However, the (A, B) and (C, D) molecules form distinct pairs that are broadly similar in conformation (Table 2 ). The aromatic rings in $\mathrm{Clmp}$ twist by between $5^{\circ}$ and $11^{\circ}$ relative to each other (i.e. by $5.19(4)^{\circ}$ in C; $10.98(9)^{\circ}$ in A), whereas the amide group is twisted away from both aromatic rings in molecules $\mathbf{A}$ and $\mathbf{B}$ only, as molecules $\mathbf{C}$ and $\mathrm{D}$ are essentially planar. The chlorine atom is located as $\mathrm{Cl}$-syn relative to the amide $\mathrm{N}-\mathrm{H}$ (as for $\mathbf{F m p}$ ). ${ }^{43}$ An intramolecular contact is present as $\mathrm{C} 22-\mathrm{H} 22 \ldots \mathrm{O} 1$ in all four molecules in a $d(\mathrm{C}, \mathrm{O})$ range from $2.8073(17)$ to $2.8709(16) \AA$, with angles $115^{\circ}$ to $121^{\circ}$. Molecules aggregate by $\mathrm{N}-\mathrm{H}$...N intermolecular interactions as $\mathrm{A} \rightarrow \mathrm{D} \rightarrow \mathrm{A} \rightarrow \mathrm{D} \ldots$ and $\mathrm{B} \rightarrow \mathrm{C} \rightarrow \mathrm{B} \rightarrow \mathrm{C} \ldots$ alternating pairs. The N1...N24 distances are 2.9431(16), 3.1913(16) iii $^{\circ}$ (for A, D) and 3.0120(16), 3.1576(16) $\AA$ (for B, C) with the $C(6)$ motif forming zigzag chains parallel with (001). In addition parallel offset amide...arene stacking contributes to structural stability and packing, especially involving centrosymmetric related C molecules with short C...C contact distances of 3.32, $3.36 \AA .{ }^{30}$ Weaker intermolecular $\mathrm{C}-\mathrm{H}$... N/O hydrogen bonds also influence with $\mathrm{C}-\mathrm{H}$...N playing an auxiliary role to the $\mathrm{N}-\mathrm{H} \ldots \mathrm{N}$, in addition to weak $\mathrm{C}-\mathrm{H} . . . \mathrm{Cl}$ contacts. ${ }^{25-30}$ Molecules stack with the relatively planar (C green, $\mathrm{D}$ yellow) molecular pairs along the $c$-axis direction as (C...C...D...D...) and forming a herringbone arrangement with the $A$ (red) and $B$ (blue) pairs (packing diagram). The Clmp crystal structure contains two slightly different molecular geometries and stacking sequences in the $(A, B)$ and $(C, D)$ pairs with packing influences from the $\mathrm{N}-\mathrm{H}$...N hydrogen bonded chains and parallel offset $\pi . . . \pi$ stacking effects. ${ }^{30}$ This may be a contributing factor in the isolation of the Clmp crystal structure with $Z^{\prime}=4 .{ }^{73-75}$
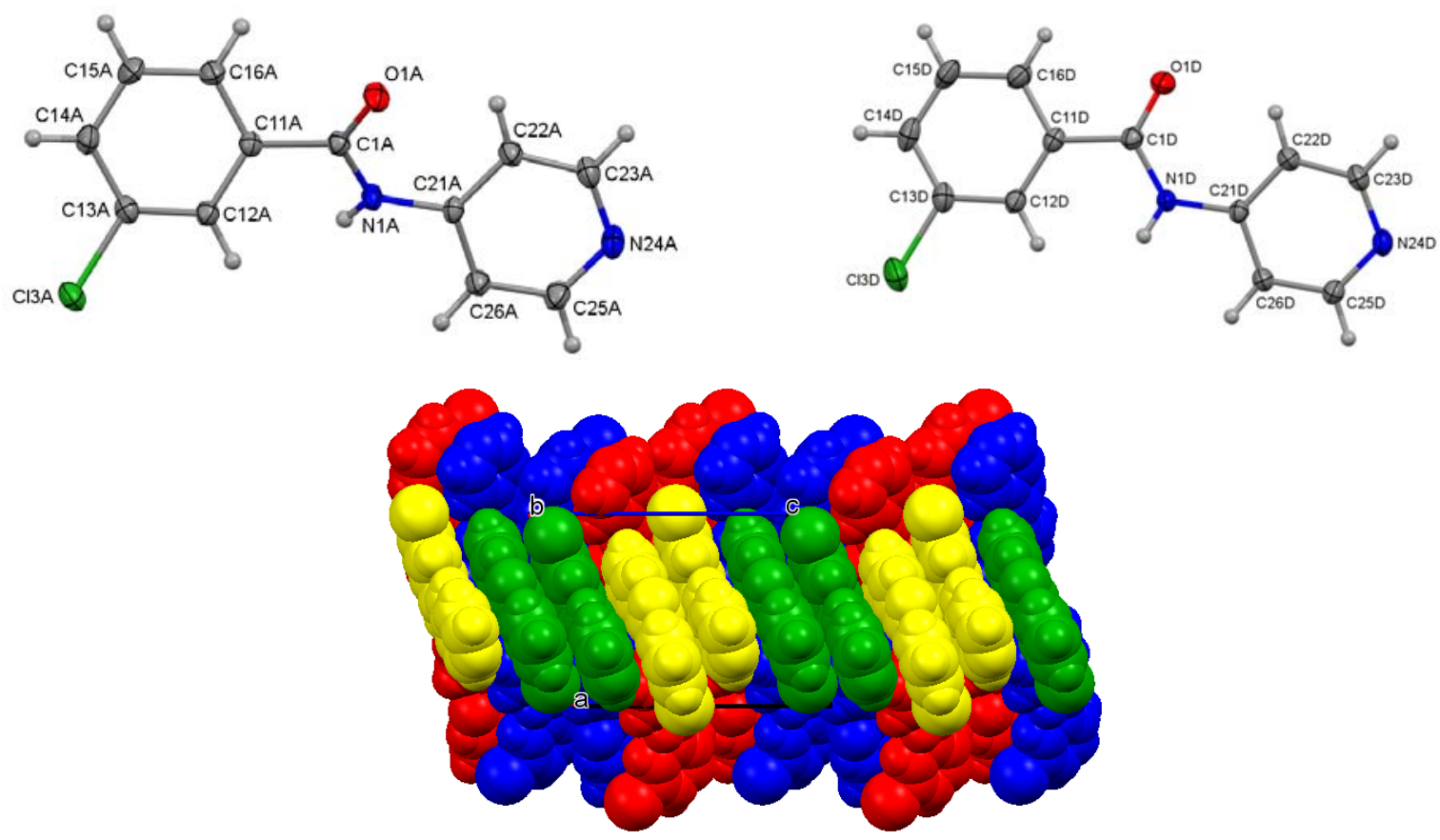

Figure 2: ORTEPs of Clmp (molecules $A$ and $D$, top) and a CPK packing view (A, B, C, D). 
Clop is isomorphous with the Brop crystal structure. ${ }^{68}$ Molecules of Clop twist from nonplanar geometry (Figure 3 ) due to the influence of the ortho- $\mathrm{Cl} 12$ atom $(\sim \mathrm{Cl}$-syn) but the amido-pyridine group remains essentially planar due to the $\mathrm{C} 26-\mathrm{H} 26 . . . \mathrm{O} 1$ intramolecular contact. Clop aggregates by intermolecular N1-H1...N24 hydrogen bonds into 1D chains [as $C(6)$ ] that are further linked into 2D sheets parallel with $(001)$ by $\mathrm{Cl} 12 \ldots .01^{x \times i}$ halogen bonding interactions $\left[\mathrm{Cl} 12 \ldots 01^{x x i}=3.1104(18) \AA ; N_{c}=0.95\right],{ }^{31-39}$ with $\mathrm{C} 12-\mathrm{Cl} 12 \ldots \mathrm{O} 1=$ $161.09(8)^{\circ}, \mathrm{Cl} 12 \ldots \mathrm{O} 1=\mathrm{C} 1=111.27(12)^{\circ}$. The $\mathrm{N}-\mathrm{H} . . . \mathrm{N}$ interaction geometry is regular with $\mathrm{N} 1 \ldots \mathrm{N} 24^{v i}=3.010(3) \AA\left(\mathrm{N} 1-\mathrm{H} 1 \ldots \mathrm{N} 24^{v i}=175.9(18)^{\circ}\right)$, but the orientation is skewed towards $120^{\circ}$ with $\mathrm{N} 1 \ldots \mathrm{N} 24^{v i} \ldots \mathrm{C} 21^{v i}\left(=137^{\circ}\right)$. A C15-H15...O $1^{\text {vii }}$ interaction is also noted.
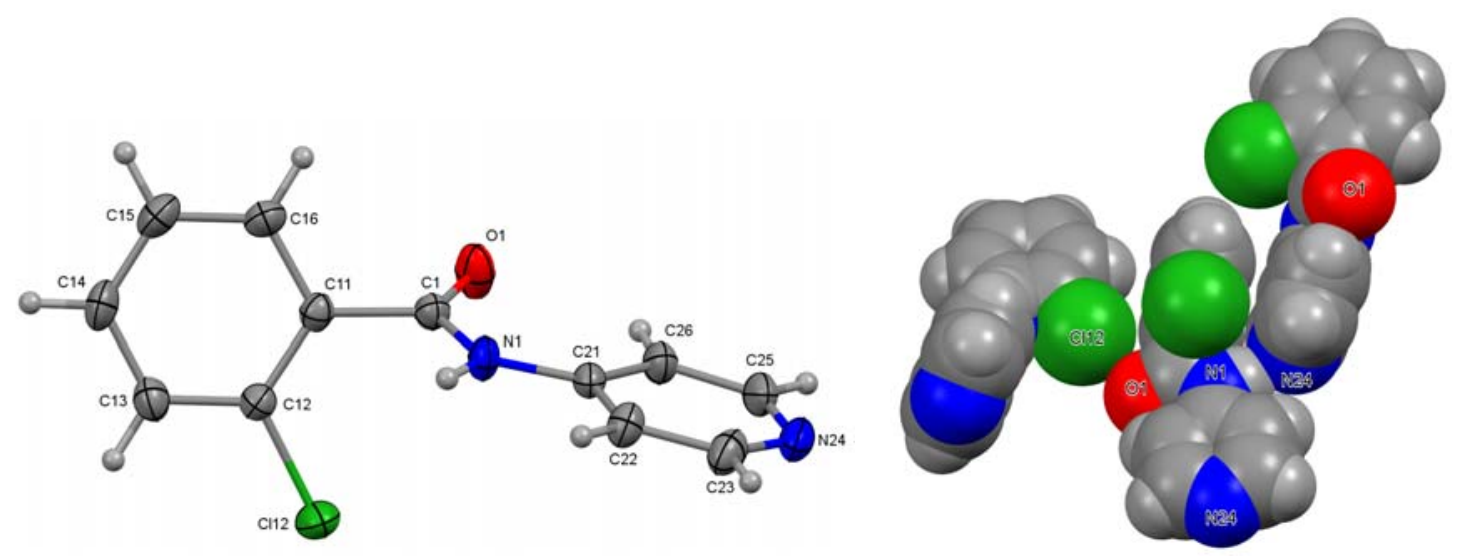

Figure 3: ORTEP of Clop; CPK view of the $\mathrm{N} 1-\mathrm{H} 1 \ldots \mathrm{N} 24^{v i}$ interaction, $\mathrm{Cl} 12 \ldots \mathrm{O} 1=\mathrm{C} 1^{x \times i}$ contact.
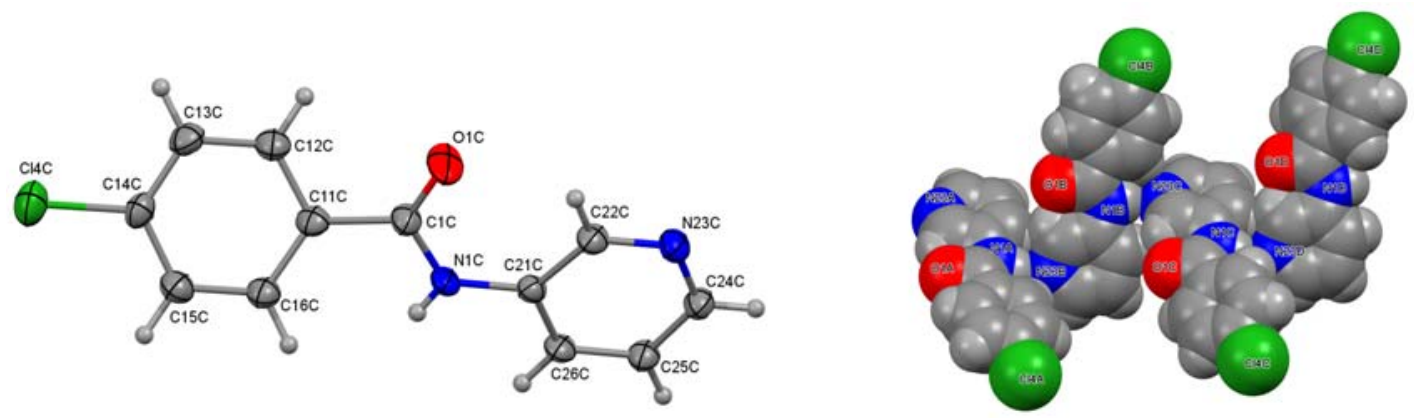

Figure 4: ORTEP of Clpm (molecule C) and a CPK view of the N1-H1...N23 chain.

The Clpm, Clmm, Clom series: twinning and isomorphous behaviour.

Clpm is a twinned structure with four molecules (A to $\left.D ; Z^{\prime}=4\right)^{73,75}$ (Figure 4), assigned as ( $A$, $B)$ and $(C, D)$ pairs in the asymmetric unit and differing slightly in their inter-planar $C_{6} / C_{5} N$ angles of $11.93(15)^{\circ}, 11.78(14)^{\circ}, 35.29(10)^{\circ}$ and $33.18(9)^{\circ}$. Geometrical differences are

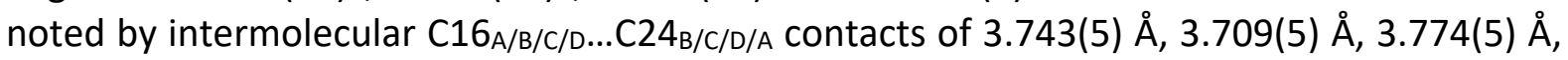
3.834(5) $\AA$ along the $(A \rightarrow B \rightarrow C \rightarrow D \rightarrow)_{n}$ hydrogen bonded chains as linked by modest N1$\mathrm{H} 1$...N23 interactions (Table 2). The N...N range is 3.150(4) to 3.203(4) $\AA$ and assisted by flanking $C 16_{A / B / C / D} / C 26_{A / B} / C / D \ldots N 23_{B / C / D / A}$ interactions and contacts (with P-anti). Additionally $\mathrm{C}-\mathrm{H} . . . \mathrm{Cl} / \mathrm{O} / \pi$ weak hydrogen bonds augment the intermolecular contacts. ${ }^{25-30,40}$ Crystal structures with $Z^{\prime}=4$ are uncommon though not unusual and have been encountered in related series; ${ }^{40-42,73-75} \mathrm{Mpm}$ crystallises in the triclinic system (space group $P 1$, with $\left.Z=Z^{\prime}=4\right),{ }^{45} \mathrm{NmpF}^{44}$ and $\mathrm{Clmp}$ likewise (space group $P \overline{\mathbf{1}}$, with $Z=8$ and $Z^{\prime}=4$ ). One can surmise 
that two independent molecules $\left(Z^{\prime}=2\right)$ can be accommodated by $\mathrm{N}-\mathrm{H}$...N interactions in a 1D chain. Statistically, structures with $Z^{\prime}=4$ are considerably less likely to arise. ${ }^{40-42,73-75}$ The cumulative effects and strengths of aromatic stacking ${ }^{30}$ together with intermolecular

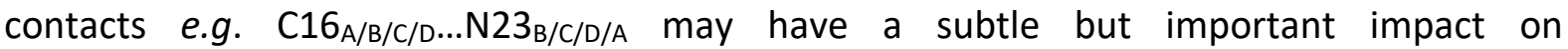
intermolecular organisation and packing. ${ }^{25-30}$

The Clmm• $\left(\mathrm{H}_{2} \mathrm{O}\right)$ monohydrate is isomorphous with $\mathrm{Brmm} \bullet\left(\mathrm{H}_{2} \mathrm{O}\right) \cdot{ }^{68}$ The $\mathrm{Clmm} \bullet\left(\mathrm{H}_{2} \mathrm{O}\right)$ structure crystallises with three main hydrogen bonds driving aggregation using N1$\mathrm{H} 1 \ldots \mathrm{O}^{\mathrm{ix}}, \mathrm{O} 1 \mathrm{~W}-\mathrm{H} 2 \mathrm{~W} \ldots \mathrm{O}=\mathrm{C}^{i}$ and $\mathrm{O} 1 \mathrm{~W}-\mathrm{H} 1 \mathrm{~W} \ldots \mathrm{N} 23 . .^{25-30}$ The former two interactions combine to form a $R_{4}^{4}(12)$ assembly with two $\mathrm{H}_{2} \mathrm{O}$ molecules sandwiched between two $\mathrm{Clmm}$ (as Cl-syn; P-syn) (Figure 5). The remaining O1W-H1W...N23 interaction links tetrameric $\left[\mathrm{Clmm} \bullet\left(\mathrm{H}_{2} \mathrm{O}\right)\right]_{2}$ assemblies via the pyridine $\mathrm{N} 23$ atom; each tetramer has two $\mathrm{O} 1 \mathrm{~W}-\mathrm{H} 1 \mathrm{~W}$ donors and $\mathrm{N} 23$ acceptors for a total of four hydrogen bonds per assembly. Hydrogen bonding is maximised whereby three donor groups $(\mathrm{N}-\mathrm{H}, 2 \times \mathrm{O}-\mathrm{H})$ and three acceptors $(\mathrm{O}=\mathrm{C}, \mathrm{O}, \mathrm{N})$ participate with water playing a critical role in aggregation. In our isomer grids, benzamide hydrates are usually obtained from recrystallization in halogenated solvents or ethyl acetate. ${ }^{43-46}$ They tend to have a meta- $\mathrm{N}_{\text {pyridine }}$ atom favouring hydrogen bonded ring formation with water molecules incorporated (adventitiously) between benzamides.
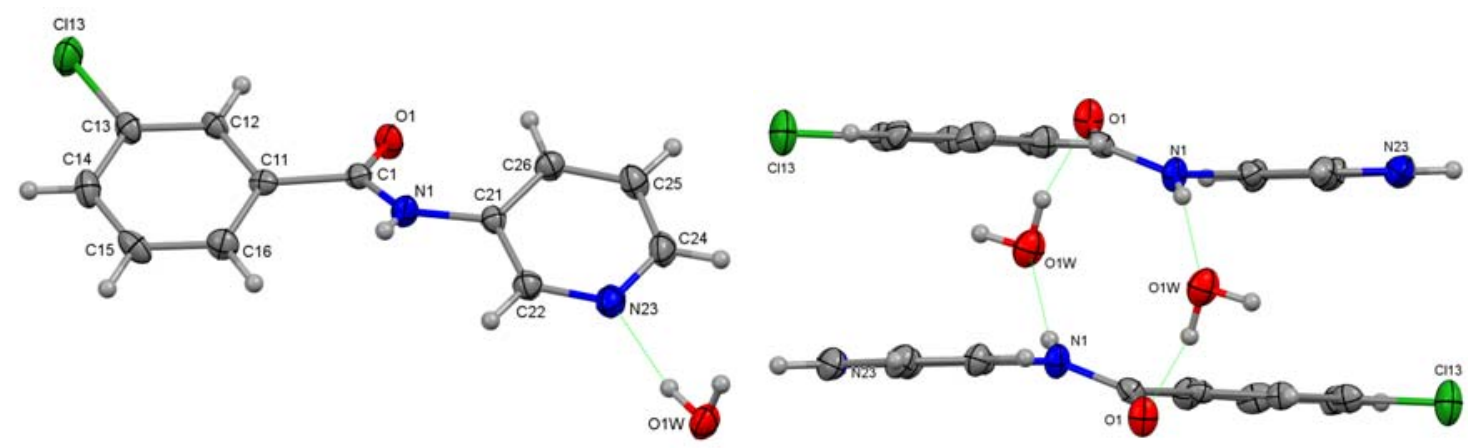

Figure 5: ORTEP view of Clmm• $\left(\mathrm{H}_{2} \mathrm{O}\right)$ and $R_{4}^{4}(12)$ assembly of $\mathrm{Clmm}$ with $\mathrm{H}_{2} \mathrm{O}$ molecules.

Clom adopts a (Cl-anti; P-anti) conformation with an intramolecular $\mathrm{C} 22-\mathrm{H} 22 \ldots \mathrm{O} 1$ interaction [2.8845(19) $\left.\left.\AA, 120^{\circ}\right)\right]$ and $\mathrm{Cl} 12 \ldots \mathrm{O} 1$ contact $[\mathrm{Cl} 12 \ldots \mathrm{O} 1=3.1811(13) \AA$ ] (Figure 6). ${ }^{25-39}$ Clom is isomorphous with Brom, ${ }^{68}$ and is similar in structure to Mom (M-anti; P-anti) aggregating with $\mathrm{N}-\mathrm{H} . . . \mathrm{N}$ chain formation. ${ }^{45}$ This arrangement contrasts with Fom (F-syn; Panti $)^{43}$ having two intramolecular $\mathrm{C}-\mathrm{H}$...O contacts, an intramolecular $\mathrm{N}-\mathrm{H}$.... interaction and weak $\mathrm{N}-\mathrm{H} . . . \mathrm{O}=\mathrm{C}$ chain association. As such, Clom molecules do not exhibit intramolecular $\mathrm{N}$ $\mathrm{H} . . . \mathrm{Cl}$ interactions but assemble by $\mathrm{N}-\mathrm{H} . . . \mathrm{N}$ interactions as 1-D chains along the $c$-axis direction. These are weakly linked into $2 \mathrm{D}$ sheets by $\mathrm{C}-\mathrm{H}$...O interactions and with type I halogen...halogen $\mathrm{C}_{\text {arom }}-\mathrm{Cl}$...( $\left(\mathrm{Cl}-\mathrm{C}_{\text {arom }}\right)^{x \times i v}$ interactions of $3.3699(10) \AA$ (Figure 6); though considerably longer than the aromatic $\mathrm{C}-\mathrm{Cl}$... Cl-C contact of $3.165(3) \AA$ noted in $(\mathrm{CllO})_{3} .{ }^{49}$ The trade-off in interactions works for Clom and one can postulate that differences between Mom, ${ }^{45}$ Fom, ${ }^{43}$ and Clom derive from an intricate balance between intramolecular (mainly $\mathrm{N}-\mathrm{H}$...F interactions for $\mathrm{F}$ in Fom) and intermolecular (mainly $\mathrm{N}-\mathrm{H}$... $\mathrm{N}$ formation for $\mathrm{Me}$ 
(Mom) and $\mathrm{Cl}$ (Clom)) forces. It also suggests that that in terms of aggregation, the Fom polymorphs are rather unexpected and influenced by intramolecular forces. ${ }^{43}$
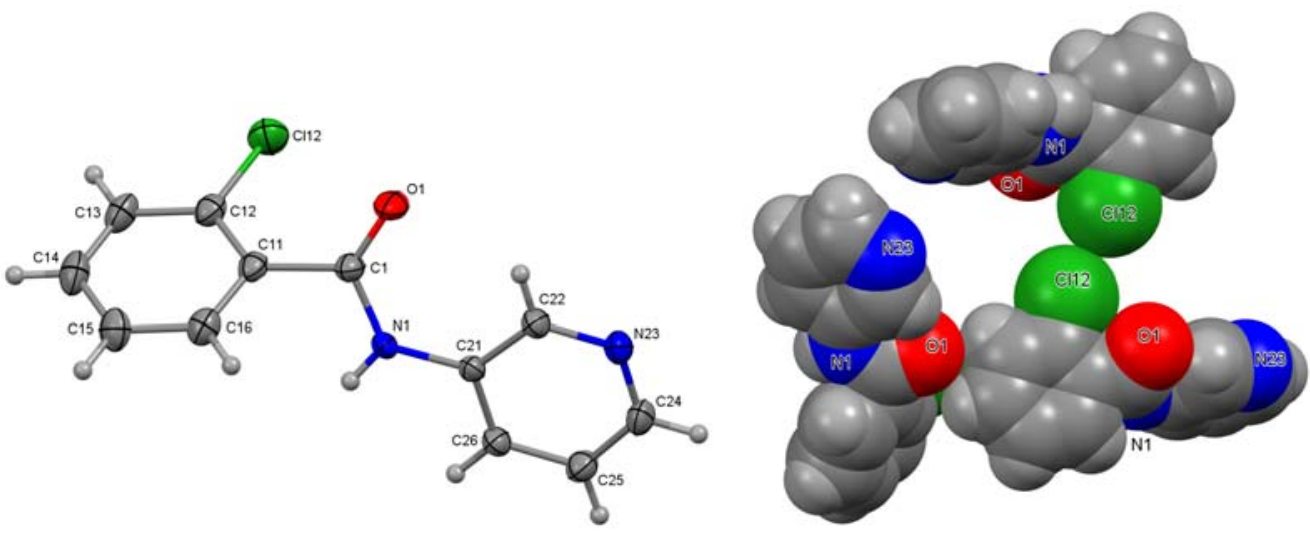

Figure 6: ORTEP of Clom and a CPK view of the $\mathrm{Cl} 12 \ldots \mathrm{Cl} 12^{\text {xxiv }}$ and $\mathrm{C}-\mathrm{H} . . . \mathrm{O}$ contacts.

The Clpo, Clmo, Cloo series: polymorphism in Clpo (Clpo_O and Clpo_N $)^{76-80}$

Clpo crystallises as two polymorphs, both P-syn, (Figures 7, 8; monoclinic system, space group $C 2 / c$, with $Z=8: Z^{\prime}=1$ ). Thus Clpo_O (from ethyl acetate) forms intermolecular interactions as $(i) \mathrm{N}-\mathrm{H}$... $\mathrm{O}=\mathrm{C}$ interactions in $C(4)$ chains along the $b$-axis direction with $\mathrm{N} 1 \ldots O 1^{x i}=3.1296(14) \AA$, (ii) parallel offset ring stacking interactions with $\mathrm{C} 1 \ldots \mathrm{C} 16^{x \times v}=$ $3.3488(19) \AA$ and (iii) C15-H15...N22 ${ }^{x i i}$ interactions forming dimers [3.5199(19) $\AA$ ] as $R^{2}{ }_{2}(16)$ rings. ${ }^{25-30}$ Clpo_O with amide....amide interactions is distinctly different to the related orthopyridine ( $\mathbf{Y} \times \mathbf{0})$ structures $\left(\mathbf{Y}=\mathbf{M e}{ }^{45} \mathrm{~F}^{43} \mathrm{Cl}\right.$ (see below), $\mathbf{B r}$ ), e.g. Mxo, Fxo (x = para-, meta-, ortho-) which aggregate as cyclic $\mathrm{N}-\mathrm{H}$... N hydrogen bonded dimers. ${ }^{43,45}$ The pyridine ortho- $\mathrm{N}$ atom facilitates the formation of compact $R^{2}{ }_{2}(8)$ rings in the six Mxo and Fxo structures (as P-syn) with secondary interactions, e.g. interdimer interactions completing the structural interactions. The driving force towards Yxo hydrogen bonded dimer formation remains, and with a range of geometries available, despite both intramolecular (C-H...O) and intermolecular interactions competing (as above) to potentially disrupt dimer formation. Clpo_0 though forms weakly held dimers that are comparable with the related Fpm_0 $\left[R^{2}{ }_{2}(18)\right],{ }^{43}$ nevertheless with a smaller hydrogen bonded ring size (16 atoms vs 18 atoms).
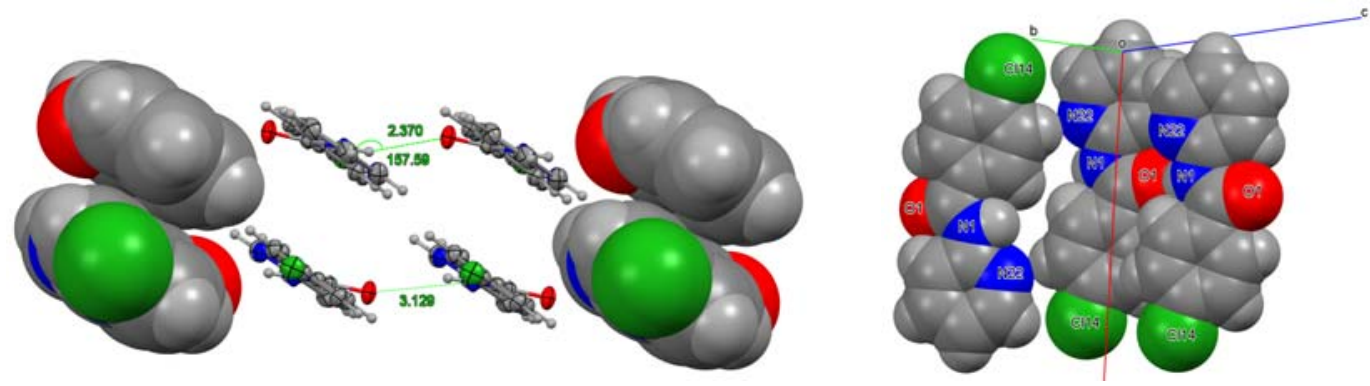

Figure 7: Views of Clpo_O with $\mathrm{N}-\mathrm{H} \ldots \mathrm{O}=\mathrm{C}$ and aromatic stacking interactions (left) and intramolecular $\mathrm{C}-\mathrm{H} . . . \mathrm{O}$ interactions and intermolecular $\mathrm{C}-\mathrm{H} . . . \mathrm{N}$ contacts (right).

Unexpectedly, and from crystallisation experiments attempts to obtain a series of benzamide hydrates, the Clpo_N polymorph was isolated from a mixture of acetonitrile and water. Clpo_N aggregates as hydrogen bonded $\mathbf{N}-\mathrm{H}$... N dimers (and similar to the six Fxo, 
Mxo), ${ }^{43,45}$ linked together into a 1-D chain by weak C-H...O contacts, further linked by $\mathrm{C}-\mathrm{H}$...O contacts aligning along the $c$-axis direction. The anticipated Clpo_N structure has a lower than expected KPI (packing index) of 67.1 compared to 70.0 for (Clpo_O) and this is due to the presence of voids in Clpo_N (Table 3). ${ }^{53}$ Analysis of the Clpo_N molecular packing shows channel formation but these voids are barely large enough to accommodate a hydrogen atom or $\mathrm{H}_{2}$ molecule (Figure 8). In summary, there is a trade-off in crystallising Clpo as (a) Clpo_O with an increased number of moderate strength interactions $(\mathrm{N}-\mathrm{H} . . . \mathrm{O}=\mathrm{C}, \mathrm{C}-\mathrm{H} \ldots \pi, \mathrm{N}$ and $\mathrm{C}$...C stacking) and optimum packing (70.0) at the expense of $(b)$ the stronger expected $\mathrm{N}-\mathrm{H}$...N cyclic dimer formation in Clpo_N with looser packing (67.1). Of note is compound ROY which is an extraordinary example of a molecular compound having ten polymorphs isolated to date. ${ }^{78}$ In ROY there are four polymorphs crystallising in the monoclinic system (space group $P 2_{1} / c$ ) making it rather unusual to have a high number of polymorphs as a subset in one space group. ${ }^{78}$

Table 3: Differences between the Clpo_O and Clpo_N polymorphs (in $\AA$, $\left.{ }^{\circ}\right)^{\text {a }}{ }^{2}$

\begin{tabular}{|c|c|c|c|c|c|}
\hline Polyr & $\mathrm{KPI}^{53}$ & $\mathrm{C}_{6} / \mathrm{C}_{5} \mathrm{~N}\left({ }^{\circ}\right)$ & $\mathrm{N}-\mathrm{H} . . . \mathrm{N} / \mathrm{O}\left(\AA{ }^{\circ},{ }^{\circ}\right)$ & C-H...N/O $\left(\AA,{ }^{\circ}\right)^{b}$ & C-H...O $\left(\AA^{\circ},{ }^{\circ}\right)^{b, c}$ \\
\hline $\mathrm{Clp}$ & 70.0 & $3.44(8)$ & $3.1296(14)^{x i}, 15$ & 3.5199(18), 168 & $(17), 116$ \\
\hline Clpo_N & 67.1 & $36.75(7)$ & $3.0715(19)^{x i i i}, 162.4(17)$ & $3.329(2), 129$ & $2.840(2), 121$ \\
\hline
\end{tabular}

a = Packing index KPI from PLATON ${ }^{53}$; aromatic interplanar angles $\mathrm{C}_{6}$ is the $\mathrm{C}_{6}$ benzene ring, $\mathrm{C}_{5} \mathrm{~N}$ is the 6 non- $\mathrm{H}$ atom of the pyridine ring in Scheme $2\left({ }^{\circ}\right)$; primary hydrogen bonding distances in $(\AA)$, angles in $\left({ }^{\circ}\right)$.

${ }^{b}=$ Aromatic $\mathrm{C}-\mathrm{H}$ hydrogen atoms as riding atoms in refinement and without esd's.

${ }^{c}=$ Intramolecular $\mathrm{C} 26-\mathrm{H} 26 \ldots . .01$ contact (distances in $\AA$; angles in ${ }^{\circ}$ ).

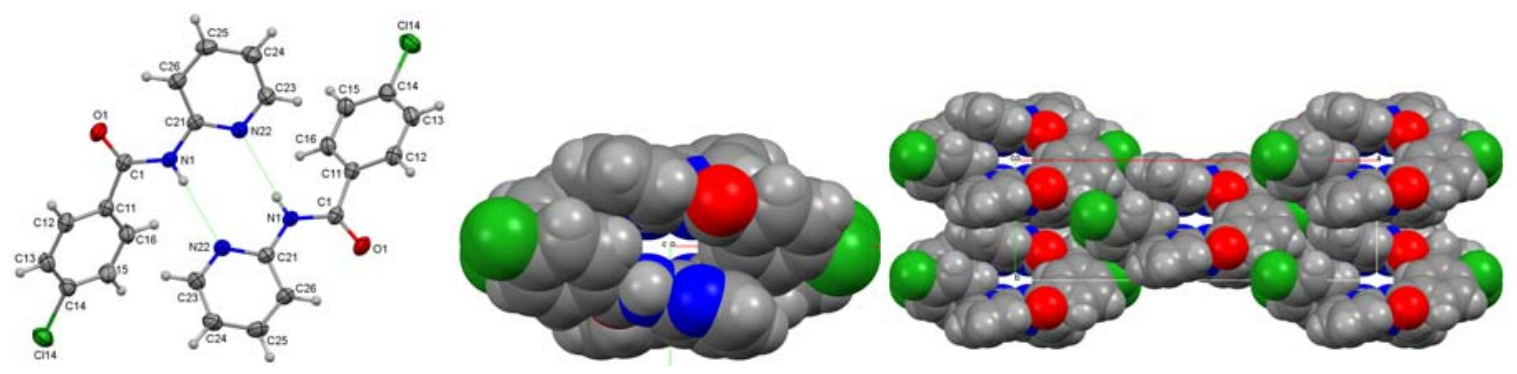

Figure 8: The cyclic dimer in Clpo_N with CPK views of the voids along the $c$-axis.

Clmo aggregates as cyclic $\mathrm{N}-\mathrm{H} . . . \mathrm{N}$ hydrogen bonded dimers and $\mathrm{N}-\mathrm{H}$... $\pi$ contacts (with slipped/stepped aromatic rings; Figure 9), contrasting with Clpo, though similar in molecular structure (dihedral angles) to Mpo. ${ }^{45}$ The N1...N22 ${ }^{x v}$ distance of 3.1990(17) $\AA$ is the longest in the nine Yxo hydrogen bonded dimers reported to date (for $\mathbf{Y}=\mathbf{M e}, \mathbf{F}, \mathbf{C l}$ ). ${ }^{43,45}$ The $\mathbf{M x o}$ triad $^{45}$ forms symmetrical, planar dimers about inversion centres, whereas the Fxo series ${ }^{43}$ aggregate as twisted hydrogen bonded dimers in Fpo (about a 2-fold axis) and with two independent molecules in the asymmetric units of Fmo, Foo (both crystallising in the triclinic system, space group $P \overline{\mathbf{1}}$ ). Of further note in Clmo is the lack of halogen bonding interactions of any consequence involving the chlorine atom $\mathrm{Cl} 13$, which is exclusively surrounded by several C-H atoms (ESI: Tables S4-S5).

Cloo is isomorphous with Broo, ${ }^{68}$ and forms $\mathrm{N}-\mathrm{H}$...N hydrogen bonded dimers about 2-fold axes and is similar in conformation to Foo. ${ }^{43}$ Compact parallel offset heterocycle stacking 
interactions involving the ortho-pyridine rings dominate with short C24...C26 $6^{x x v i i}$ distances of $3.3049(18) \AA$ about inversion centres (Figure 9). In tandem, C-H... $\pi$ (arene) contacts arise involving the aromatic $\mathrm{C} 16-\mathrm{H} 16$ and $\mathrm{C} 23-\mathrm{H} 23$ moieties with symmetry related benzene rings. The aggregation can also be viewed as Cloo dimers that stack in columns in the $b$-axis direction with tight pyridine...pyridine stacking interactions contributing to form tightly interwoven 2-D sheets. For comparisons, although both $\mathrm{Clmo}$ and $\mathrm{Cloo}$ exhibit regular behaviour in their respective aggregation, for all three Clxo isomers the carbonyl atom 01 has barely any influence on molecular aggregation.
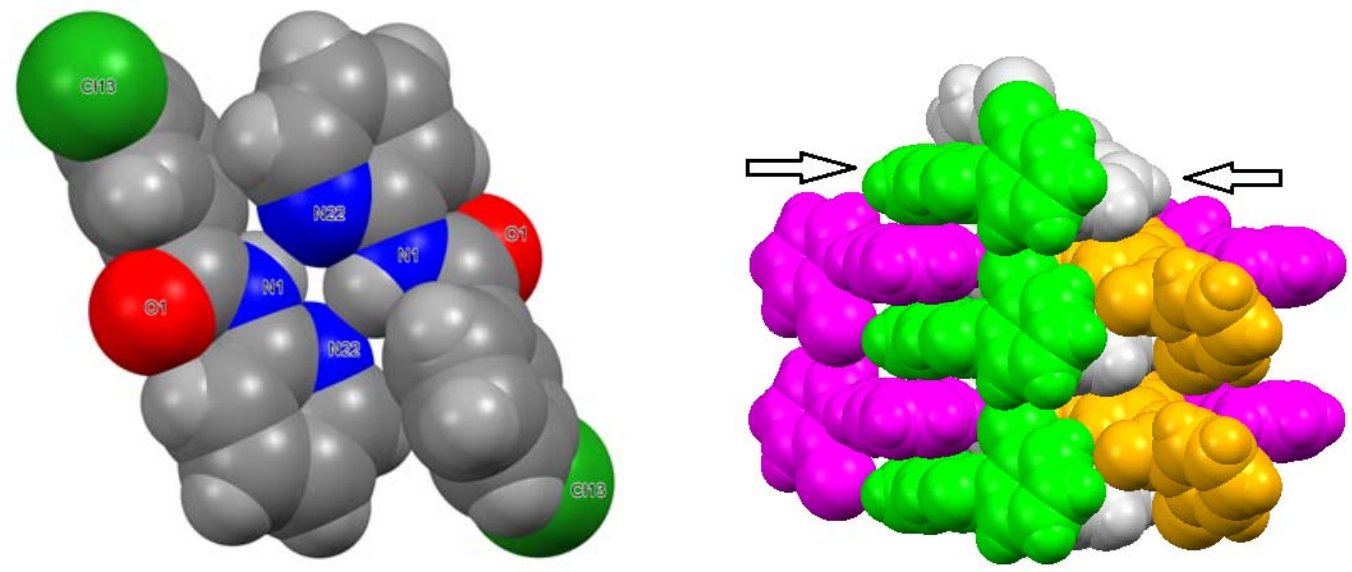

Figure 9: The Clmo dimer and pyridine...pyridine ring parallel stacking interactions in Cloo.

\section{Summary of the Clxx solid-state structural results}

The notable structural results for the $\mathbf{C l x x}$ series are: $(i)$ the $\mathbf{C l p o} \mathbf{0}, \mathbf{C l p o} \mathbf{N}$ polymorphic pair $^{76-80}$ (both as $Z^{\prime}=1$ in space group $C 2 / C$ ) and with voids present in the Clpo_N polymorph, (ii) the Clmp and Clpm structures having a relatively high $Z^{\prime}=4$ in the asymmetric unit, ${ }^{73-75}$ which is rather uncommon in benzamide structures reported to date, ${ }^{43}$ and (iii) the distinct lack of intermolecular $\mathrm{Cl}$... $\mathrm{O}$ and $\mathrm{Cl}$... $\mathrm{N}$ halogen bonding, apart from clear-cut cases such as Clop (as aromatic $\mathrm{C}-\mathrm{Cl} . . . \mathrm{O}=\mathrm{C}$ interactions) and $\mathrm{Clom}$ (with aromatic $\mathrm{C}-\mathrm{Cl}$.... $\mathrm{Cl}-\mathrm{C}$ contacts). There is, however, a $\mathrm{C}-\mathrm{Cl} . . . \pi$ intermolecular contact where the $\mathrm{Cl} \sigma$-hole faces the pyridine ring in Clpp at an angle $(\mathrm{C}-\mathrm{Cl}, \pi$ ring centroid $)=163.34(7)^{\circ} .{ }^{31-39}$

The Clxx isomer grid places in context the structural relationships that exist between isomer grids, e.g. $\mathbf{M x x},{ }^{45} \mathbf{F x x}^{43}$ and $\mathbf{B r x x} .{ }^{68}$ Overall, the structural landscape is broad, but overlaps include (a) five Clxx isomers that are isomorphous with their $\mathbf{B r x x}{ }^{68}$ analogues as the Clpp/Brpp, Clop/Brop, Clmm/Brmm monohydrates, Clom/Brom and Cloo/Broo pairs, and (b) the Clpp isomer being isomorphous with several related structures, including the parent Hpp, ${ }^{65}$ Fpp, Fmp, Fop triad, ${ }^{43,66} \mathbf{2 5 p},{ }^{67}$ Clpp and Brpp. ${ }^{68}$

Our results show the considerable overlap between the $\mathbf{C l x x}$ and $\mathbf{B r x x} \mathbf{x}^{68}$ structures and greater differences with their Fxx and $\mathbf{M x x}$ isomer grid analogues. ${ }^{43,45}$ The only molecular series where there is continuity between the structures is for the Xpp series, which is extensive at the isomorphous and isostructural level, especially so as it overlaps with Fpp/Fmp/Fop triad. Subtle differences at the molecular level do not impact on the overall 
molecular aggregation (isomorphous series) and differences between the crystal structures are noted at the secondary level. ${ }^{40-42,65-72}$

\section{Why is there such a considerable overlap between Clxx, Brxx but not with Fxx or Mxx?}

In order to quantify the isomorphous relationships in the isomer grids studied to date, Table 4 is presented and highlights the isomorphous behaviour and relationships between various $\mathbf{Y} \mathbf{x x}$ benzamide structures $\left(\mathbf{Y}=\mathbf{M e}{ }^{45} \mathbf{F}^{43} \mathbf{C l}^{\text {this work }} \mathbf{B r}^{68} ; \mathbf{x}=\right.$ para-, meta-, ortho-). ${ }^{40-42,66-72}$ Another set of relationships is to be expanded upon in the $\mathbf{C l} \mathbf{x x} / \mathbf{N x} \mathbf{x x C l}$ isomer series in future papers in addition to the Brxx and $\mathbf{N x x B r}$ series ( $\mathbf{N x x C l}$ and $\mathbf{N x x B r}$ are the amide bridged reversed isomers of $\mathbf{C l x x}$ and $\mathbf{B r x x}$, respectively).$^{68}$

Table 4: Isomorphous relationships in several series of benzamides ${ }^{40-46,68}$

\begin{tabular}{|c|c|c|c|c|}
\hline Other & Fxx $^{43}$ & Clxx & Brxx $^{68}$ & $\mathrm{Mxx}^{45}$ \\
\hline Hpp 65 & Fpp & Clpp & Brpp & $M p p$ \\
\hline \multirow[t]{8}{*}{$25 p^{67}$} & Fmp & Clmp & Brmp & $\mathrm{Mmp}$ \\
\hline & Fop & Clop & Brop & Mop \\
\hline & Fpm & Clpm & Brpm & Mpm \\
\hline & Fmm & Clmm* & Brmm* & $\mathrm{Mmm}$ \\
\hline & Fom & Clom & Brom & Mom \\
\hline & Fpo & Clpo & Brpo & Mpo \\
\hline & Fmo & Clmo & Brmo & Mmo \\
\hline & Foo & Cloo & Broo & Moo \\
\hline
\end{tabular}

Isomorphous pairs highlighted in colour. ${ }^{*}$ crystallises as a monohydrate

Table 4 highlights the significant overlap in isomorphous behaviour between 5 of the 9 pairs of structures (55\%) in the $\mathbf{C l x x}$ and $\mathbf{B r x x}$ isomer grids. ${ }^{68}$ This is not altogether unexpected and the isomer series as presented demonstrates mutual similarities and differences with their Fxx and $\mathbf{M x x}$ analogues. Another group is the para-para series (Ypp) spanning at least seven benzamides from the parent $\mathbf{H p p}$ to Brxx, with differences only obvious at the secondary interaction level. ${ }^{40-42,65,68-72}$

A question arises as to why is there so much structural overlap between the $\mathbf{C l x x}$ and $\mathbf{B r x x}$ analogues? This can be addressed by comparing our results with a $\mathrm{CSD}^{40-42}$ study by Mukherjee and Desiraju in 2014, ${ }^{34}$ in which they analysed a series of $\mathrm{Cl} / \mathrm{Br}$-containing structures where the pairs differ by replacement of a $\mathbf{C}-\mathbf{X}(\mathbf{X}=\mathrm{Cl}$ or $\mathrm{Br}) .^{34}$ In providing an insight into the behaviour of analogous pairs their statistical analysis highlights a high degree of similarity between both sets and with $\sim 57 \%$ of the $\mathrm{C}-\mathrm{Cl} / \mathrm{Br}$ pairs sharing the same space group, $Z$ and reduced cell parameters (within $1 \AA$ ). In their comprehensive study, ${ }^{34}$ the relative absence of $\mathrm{Cl} . . . \mathrm{Cl}$ (or $\mathrm{Br}$...Br) contacts was further noted and only observed in $<8 \%$ of structures (including disorder, classification ambiguities and $\mathrm{Cl} . . . \mathrm{Br}$ interactions). Our 
present results and statistics ( $55 \%)$ therefore correlate well with those reported from Mukherjee and Desiraju. ${ }^{34,40-42}$ The interchange of $\mathrm{Cl} / \mathrm{Br}$ in the majority of structural pairs from the Mukherjee and Desiraju CSD study, ${ }^{40-42}$ does not result in major structural changes or diversity and hence the high degree of structural overlap. ${ }^{34,40-42}$ 


\section{$A b$ initio modelling and conformational analyses}

In order to investigate the modelled, optimised structures of the nine Clxx molecules and differences with their solid-state molecular structures, optimisation of the modelled Clxx molecules was performed using the $a b$ initio software Gaussian0955 based on the DFT method (hybrid density functional B3LYP with $6-311 \mathrm{G}++(\mathrm{d}, \mathrm{p})$ basis set, gas phase). ${ }^{56,57}$ Models with optimised geometries (Table 5) were then used in the conformational analysis procedure. ${ }^{43-46}$ Each of the Clxx structures was subject to full Potential Energy Surface (PES) scans $\left( \pm 180^{\circ}\right.$, increment of $\left.5^{\circ}\right)$ of the two key $\mathrm{C} 12-\mathrm{C} 11-\mathrm{C} 1=\mathrm{O} 1(\alpha, \mathrm{Cl}$-ring $)$ and $\mathrm{C} 1-\mathrm{N} 1-\mathrm{C} 21-$ C26 ( $\beta$, P-ring) dihedral angles. Each of the asymmetric (meta- or ortho-) chlorophenyl (Clring) or pyridine (P-ring) groups, can adopt, relative to the amide linker, two conformations (syn or anti) (Scheme 3), as denoted by syn (Cl-syn, P-syn) or anti (Cl-anti, P-anti). Aromatic rings with a para-pyridine $\mathrm{N}$ and/or para-phenyl $\mathrm{Cl}$ atoms are not subject to this convention. The results provide nine diagrams with two PES curves highlighting the conformational preferences (syn/anti) and with the rotational barriers for both dihedral angles in $\mathrm{kJ}^{\mathrm{mol}}{ }^{-1}$. ${ }^{43-}$ 46,63-64

Table 5: Torsion angles $\left({ }^{\circ}\right)$ of optimised Clxx isomers $^{a}$

\begin{tabular}{lccc}
\hline Clxx & $\alpha /^{\circ}$ & $\beta /^{\circ}$ & $\delta /^{\circ}$ \\
Clpp & -24.41 & -5.29 & -2.90 \\
Clmp & 26.57 & 5.26 & 2.89 \\
Clop & 32.98 & -1.52 & 3.19 \\
Clpm & -24.17 & -5.65 & -2.31 \\
Clmm & 26.50 & 6.05 & 2.19 \\
Clom & -32.75 & 0.94 & -3.10 \\
Clpo & -21.57 & -3.63 & -2.34 \\
Clmo & 22.16 & 2.96 & 2.56 \\
Cloo & 37.22 & 0.07 & 3.06 \\
\hline
\end{tabular}

${ }^{a}$ Angle $\mathrm{C} 12-\mathrm{C} 11-\mathrm{C} 1=\mathrm{O} 1$ (Cl-ring) is $\alpha$; angle C1-N1-C21-C26 angle (P-ring) is $\beta$ and the O1-C1-N1-C21 angle (amide linkage) is $\delta$. All geometries are based on $\mathrm{B} 3 \mathrm{LYP} / 6-311++\mathrm{G}(\mathrm{d}, \mathrm{p})$ optimisation in gas phase. ${ }^{56,57}$<smiles></smiles>

Scheme 3: The four possible Clxx conformations for the $\mathrm{ClC}_{6} \mathrm{H}_{4}$ and $\mathrm{C}_{5} \mathrm{NH}_{4}$ pyridyl rings.

The conformational diagrams of the Clxx gas phase modeled structures (Figure 10) have PES curves for the P-rings (pyridyl, $\beta$ dihedral angle) depicted as full red lines and Cl-rings (chlorophenyl, $\alpha$ dihedral angle) as blue dashed lines. The $x$-axis shows the dihedral angle difference $(\theta)$ against the optimized dihedral angle in degrees $\left(\theta=0^{\circ}\right.$ is the dihedral angle in 
its optimized state, Table 5) and $y$-axes are the relative energies $(\Delta \mathrm{E})$ in $\mathrm{kJ}^{\mathrm{mol}}{ }^{-1}$. At $\theta=0^{\circ}$ and $\pm 180^{\circ}$, the asymmetric $\mathbf{C l}$ - or P-ring conformation is denoted as either syn or anti.

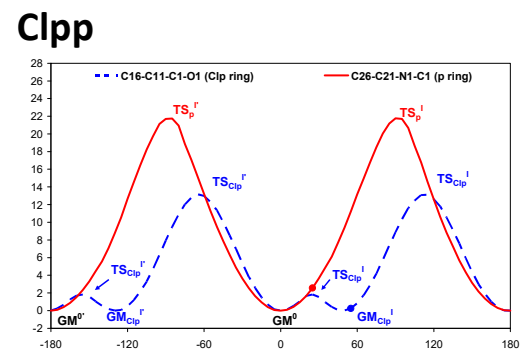

Clpm

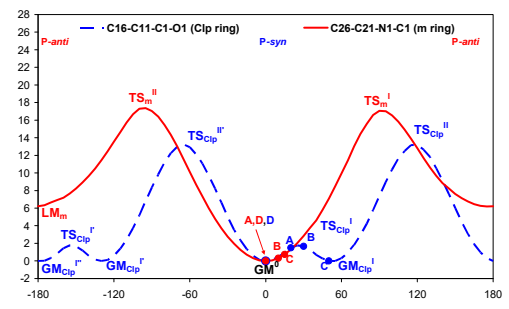

Clpo

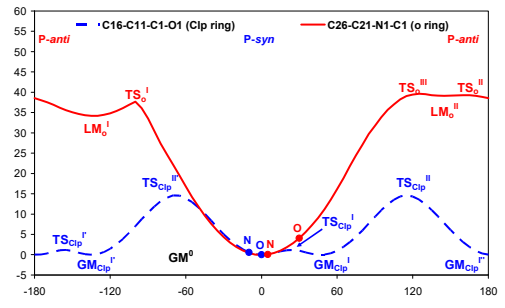

Clmp

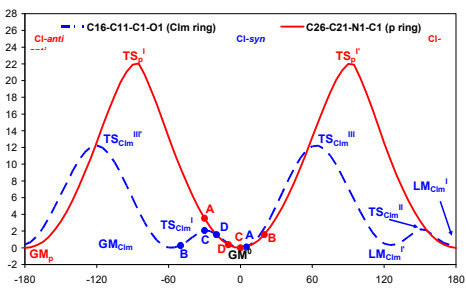

Clmm

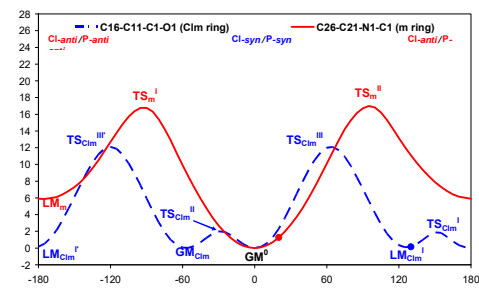

Clmo

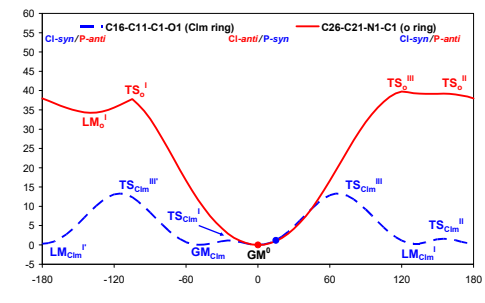

Clop

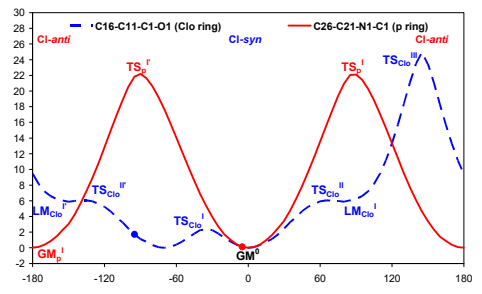

Clom

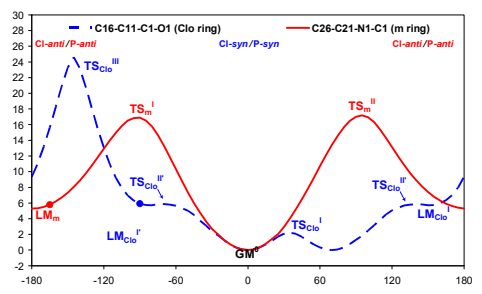

Cloo

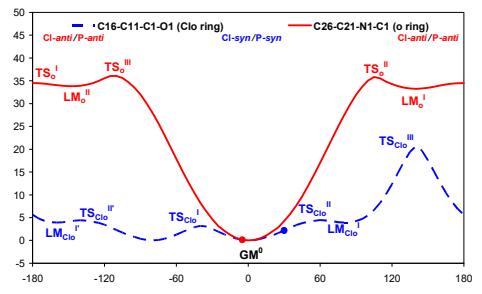

Figure 10: The Potential Energy Surface conformational analysis for nine Clxx optimized in the gas phase: the equivalent solid-state angle is shown by $(\bullet)$ with, if applicable, an assigned identifier. Enlarged versions are available in the ESI (Figure S3).

The geometry optimization and conformational analysis of the nine Clxx structures reveals several interesting observations. Firstly, the optimized Clxx geometries more closely resembles the methylbenzamide $(\mathbf{M x x})^{45}$ isomer grid than the related fluorine analogues (Fxx). ${ }^{43}$ The Clox triad is not planar like the equivalent Fox triad. ${ }^{43}$ This is mainly due to the absence of intramolecular $\mathrm{N}-\mathrm{H} . . . \mathrm{Cl}$ hydrogen bonding in the former and to the presence of intramolecular $\mathrm{N}-\mathrm{H}$...F interactions in the latter. However, the P-ring is still co-planar with the amide linker plane. In addition, the $\mathrm{Cl}$-ring in the Clox triad exhibits a greater deviation from planarity, as already noted in the Mox triad, ${ }^{45}$ since the $\mathrm{Cl}$ atoms in the Clox triad do not form intramolecular hydrogen bonds with the amide $\mathrm{N}-\mathrm{H}$ as the latter moiety prefers to interact with strong hydrogen bond acceptors such as amide $\mathrm{C}=\mathrm{O}$ and pyridine $\mathrm{N}$ atom. It is interesting also to note that the $\mathrm{Clmo}$ calculations suggest that the $\mathrm{Cl}$-anti conformation is more stable than the $\mathrm{Cl}$-syn conformation as would be expected.

The height of rotational barriers (energy differences) is comparable with the equivalent PES diagrams in the Fxx isomer series as well as for P-rings in $\mathbf{M x x} .{ }^{45}$ The profiles of the Clo-rings are asymmetric, though similar in shape to the Fo-rings (which are symmetric due to planarity/hydrogen bonding) and with slightly lower energy barriers. The Clp and Clm PES diagrams are very similar both in shape and barrier height to the $\mathbf{F p}$ and $\mathbf{F m}$ rings in Fxx. ${ }^{45}$ 
In each PES curve in Figure $\mathbf{1 0}$ the position of the solid-state dihedral angles of the $\mathbf{C l}$ - and $\mathbf{P}$ rings are marked by a dot (either $\bullet$ or $\bullet$ ) and if there is more than one molecule/polymorph these are marked with a corresponding letter. These marks illustrate the deviation of the solid-state angles from the optimized ones (at $\theta=0^{\circ}$ ) and from the closest global minimum. In most of the nine Clxx isomers there are small deviations $\left(+/-30^{\circ}\right)$ from the optimized starting points or closest minima, and up to ca. 3-4 kJ.mol-1 of energy difference. Although for Clmm and Clop, energy differences from the most stable conformer are noticeable, in general, there are no significant deviations between the global minima except for Clom.

In Clmm the most stable conformer in vacuo is $\mathrm{Cl}$-syn but the $\mathrm{Cl}$-anti conformation is observed in the solid-state. This conformational change from $\mathrm{Cl}$-syn to $\mathrm{Cl}$-anti is necessary to allow the formation of $\mathrm{N} 1-\mathrm{H} 1 \ldots \mathrm{O} 1 \mathrm{~W}$ hydrogen bonding that is essential for molecular aggregation in the crystal structure. If the $\mathrm{Clmm}$ molecule retained the $\mathrm{Cl}$-syn conformation, then formation of this hydrogen bonding arrangement would be hampered. In the Clop crystal structure the Clo-ring deviates by $\sim 90^{\circ}$ from its gas phase optimized minimum and is positioned between the $\mathrm{Cl}$-syn and $\mathrm{Cl}$-anti conformation. However, the energy expense of this deviation is just $\sim 3 \mathrm{~kJ}^{\mathrm{mol}} \mathrm{m}^{-1}$ and the angle change (deviation) is preferred as it facilitates the $\mathrm{C} 12-\mathrm{Cl} 12 \ldots(\mathrm{O} 1=\mathrm{C} 1)^{x x i}$ halogen bonding and $\mathrm{C} 15-\mathrm{H} 15 . . .01^{\text {vii }}$ hydrogen bonding formation.

In the Clom crystal structure the meta-pyridine ring adopts the unfavorable P-anti conformation which is $\sim 5 \mathrm{~kJ}^{\mathrm{mol}}{ }^{-1}$ higher in energy than the alternative P-syn conformation. This conformational change is also seen in Brom ${ }^{68}$ and Mom $^{45}$ and allows the formation of regular hydrogen bonded $\mathrm{N}-\mathrm{H}$... $\mathrm{N}$ zig-zag chains. There is a chlorine...chlorine contact which is almost in a head-to-head geometry as $\mathrm{C} 12-\mathrm{Cl} 12 . . . \mathrm{Cl} 12=167.66(6)^{\circ}$; see ESI (Figure S10). This configuration seems unfavourable at first glance as the two $\sigma$-holes are almost oriented towards each other. Moreover, the electrostatic energy from the deformation electron density part is indeed positive $\left.E_{\text {elec-Def }}(\mathrm{Cl} . . . \mathrm{Cl})=+0.8 \mathrm{~kJ} \cdot \mathrm{mol}^{-1}\right)$. However, as the neutral spherical atom contribution $\left(E_{\text {elec-Neu }}=-4.5 \mathrm{~kJ} \cdot \mathrm{mol}^{-1}\right.$ ) is very negative and the penetration energy (cross term describing the interaction between deformation and neutral spherical components) is very small, the interaction is globally stabilized from an electrostatic viewpoint $\left(E_{\text {elec }}=-3.5 \mathrm{~kJ} \cdot \mathrm{mol}^{-1}\right)$.

In general terms, conformational analysis of the nine Clxx isomers exhibits agreement between the conformations of the solid-state and modeled molecular structures, apart from the Clop, Clmm and Clom isomers (as noted above in the PES diagrams, Figure 10). These findings are consistent with our previous results in similar, related isomer grids though the optimized Clxx geometries more closely resemble the methylbenzamide ( $\mathbf{M x x})^{45}$ isomers than the related fluorine analogues (Fxx). ${ }^{43}$ 


\section{Melting point analysis: ${ }^{81-89}$ comparisons with related series}

For the Clxx series, it is noted that Carnelley's rule ${ }^{81}$ is adhered to on symmetry grounds with the most symmetrical Clpp (para-Chloro- $N$ '-(para-pyridyl)benzamide) having the highest melting point $\left(\mathrm{mp}=207^{\circ} \mathrm{C}\right.$ ) and the unsymmetrical Clmo (meta-Chloro- $N$ '-(orthopyridyl)benzamide having the lowest $\mathrm{mp}\left(100^{\circ} \mathrm{C}\right)$. The trends in Table 6 generally correspond with the average mps of the $\mathbf{F} \mathbf{x x}^{43}$ and $\mathbf{M} \mathbf{x x}^{45}$ series as well as the $\mathbf{B r x x}$ series ${ }^{68}$ where five isomorphous pairs of $\mathbf{C l} \mathbf{x x} / \mathbf{B r x x} \mathbf{x}^{68}$ are noted to have similar melting points (and within a range of $10-15^{\circ} \mathrm{C}$ ). The highest $\mathrm{mp}$ usually corresponds to a para-para (pp) isomer and the lowest typically from one of the ortho-meta/meta-ortho (om/mo) pairs. ${ }^{43}$ The Clxp triad has, on average, higher mps than Clxm or Clxo. For the corresponding analysis, the Clpx triad has the highest average compared to $\mathbf{C l m x}$ and Clox. Differences can be attributed to subtle and distinct secondary interactions that arise in the $\mathbf{C l x x} / \mathbf{B r x x}$ pairs and their effect on melting points.

Table 6: Melting point averages for Clxx isomer grid.

\begin{tabular}{|l|l|l|l|}
\hline Clxx isomers & Clpx & Clmx & Clox \\
\hline para (Clxp) & $207^{\star}$ & 187 & 169 \\
\hline meta (Clxm) & 151 & $113^{\#}$ & 136 \\
\hline ortho (Clxo) & 133 & $100^{*}$ & 136 \\
\hline
\end{tabular}

Footnote: Clpp has the highest $\mathrm{mp}{ }^{\star}$; Clom the lowest $\mathrm{mp}^{*}, \mathrm{Clmm}$ is a hydrate, Clpo is Clpo_o

The Clxx melting point ranges (Table 6) exhibit distinct differences when compared with their fluorine $(\mathbf{F x x})^{43}$ and methylbenzamide analogues (Mxx), (ESI, Table S3). ${ }^{45}$ The Clxx melting point ranges are on average $\sim 20^{\circ} \mathrm{C}$ higher than the equivalent fluorinated Fxx systems (ESI; Figure S2, Table S3), with an average( \pm standard deviation) $\mathrm{mp}$ for the nine Clxx isomers of $148 \pm 34^{\circ} \mathrm{C}$ compared with $131^{\circ} \mathrm{C}$ for Fxx..$^{43}$ Moreover, the average mp for the Brxx series $\left(147^{\circ} \mathrm{C}\right)^{68}$ is similar to $\mathbf{C l x x}$. This is not surprising given that five of the $\mathbf{C l x x}$ and Brxx $^{68}$ structures are isomorphous pairs with melting points within $10-15^{\circ} \mathrm{C}$ of each other. These values differ considerably from the average $\mathrm{mps}$ for the $\mathbf{M x x},{ }^{45} \mathbf{N} \mathbf{x} \mathbf{x F}^{44}$ and $\mathbf{N} \mathbf{x} \mathbf{M}^{46}$ series (ESI, Table S3) with average values of $116^{\circ} \mathrm{C}, 117^{\circ} \mathrm{C}$ and $113^{\circ} \mathrm{C}$, respectively. The distinct differences stem from the chloro, fluoro and methyl substitution in Clxx, Fxx, Mxx and the reversed amide bridge for their $\mathbf{N x x F}$ and $\mathbf{N x x M}$ analogues. The question arises as to why differences arise between related series of isomer grids? All other things being equal, the effect of chlorine substitution in Clxx compared to fluorine or methyl is to bestow an average higher $\mathrm{mp}$ of $17^{\circ} \mathrm{C}$ compared to $\mathbf{F x x}$, which is $15^{\circ} \mathrm{C}$ greater than $\mathbf{M x x}$ (as $\mathrm{Br} \approx \mathrm{Cl}>\mathrm{F}>\mathrm{Me}$ ). The $\mathbf{C l} \mathbf{x x}, \mathbf{F} \mathbf{x} \mathbf{x}, \mathbf{M} \mathbf{x x}$ series have higher average melting points than their corresponding amide bridge reversed $\mathbf{N x x C l}\left(134^{\circ} \mathrm{C}\right), \mathbf{N x x F}\left(117^{\circ} \mathrm{C}\right)$ and $\mathbf{N x x M}\left(113^{\circ} \mathrm{C}\right)$ isomer grids. ${ }^{43-46}$

In analysis of series of isomers and related congeners, it is important to be able to examine related structures and their physicochemical properties. ${ }^{40-42,69-72,90-94}$ The CSD as a repository for structural information is important for ancillary information such as melting points. ${ }^{40-}$ 42,90-94 In designing series of compounds, the drive to obtain a high melting point isomer should be influenced by the choice of $\mathrm{Cl}$ or $\mathrm{Br}$-derivatives over $\mathrm{F}$ or $\mathrm{Me}$ and with parasubstitutions where possible. Conversely, methyl-substituted and meta- or orthosubstituted are preferred for lower melting point compounds. ${ }^{40-46,81-89}$ 


\section{Physicochemical and melting point relations}

In order to try to relate the melting point temperatures to energies, additional analyses were conducted to identify correlations and trends. ${ }^{58-62}$ The variation in the Gibbs free energy involves changes in enthalpy $(\Delta H)$ and entropy $(\Delta S): \Delta G=\Delta H-T \Delta S$. At the melting point $T_{\mathrm{m}}$, the system is in equilibrium so that the free energy of the melting equals zero $\left(\Delta G_{f}\right.$ $=0),{ }^{86}$ and the following equation holds:

$$
\left.T_{\mathrm{m}}=\Delta H_{\mathrm{m}} / \Delta S_{\mathrm{m}} \quad \text { (equation } 1\right)
$$

Consequently, enthalpy and entropy changes are both determining in the melting point temperatures. A larger enthalpy of melting leads to a higher temperature value. Here, the melting point temperatures $T_{\mathrm{m}}$ are shown together with the estimated lattice electrostatic energy $\left(E_{\text {lat }}\right)$ of the compounds in the ESI (Figure S4). The Clmm monohydrate crystal structure is not included as it has a different chemical content; it has the largest electrostatic cohesive energy but a small $T_{\mathrm{m}}$ value.

Globally, it appears that the two quantities $T_{\mathrm{m}}$ and $E_{\text {lat }}$ are only moderately correlated (correlation factor $=47 \%$ ). The isomers with highest $T_{\mathrm{m}}$ tend however to have the largest negative $E_{\text {lat }}$ values, as shown by the positive sign of the correlation between $-E_{\text {lat }}$ and $T_{\mathrm{m}}$ for the Clxx isomer grids. Assuming electrostatics play a significant role in the stabilization of the crystal structure, it can indeed be expected that the electrostatic lattice energy $E_{\text {lat }}$ of the $\mathbf{C l x x}$ isomers relates to their melting enthalpy, and therefore to $T_{\mathrm{m}}$ from equation 1 , as discussed hereafter.

The entropy change $\Delta S_{\mathrm{m}}$ also contributes to the melting point temperature. This quantity is largely dependent on the arrangement of the constituent groups in the molecule and therefore to the increase in the number of different available states $\left(\Delta S_{m}>0\right)$ upon the phase transition from an organized crystal structure to a liquid state. ${ }^{86}$ Hence, one can expect a molecule with a high degree of rotational symmetry to show a smaller increase in entropy and, as a result, an increased $T_{\mathrm{m}}$ temperature (equation 1 ). For para-substituted compounds, the rotational symmetry of the molecule is higher with respect to the more unsymmetrical ortho- and meta-substituted $\mathbf{C l x x}$ isomers.

In an attempt to model Carnelley's rule, the ortho-/meta-/para-position descriptor $f$ is introduced (Figure 11a). ${ }^{81-89}$ The $f(\mathrm{Cl} x \mathrm{x}$ ) function, defined as:

$$
f(\mathrm{Clxy})=g(\mathrm{x})+g(\mathrm{y}) \quad \text { (equation } 2)
$$

with $g(\mathrm{~m})=g(0)=0$ and $g(\mathrm{p})=1$, takes values 0,1 or 2 as resulting from addition of ortho $=$ meta $=0$, para $=1$ contributions. This descriptor yields, alone, a correlation value of 0.82 with the melting temperature values (Figure 11a). It represents, in a rudimentary way, the differences in entropy changes due to the variations in the substituent moiety positions. The variable $f(\mathbf{C l} \mathbf{x x})$, defined to model Carnelley's rule is therefore anti-correlated with the entropy variation upon melting. 

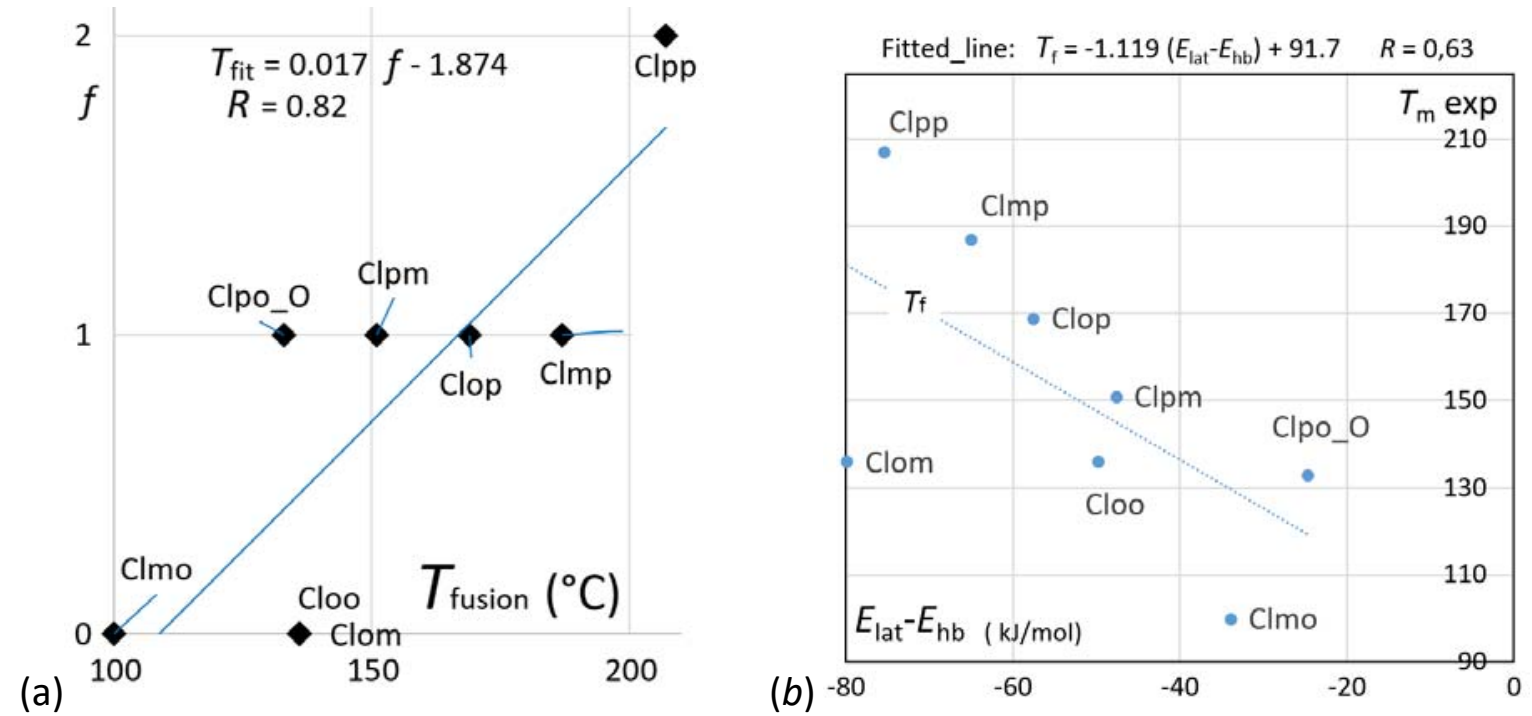

(c)

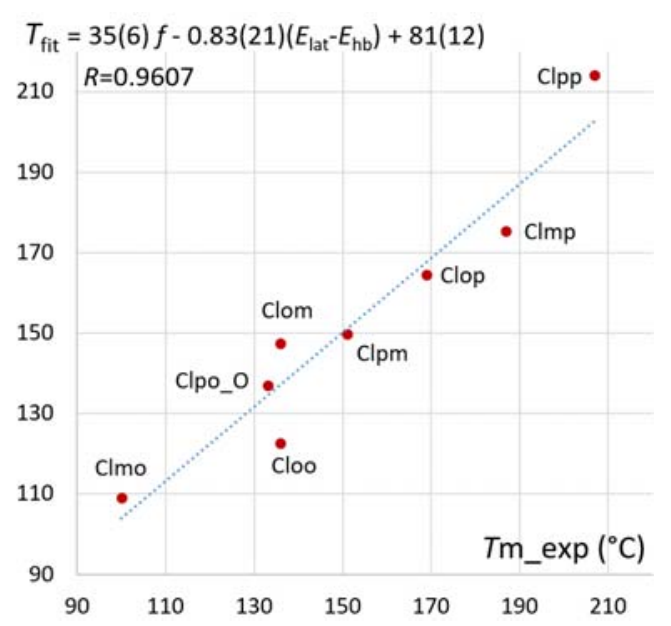

Figure 11. (a) Scatterplot of the experimental melting point $T_{\mathrm{m}}$ and and $f(\mathrm{Clxx})$ symmetry descriptor. The ortho-/meta-/para-positions descriptor $f(\mathrm{Clxy})$ is defined as $f(\mathrm{Cl} x \mathrm{y})=g(\mathrm{x})+$ $g(\mathrm{y})$, where $g(\mathrm{~m})=g(\mathrm{o})=0$ and $g(\mathrm{p})=1)$. The line shows the linear fit of the two variables $T_{\mathrm{m}}$ and $f$. (b) Scatterplot of $T_{\mathrm{m}}$ and $\left(E_{\mathrm{lat}}-E_{\mathrm{HB}}\right)$, where $E_{\text {lat }}$ is the lattice electrostatic energy and $E_{\mathrm{HB}}$ is the electrostatic energy between the two atoms involved in the strong hydrogen bond $\left(\mathrm{N} . . . \mathrm{H}_{\mathrm{N}}\right.$ or $\left.\mathrm{O} \ldots \mathrm{H}_{\mathrm{N}}\right)$ atoms using the transferred multipolar atom model. (c) Double linear fit of melting point using the $f$ and $E_{\mathrm{lat}}-E_{\mathrm{HB}}$ parameters.

A double linear regression to fit $T_{\mathrm{m}}$ against the Carnelley $f$ function values and $E_{\text {lat }}$ set of variables leads to a correlation of 0.957 (ESI, Figure S5). This model has the advantage to account simultaneously for the enthalpic (through $E_{\text {lat }}$ ) and the entropic (through $f$ ) contributions to the melting temperature $T_{\mathrm{m}}$.

The energetic contributions of strong $\mathrm{N}-\mathrm{H}$...N/O hydrogen bonds $\left(E_{\mathrm{HB}}\right)$ and the rest of interactions $\left(E_{\text {lat }}-E_{\mathrm{HB}}\right)$ were also evaluated. While the electrostatic energy between $\mathrm{H}_{\mathrm{N}}$ and $\mathrm{N} / \mathrm{O}$ atoms is on average $-44 \mathrm{~kJ}^{\mathrm{mol}}{ }^{-1}$, weaker $\mathrm{C}-\mathrm{H}$... O and $\mathrm{C}-\mathrm{H}$... N contacts have an energy lower than $-20 \mathrm{~kJ} \cdot \mathrm{mol}^{-1}$. The single fitting of $T_{\mathrm{m}}$ against $E_{\mathrm{lat}}-E_{\mathrm{HB}}$ (correlation $=-0.63$ in Table 7, Figure 11b) is stronger than against $E_{\text {lat }}$ (correlation factor $=-0.47$ in Table 7 and Figure S4; ESI), suggesting that contributions to $\Delta H_{\mathrm{m}}$ enthalpy are rather due to the weaker 
interactions. Moreover, the non-existent dependence between $T_{\mathrm{m}}$ and $E_{\mathrm{HB}}$ (correlation factor $=0.09$ in Table 7) also accounts for the same trend.

Comparison of the double linear regressions in Figure S5 (ESI) and Figure 11c further supports the evidence. Indeed, the 0.957 correlation found in Figure S5 (involving all electrostatic interactions) is only slightly lower than that described by the contributions of weaker interactions only (those excluding stronger $\mathrm{HB}^{\prime} \mathrm{s}$ ) in Figure 11c. The $E_{\mathrm{HB}}$ contribution in the former is compensated by the variation of the other fitting parameter $f$ in the corresponding $T_{\text {fit }}$ function.

Table 7. Linear correlation coefficients (\%) $(R)$ between several properties and variables.

\begin{tabular}{|c|ccccc|}
\hline Correlation & $T_{\mathrm{m}}$ & $E_{\text {lat }}$ & $f$ (Carnelley) & density & $E_{\mathrm{HB}}$ \\
\hline$E_{\text {lat }}$ & -47 & & & & \\
$f$ (Carnelley) & 83 & 45 & & & \\
Crystal density & 1 & 54 & 25 & & \\
$E_{\mathrm{HB}}$ & 89 & 72 & 42 & 79 & \\
$E_{\text {lat }}-E_{\mathrm{HB}}$ & -63 & 94 & -14 & 30 & 44 \\
\hline Dipole $\mu^{\#}$ & 26 & -75 & -2 & 79 & -60 \\
\hline
\end{tabular}

\# The Clxx single molecule dipole moment

Accordingly, one can think that, at the melting point, weaker interactions will firstly dissociate because their intermolecular forces will not be able to restore their equilibrium solid-state geometries, while stronger interactions maintain their restoring forces. Overall, a high correlation such as presented herein (Figure 11c) might suggest a possible predictive behavior of the model, which will be further tested in studies of related series of $\mathbf{Y x x}$ substituted benzamides. ${ }^{68}$

The mean disagreement (as defined from the $\left|T_{\text {fit }}-T_{\mathrm{m}}\right| / T_{\mathrm{m}}$ value calculated over the eight data points) is respectively, $<5.2 \%$ and $<5.5 \%$ in the double linear regression fittings in Figure 11c and Figure S5 (ESI). The most important deviation (10\%) is observed for Cloo in both fittings.

The lattice electrostatic energy $E_{\text {lat }}$ was compared with $E_{\text {Syms, }}$ the electrostatic interaction energy of the molecule with its immediate neighbouring molecules in the crystal packing (Figure 12). For all Clxx isomers, the $E_{\text {Syms }}$ and $E_{\text {lat }}$ values are very similar (Figure 12a), which shows that most of the lattice electrostatic energy originates from interactions with molecules directly in contact with the original molecule under study (i.e. the nearest neighbours). The energy values were computed for the four independent molecules (labelled as $A=1, B=2, C=3, D=4$ ) in the Clmp and Clpm crystal structures and averaged. The Clpm crystal structure is rather peculiar with molecules related by translation along the short unit cell axis $a=4.0095$ (4) $\AA$ which interact and result in an unfavourable electrostatic energy as electropositive/negative complementarity is not achieved. The $E_{\text {elec }}$ values are all positive between dimers related by translation vector a in the Clpm crystal structure, +1.5, $+1.8,+12.4$ and $+11.7 \mathrm{~kJ} \cdot \mathrm{mol}^{-1}$ for dimers 1 (A), 2 (B), 3 (C) and 4 (D), respectively.

For the 10 Clxx structures (including both Clpo_O and Clpo_N polymorphs, the hydrated Clmm and the averaged values for the four independent molecules in Clmp and Clpm), the 
plotted $E_{\text {syms }} v s E_{\text {lat }}$ data (Figure $\mathbf{1 2 b}$ ) are highly and linearly correlated. Indeed, the linear fitting between the two sets of values is $E_{\text {Syms }}=1.028(57)$ and $E_{\text {lat }}+0(6)$ (with a correlation factor $R=0.9877$ ). The external disagreement (as defined by the fitting parameter of the slope) is lower than $3 \%$, while the internal disagreement (as defined by the mean $\mid E_{\text {syms }}-$ $\left.E_{\text {lat }} \mid / E_{\text {lat }}\right)$ value calculated for the data) is $5 \%$. The most important deviation in the internal disagreement is found for Clmo (14\%).

The hydrogen bond contribution $E_{\mathrm{HB}}$ to the electrostatic energies were also computed as $E_{\text {elec }}$ between $\mathrm{H}_{\mathrm{N}}$ and $\mathrm{N} / \mathrm{O}$ atoms) (ESI, Figure S9). The $E_{\mathrm{HB}}$ values are inversely correlated with the $\mathrm{d}\left(\mathrm{H}_{\mathrm{N}} \ldots \mathrm{N} / \mathrm{O}\right)$ distances. The Clom structure has the strongest $E_{\text {lat }}$ value, which is due

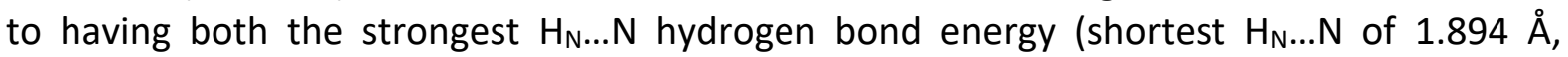
2.073(17) $\AA$ and $E_{\text {lat }}-E_{\mathrm{HB}}$ complement. The longest $\mathrm{N}-\mathrm{H}$...N bond is noted in Clmo, with $d\left(\mathrm{~N}, \mathrm{H}_{\mathrm{N}}\right)=2.302,2.45(2) \AA$; it has the weakest $E_{\mathrm{HB}}$; Clmo has two molecules related by an inversion centre to form a hydrogen bonded dimer as a cyclic $R^{2}{ }_{2}(8)$ ring with two N-H...N interactions in close proximity. ${ }^{43-46}$

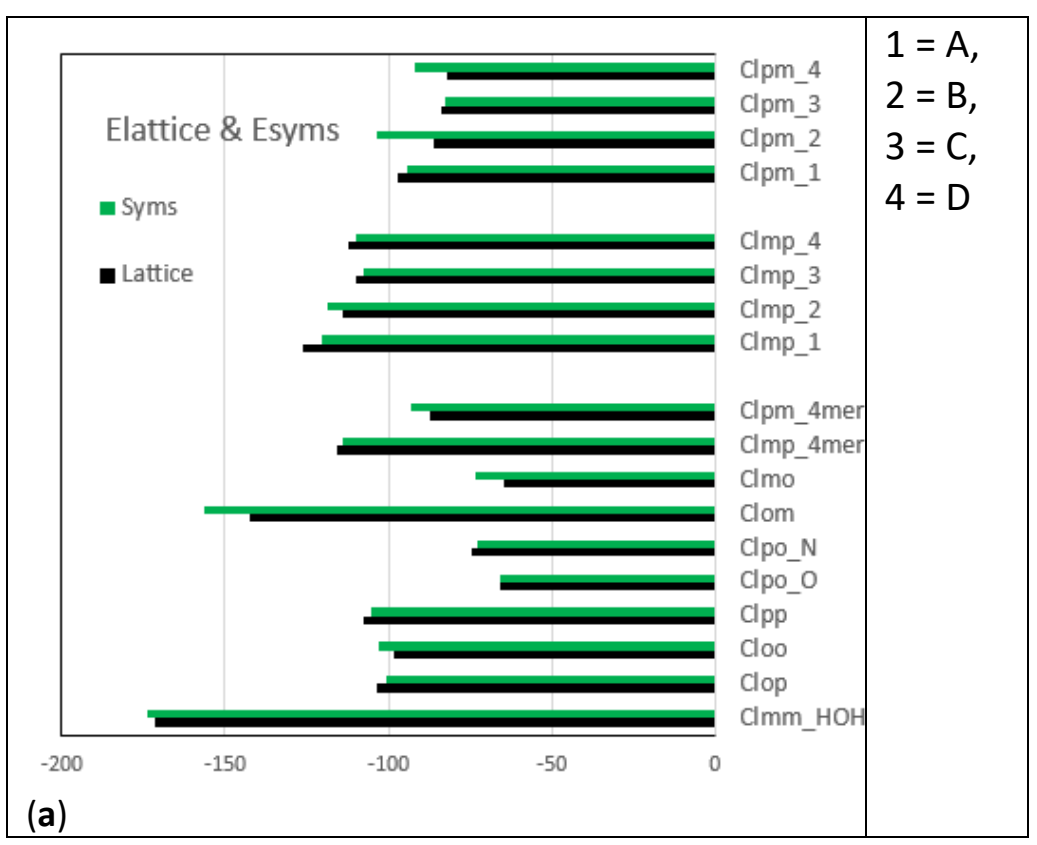




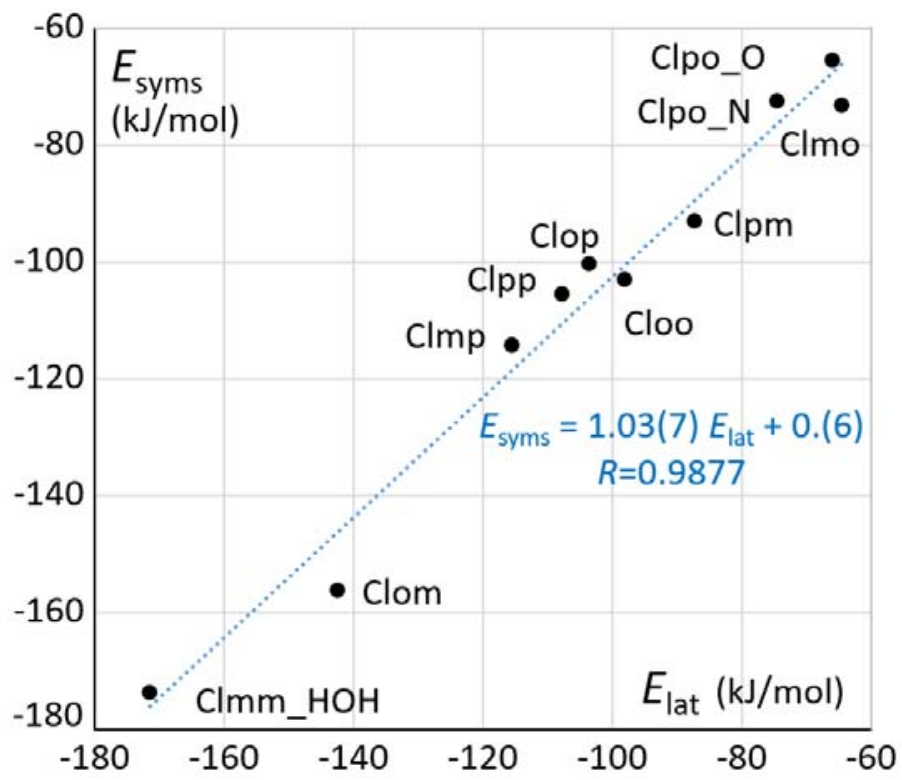

(b)

Figure 12. (a) A plot of $E_{\text {lat }}$ (electrostatic lattice energy) and $E_{\text {Syms }}$ (electrostatic interaction energy between a central molecule and its nearest neighbours) for the ten Clxx crystal structures. (b) Linear fitting of $E_{\text {syms }} v s$. Elat. Energies are in $\mathrm{kJ} . \mathrm{mol}^{-1}$.

Other properties have also been analysed in the search for correlations that could be related to the melting temperature variations amongst the $\mathbf{C l x x}$ benzamides studied (Table 7). For instance, there is no correlation established between the $\mathrm{mp}$ temperature and the crystal density.

\section{Contacts analysis}

The intermolecular interactions of the isomer grid have been quantified using Hirshfeld surface analysis. The definition of enrichment ratios of contact has been detailed. ${ }^{95-96}$ The enrichment ratio $\varepsilon_{X Y}$ for a pair of elements $(X, Y)$ is defined as the ratio between the proportion of actual contacts in the crystal and the theoretical proportion of equidistributed random contacts. An enrichment ratio larger than unity reveals that the contacts between a pair of elements are over-represented.

Table 8. Average \% of intermolecular contacts $C_{\mathrm{xy}}$ and their enrichment $\varepsilon_{\mathrm{xy}}$ in the 9 non-

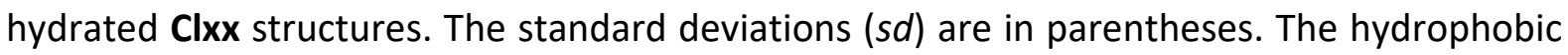
and hydrophilic groups are separated by lines. The $\varepsilon_{x y}>>1$ ratios are in bold and correspond to the significantly enriched contacts. $\mathrm{H}_{\mathrm{N}} \ldots \mathrm{H}_{\mathrm{N}}$ and $\mathrm{O} \ldots \mathrm{H}_{\mathrm{N}}$ contacts have three large $\varepsilon$ values and six small or zero values, therefore their standard deviations ( $s d$ 's) are large. The last row shows the average chemical content on the Hirshfeld surface.

\begin{tabular}{|c|c|c|c|c|c|c|}
\hline$C_{\mathrm{xy}}$ & C & $\mathrm{H}_{\mathrm{C}}$ & $\mathrm{Cl}$ & $\mathbf{N}$ & 0 & $\mathrm{H}_{\mathrm{N}}$ \\
\hline C & $13(3)$ & & & \multirow{3}{*}{\multicolumn{3}{|c|}{$\underline{\% \text { contacts }}$}} \\
\hline $\mathrm{H}_{\mathrm{C}}$ & $29(6)$ & $11(4)$ & & & & \\
\hline $\mathrm{Cl}$ & $7(3)$ & $16(4)$ & $1(1)$ & & & \\
\hline $\mathbf{N}$ & $2.3(12)$ & $4.4(18)$ & $0.5(11)$ & $0.1(1)$ & \multirow{2}{*}{\multicolumn{2}{|c|}{$0(0)$}} \\
\hline 0 & $3.1(13)$ & $5.5(23)$ & $0.5(12)$ & $0.2(3)$ & & \\
\hline $\mathrm{H}_{\mathrm{N}}$ & $0.6(6)$ & $0.6(4)$ & $0.2(4)$ & $3.6(16)$ & $1.1(17)$ & $0.0(3)$ \\
\hline C & $1.2(3)$ & & & \multirow{2}{*}{\multicolumn{3}{|c|}{ enrichment }} \\
\hline $\mathrm{H}_{\mathrm{C}}$ & $1.0(3)$ & $0.8(3)$ & & & & \\
\hline
\end{tabular}




\begin{tabular}{|l|lll|lll|}
$\mathbf{C l}$ & $0.8(3)$ & $1.6(3)$ & $0.6(7)$ & & & \\
$\mathbf{N}$ & $0.7(3)$ & $0.9(4)$ & $0.3(7)$ & $0.2(4)$ & & \\
$\mathbf{O}$ & $0.8(4)$ & $\mathbf{1 . 5 ( 6 )}$ & $0.3(8)$ & $0.3(6)$ & $0.2(6)$ & \\
$\mathbf{H}_{\mathbf{N}}$ & $0.3(3)$ & $0.3(2)$ & $0.1(4)$ & $\mathbf{1 1 ( 4 )}$ & $\mathbf{2 . 7 ( 4 8 )}$ & $1.9(27)$ \\
\hline \% surface & 36.1 & 36.5 & 13.6 & 5.5 & 5.1 & 3.2 \\
\hline
\end{tabular}

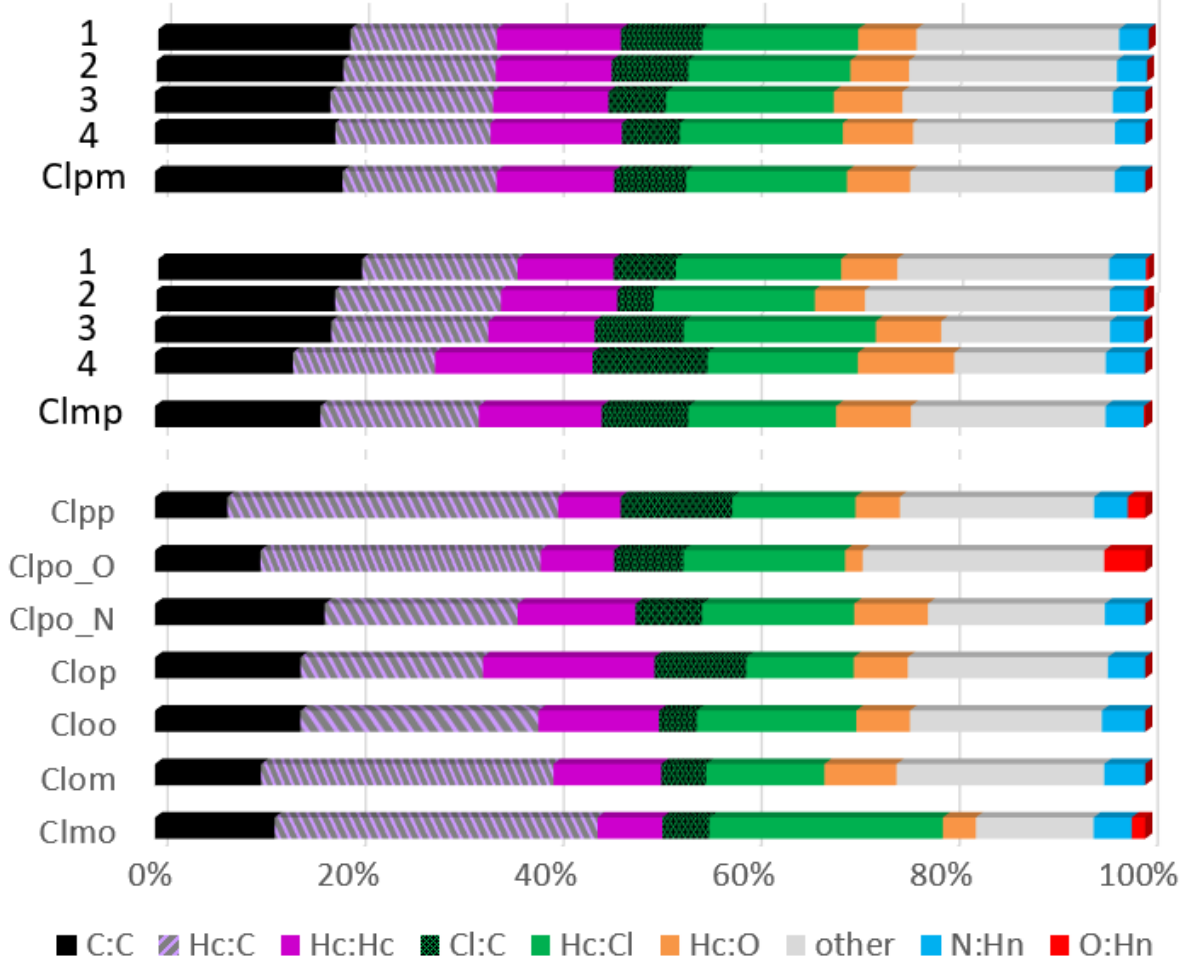

Figure 13. The \% of contacts in the 9 non-hydrated Clxx crystal structures. The contacts of all four independent molecules in Clmp and Clpm crystal structures are depicted.

The average statistics on crystal contacts are listed in Table 8, while data on each individual crystal structure are presented (Figure $\mathbf{1 3}$ and ESI, Table S4). The Clxx benzamide molecules are reasonably hydrophobic as the surface comprises just $14 \%$ of hydrophilic atoms $\left(O, \mathrm{H}_{\mathrm{N}}\right.$, $\mathrm{N})$. The contacts between hydrophobic atoms $\left(\mathrm{C}, \mathrm{H}_{\mathrm{C}}, \mathrm{Cl}\right)$ account for $78 \%$ of the interaction surface while polar contacts involving only $\left(\mathrm{H}_{N}, \mathrm{O}, \mathrm{N}\right)$ atoms represent just $5 \%$ in the nine Clxx crystal structures. The cross contacts between hydrophobic and polar atoms constitute $17 \%$ of the surface and are mainly weak hydrogen bonds of $\mathrm{C}-\mathrm{H} . . . \mathrm{O}$ type $(5.5 \%)$ and $\mathrm{C}-\mathrm{H} . . . \mathrm{N}$ (4.4\%). All polar...non-polar cross interactions between atoms are, on average, underrepresented, except the weak $\mathrm{C}-\mathrm{H}$... O hydrogen bonds. The partition between hydrophobic contacts $(78 \pm 1) \%$, hydrophilic $(5 \pm 1) \%$ and cross contacts $(17 \pm 2) \%$ is quite stable in the nine non-hydrated Clxx isomers (ESI, Table S6).

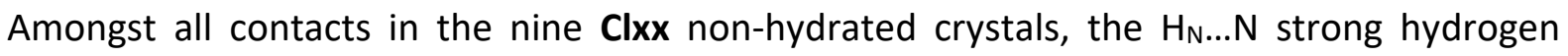
bond is on average the most enriched at $\varepsilon=11(4)$. The Clpo_O structure is the only one where the hydrogen bond donor $\mathrm{N}-\mathrm{H}$ interacts strongly with the amide oxygen atom (as amide...amide interactions). The Clpp crystal structure is also peculiar, as both $\mathrm{H}_{\mathrm{N} . . . \mathrm{N} \text { and }}$ $\mathrm{H}_{\mathrm{N} . . . \mathrm{O}}$ are enriched $(\varepsilon=4.0$ and 2.0$)$ due to the presence of a bifurcated hydrogen bond (contact), with $d\left(\mathrm{~N} . . . \mathrm{H}_{\mathrm{N}}\right)=2.441(19) \AA$ and $d\left(\mathrm{O} . . . \mathrm{H}_{\mathrm{N}}\right)=2.837(17) \AA$. In the Clmo crystal 
structure, a secondary long distance electrostatic interaction $d\left(\mathrm{H}_{\mathrm{N}} \ldots \mathrm{O}\right)=3.266(18) \AA$ also forms, in addition, to the primary $d\left(\mathrm{H}_{\mathrm{N}} \ldots \mathrm{N}\right)=2.45(2) \AA$ hydrogen bond. ${ }^{25-30,40-42}$

All self contacts between charged atoms $\left(\mathrm{O}, \mathrm{N}, \mathrm{H}_{\mathrm{N}}\right)$ are generally avoided as they are not favourable from an electrostatic viewpoint. ${ }^{95,96}$ However, in the Cloo and Clmo crystal structures, the $\mathrm{N}-\mathrm{H}$ and $\mathrm{N}$ acceptor atoms are in close proximity resulting in the formation of a double $\mathrm{N}-\mathrm{H}$... N hydrogen bond with graph set $R^{2}{ }_{2}(8)$ (around a two-fold axis and inversion centre, respectively) leading to secondary $\mathrm{H}_{\mathrm{N} . . .} \mathrm{H}_{\mathrm{N}}$ contacts. ${ }^{43-46}$

The vast majority of intermolecular interactions are hydrophobic in nature, they constitute the five most represented contacts and four of them have $C_{x y}$ proportions larger than $11 \%$. The $\mathrm{Cl}^{\delta-} \ldots \mathrm{Hc}_{\mathrm{c}}^{\delta+}$ contact is the most enriched between the hydrophobic atom types and is considered as a weak hydrogen bond. ${ }^{25-30}$ It is slightly attractive from an electrostatic point of view; for example the $\mathrm{Cl} 3 \ldots \mathrm{H} 13$ contact in $\operatorname{Clmp}(x-1, y, z+1, d=3.00 \AA)$ yields an energy between the two multipolar atoms of $-2.4 \mathrm{~kJ}_{\text {. mol }}{ }^{-1}$. The $\mathrm{H}_{\mathrm{c}} . . \mathrm{Cl}$ contact is, on average, the only enriched contact formed by chlorine in the Clxx series. $\mathrm{H}_{\mathrm{C}}$ has been noted to be a favoured partner for organic halogen atoms in several families of molecules. ${ }^{96}$ The $\mathrm{O} . . . \mathrm{Cl}$ and $\mathrm{N} . . . \mathrm{Cl}$ contacts are, on average, quite disfavoured (with $\langle\varepsilon\rangle=0.3$ ) with halogen bonding absent in all but one structure. ${ }^{31-39}$ Clop exhibits a typical $\mathrm{Cl}$... $\mathrm{O}$ halogen bond with $d(\mathrm{O}, \mathrm{Cl})=$ $3.1104(18) \AA$ and a C-Cl...O angle of $161.08(8)^{\circ}$ which is not far from linearity $\left(180^{\circ}\right)$. The electrostatic energy between $\mathrm{Cl}$ and $\mathrm{O}$ atoms is however, slightly positive (unfavourable) at $1.5 \mathrm{~kJ} \mathrm{~mol}^{-1}$. In two other crystal structures, these contacts do occur and leading to enrichment values larger than unity. The Cloo structure has three long range $\mathrm{Cl}$... $\mathrm{N}$ contacts, while $\mathrm{Clmm} \bullet \mathrm{H}_{2} \mathrm{O}$ has several long $\mathrm{Cl} . . . \mathrm{O}$ and $\mathrm{Cl} . . . \mathrm{N}$ contacts. ${ }^{31-39}$ The $\mathrm{Cl}$...Cl contacts have on average an enrichment equal to unity but they only occur in half of the Clxx crystal structures. A significantly enriched and short $\mathrm{Cl}$...Cl contact occurs only in the Clom structure (ESI, Figure S10)..$^{31-39}$

In the Clxx benzamides the C...C contacts are slightly enriched due to the occurrence of aromatic donor...acceptor interactions between aromatic rings. ${ }^{30}$ Two aromatic rings with the $\mathrm{Cl}^{\delta-}$ and $\mathrm{N}^{\delta-}$ atoms have the ability to form favorable stacking interactions. Heterocycles have a good propensity to form ring stacking as the electropositive and electronegative atoms can be interacting partners. ${ }^{97}$ For example in the Cloo and Clom structures, the N$\mathrm{C}_{5} \mathrm{NH}_{4}$ group is in a parallel displaced interaction with symmetry related rings through an inversion center and the $\mathrm{N}$ atoms are located in opposite directions. In $\mathbf{C l p o}$ - $\mathbf{N}$, the entire $\mathrm{O}=\mathrm{C}-(\mathrm{NH}) \mathrm{C}_{5} \mathrm{H}_{4} \mathrm{~N}$ moiety is in a parallel stacking mode with itself through an inversion center. In Clop, the same self-interaction occurs and in addition the pyridine ring forms a cross interaction with the chlorobenzene ring of a symmetry related Clop molecule. The $\mathrm{Clmm} \bullet \mathrm{H}_{2} \mathrm{O}$ crystal structure has the highest $\varepsilon_{\mathrm{CC}}=2.0$ ratio and shows extensive aromatic ring stacking in the $a$-axis direction of the whole (nearly planar) benzamide molecule with symmetry-related rings through an inversion center. This occurs in the $\mathrm{Clmp}$ crystal $\left(Z^{\prime}=4\right)$ as well, where stacking along the $c$-axis occurs through an alternation of crystallographic inversion and non-crystallographic pseudo-inversion symmetry operations. The Clpm crystal is unusual as the four independent molecules (A-D) show parallel displaced stacking through a translation (and not an inversion) along the short axes $(a=4.01 \AA$ ). Consequently, this $\mathrm{Clpm}$ crystal structure exhibits unusually enriched $\mathrm{O}$...O and $\mathrm{Cl} . . . \mathrm{Cl}$ contacts. ${ }^{31-39}$ 
The linear correlation coefficient $R$ between the enrichment ratios found in the nine $\mathbf{C l x x}$ non-hydrate crystals is displayed in Table S7 (ESI). As a reference, a set of 9 random variables taking values in the $[0,1]$ interval, yields a root mean square $\mathrm{rms}(R)$ value of 0.35 . For further reference, $\mathrm{rms}(R)$ is 0.40 and the average is $\langle R\rangle=-0.05$ for the enrichment ratios in Clxx. However, a few correlations take significant values up to 0.96 , in terms of absolute value. Very large correlations should have a chemical meaning while moderate values may be explained or may be incidental due to limited sample size. The analysis highlights some clear trends but also shows some absence of correlations.

The two strong hydrogen bonds $\mathrm{O} \ldots . . \mathrm{H}_{\mathrm{N}}$ and $\mathrm{N} . . . \mathrm{H}_{\mathrm{N}}$ are inversely-correlated, as could be expected (with $r=-0.45$ ). The strong and weak hydrogen bonds $\mathrm{N} . . . \mathrm{H}_{\mathrm{N}}$ and $\mathrm{N}$.... $\mathrm{H}_{\mathrm{C}}$ turn out to be the most anti-correlated contacts (with $R=-0.96$ ), as all Clxx crystals, except for Clpo_0, have a $\mathrm{N}-\mathrm{H} \ldots \mathrm{N}$ hydrogen bond. Conversely, the $\mathrm{O} \ldots \mathrm{H}_{\mathrm{N}}$ and $\mathrm{O} \ldots \mathrm{H}_{\mathrm{C}}$ which are both mildly enriched, on average, occur in an unrelated way in the crystal packings (with $R=0.07$ ). Among the hydrophobic contacts, the $\varepsilon_{\mathrm{CC}}$ and $\varepsilon_{\mathrm{CHc}}$ values are $56 \%$ correlated while the $\varepsilon_{\mathrm{CC}}$ and $\varepsilon_{\mathrm{HcHc}}$ values display an $R$ value of $-50 \%$. The correlation $R=0.79$ between $\varepsilon_{\mathrm{CC}}$ and $\varepsilon_{\mathrm{NN}}$ may be explained by the concomitant occurrence of stacking between the pyridine heterocycles.

\section{Conclusions}

A series of nine Clxx benzamide isomers have been analysed for comparisons and show a degree of correlation with the related Fxx, $\mathbf{M x x}$ benzamides, ${ }^{43,45}$ and especially with $\mathbf{B r x x}{ }^{68}$ in terms of isomorphous behaviour. ${ }^{90-94}$ In terms of their physicochemical behaviour, the series builds on our knowledge of isomeric relationships and shows that Clxx and $\mathbf{B r x x}$ behave largely in a similar fashion and differing substantially from the Fxx and $\mathbf{M x x}$ isomer grids. The Clxx series provides examples such as the Clpp isomorphous/isostructural relationship with several $\mathbf{X p p}$ relatives ${ }^{43-46}$ and considerable overlap between $\mathbf{C l} \mathbf{x x}$ and $\mathbf{B r x x}$ (with five isomorphous pairs), though much less so with Fxx and Mxx. Both can be rationalised as being influenced by strong hydrogen bonding dominating the interactions in solution and at the crystallization event, with the halogens having similar $(\mathrm{Br}, \mathrm{Cl})$ and different $(\mathrm{Cl}, \mathrm{F})$ steric and electronic influences on intermolecular interactions. ${ }^{31-39}$ Our results indicate the dominance of $\mathrm{N}-\mathrm{H}$...N over $\mathrm{N}-\mathrm{H}$...O $=\mathrm{C}$ interactions in $\mathbf{Y x x}$ work ${ }^{43-46,68}$ The transition from $\mathrm{Me}$ to $\mathrm{F}$ to $\mathrm{Cl}$ to $\mathrm{Br}$ shows the differences between the role of switching $\mathrm{F} / \mathrm{H}$ position (steric/electronic) to structures where replacement by $\mathrm{Cl}$ or $\mathrm{Br}$ shows increasing crystal structure overlap, ${ }^{34}$ and where the effect of the halogen on structure and interactions is more noteable.

Within the Clxx grid, examples include the two Clpo polymorphs which crystallise in the same space group $\left(Z^{\prime}=1\right)$ which is relatively rare though not unusual. ${ }^{40-42,78}$ The Clpo_N crystal structure crystallises with lattice voids of dimensions similar in size to $\mathrm{H}_{2}$ molecules. Of interest is the preponderance of para-meta substituted (pm) crystal structures observed with $Z^{\prime}=4$ in the $\mathrm{Cl}, \mathrm{F}$, Me series of compounds studied to date, including Clpm and Clmp from this study. However, the $\mathbf{B r x x}$ and $\mathbf{N x x B r}$ series $^{68}$ do not contain any crystal structures with $Z^{\prime}>2 .{ }^{73,75}$ Of note is that there is a lack of $\mathrm{Cl}$...O and $\mathrm{Cl}$... N halogen bonding interactions in Clxx apart from the Clpp, Clop and Clom structures. ${ }^{31-39}$ This can be attributed to the fact that there is only one halogen atom $(\mathrm{Cl})$ per molecule and there is considerable competition with other interactions. The pyridine $\mathrm{N}$ atom is rather involved in the formation of strong 
hydrogen bonds with $\mathrm{H}-\mathrm{N}$, while the amide $\mathrm{O}$ atom generally forms weaker $\mathrm{C}-\mathrm{H}$...O hydrogen bonds. On the other hand, the $\mathrm{C}-\mathrm{H} . . . \mathrm{Cl}$ weak hydrogen bonds have a more favourable electrostatic energy than the $\mathrm{Cl} . . . \mathrm{O} / \mathrm{N}$ halogen bonding. ${ }^{31-39}$

The Clxx isomer grid provides an illustration of Carnelley's rule, which relates the crystal melting temperature to the symmetry of the crystallized molecule. ${ }^{81-89}$ An empirical function based on the substituent positions and the lattice electrostatic energy is introduced, allowing us to obtain the fitted melting temperatures which are more than $95 \%$ correlated with the experimental values. Given the high correlation, this model will be further refined in series of related benzamides and its possible predictive behaviour will be evaluated.

The entropic component of $T_{\mathrm{m}}$ has been related to molecular symmetry using the $f$ descriptor, which accounts for the ortho-/meta-/para-positions differentiating the local symmetry of the Clxx molecular structures. On the other hand, from an investigation of simple fittings of the melting point $T_{\mathrm{m}}$, it demonstrates that the one based on $E_{\text {lat }}-E_{\mathrm{HB}}$ accounts for a better correlation than from the total lattice electrostatic energy $E_{\text {lat }}$. This trend suggests that the enthalpic component of $T_{\mathrm{m}}$ is better described by weaker solid-state interactions. When a double linear regression of $T_{\mathrm{m}}$ against either $\left(E_{\mathrm{lat}}-E_{\mathrm{HB}}, f\right)$ or $\left(E_{\mathrm{lat}}, f\right)$ is carried out, a similar good correlation is however, obtained in both cases, because the fitting parameters absorb the electrostatic contribution of stronger HB's that are included in $E_{\text {lat }}$. Hence, any of the $T_{\text {fit }}$ models could be used in the prediction of melting points for related series of Yxx substituted benzamides. ${ }^{43-46,68}$

Similar melting points were found for the Clxx and Brxx series, ${ }^{68}$ which exhibit five isomorphous pairs with $T_{\mathrm{m}}$ values within $10-15^{\circ} \mathrm{C}$ of each other. This suggests that the $\Delta H_{\mathrm{m}}$ component of $T_{\mathrm{m}}$ could be strongly dependent on the relative orientations of molecules found in the molecular assembly that forms the solid-state. Indeed as related Clxx and Brxx ${ }^{68}$ pairs exhibit the same molecular symmetry, the $\Delta S_{m}$ entropic component is expected to be comparable. Similar $T_{\mathrm{m}}$ values are thus pointing towards similar $\Delta H_{\mathrm{m}}$ values in the isomorphous structures. The related pairs in the Clxx and Brxx series are built by equivalent molecular packing and molecular orientations in their assemblies. This trend could be brought close to the previous indications on the enthalpic contributions to $T_{\mathrm{m}}$, is mainly driven by the weaker interactions rather than by the intensity difference of stronger interactions.

The Hirshfeld surface analysis shows that the strong hydrogen bond $\mathrm{O} \ldots \mathrm{H}_{\mathrm{N}}$ (or $\mathrm{O} \ldots \mathrm{H}_{\mathrm{N}}$ in Clpo_O) is the most enriched contact type followed by the weak hydrogen bonds $\mathrm{Cl}_{\text {.... } \mathrm{H}_{\mathrm{C}} \text { and }}$ $\mathrm{O}$.... $\mathrm{H}_{\mathrm{c}}$. Hydrophobic atoms $\left(\mathrm{C}, \mathrm{H}_{\mathrm{c}}, \mathrm{Cl}\right)$ generally prefer to interact within their subgroup with the exception of the over-represented $\mathrm{O}$.... $\mathrm{H}_{\mathrm{C}}$ contacts.

In conclusion, the $\mathrm{N}-\mathrm{H} \ldots \mathrm{N}$ intermolecular interaction type dominates in $\mathbf{C l x x}$, and largely in the absence of solvates and the $\mathrm{Cl}$ atoms only engage in weak $\mathrm{C}-\mathrm{H}$... $\mathrm{Cl}$ hydrogen bonds. Five of the Clxx form isomorphous pairs with their Brxx analogues and with Clpp isomorphous with several close benzamide relatives. Analysis of the melting point temperatures $T_{\mathrm{m}}$ reveals correlations involving both molecular symmetry and electrostatic energies. In future work, the structural and physicochemical aspects of the amide bridge reversed $\mathbf{N x x C l}$ series and bromo-containing derivatives ( $\mathbf{B r x x}, \mathbf{N x x B r}$ ) will be reported as well as an overview of 
the halogenated benzamide research. ${ }^{43-46,68}$ This $\mathbf{Y x x}$ research will be placed in context in light of on-going developments in related areas. ${ }^{43-46,68,98}$ Expanding the domain of X-ray crystallography in combination with theoretical calculations will enhance our knowledge and understanding of the physicochemical properties of molecular systems. ${ }^{98}$ 


\section{Supplementary Information}

Crystallographic data for the ten Clxx crystal structures have been deposited with the Cambridge Crystallographic Data Centre, CCDC no. 1878555 to 1878564 . CIF data may be downloaded from the CCDC website https://summary.ccdc.cam.ac.uk/structure-summaryform or obtained free of charge from The Director, CCDC, 12 Union road, Cambridge, CB2 1EZ, U.K. (fax: +44-1223-336033; e-mail: deposit@ccdc.cam.ac.uk). The structural data are available as CIF files from the corresponding author Professor John F. Gallagher (DCU).

\section{Acknowledgements}

This research was part-funded by the Programme for Research in Third Level Institutions (PRTLI) Cycle 4 (Ireland) and co-funded through the European Regional Development Fund (ERDF), part of the European Union Structural Funds Programme (ESF). The Irish Centre for High End Computing (ICHEC) is thanked for computer resource allocation, support and assistance with the computational calculations (http://www.ichec.ie). The authors warmly thank the Region Lorraine for a FEDER Chercheur d'Avenir grant (2015-2018). 


\section{References}

(1) Gribble, G. W. Naturally Occuring Organohalogen Compounds - A Comprehensive Survey. Prog. Chem. Org. Nat. Prod. 1996, 68, 1-423.

(2) Gribble, G. W. Naturally occurring organohalogen compounds. Acc. Chem. Res. 1998, 31, 141-152.

(3) Gribble, G. W. The diversity of naturally occurring organobromine compounds. Chem. Soc. Rev. 1999, 28, 335-346.

(4) Gribble, G. W. The diversity of naturally produced organohalogens. Chemosphere 2003, 52, 289-297.

(5) Gribble, G. W. Recently Discovered Naturally Occurring Heterocyclic Organohalogen Compounds. Heterocycles, 2012, 84, 157-207.

(6) Gribble, G. W. A recent survey of naturally occurring organohalogen compounds. Environmental Chemistry 2015, 12, 396-405.

(7) Müller, K.; Faeh, C.; Diederich, F. Fluorine in pharmaceuticals: Looking beyond intuition. Science 2007, 317, 1881-1886.

(8) Wang, J.; Sánchez-Roselló, M.; Aceña, J. L.; del Pozo, C.; Sorochinsky, A. E.; Fustero, S.; Soloshonok, V. A.; Liu, H. Fluorine in Pharmaceutical Industry: Fluorine-Containing Drugs Introduced to the Market in the Last Decade (2001-2011) Chem. Rev. 2014, 114, 2432-2506.

(9) Banks, R. E.; Smart, B. E.; Tatlow. J. C. Eds., Organofluorine chemistry: Principles and Commercial Applications 1994, 11, Springer Science.

(10) Jeschke, P. The unique role of halogen substituents in the design of modern agrochemicals. Pest Manage. Sci. 2010, 66, 10-27.

(11) Jeschke, P. Progress of modern agricultural chemistry and future prospects. Pest Manage. Sci. 2016, 72, 433-455.

(12) Jeschke, P. Latest generation of halogen-containing pesticides. Pest Manage. Sci. 2017, 73, 1053-1066.

(13) Yoder, N. C.; Kumar, K. Fluorinated amino acids in protein design and engineering. Chem. Soc. Rev. 2002, 31, 335-341.

(14) Luthe, G.; Swenson, D. C.; Robertson, L. W. Influence of fluoro-substitution on the planarity of 4-chlorobiphenyl (PCB 3). Acta Crystallogr. 2007, B63, 319-327.

(15) Klösener, J.; Swenson, D. C.; Robertson, L. W.; Luthe, G. Effects of fluoro substitution on 4-bromodiphenylether (PBDE 3). Acta Crystallogr. 2008, B64, 108-119.

(16) Babudri, F.; Farinola, G. M.; Naso, F.; Ragni, R. Fluorinated organic materials for electronic and optoelectronic applications: the role of the fluorine atom. Chem. Commun. 2007, 1003-1022.

(17) Berger, R.; Resnati, G.; Metrangolo, P.; Weber, E.; Hulliger, J. Organic fluorine compounds: a great opportunity for enhanced materials properties. Chem. Soc. Rev. 2011, 40, 3496-3508.

(18) Marsh, E. N. G. Fluorinated Proteins: From Design and Synthesis to Structure and Stability. Acc. Chem. Res. 2014, 47, 2878-2886.

(19) Gillis, E. P.; Eastman, K. J.; Hill, M. D.; Donnelly, D. J.; Meanwell, N. A. Applications of Fluorine in Medicinal Chemistry. J. Med. Chem. 2015, 58, 8315-8359.

(20) Lehn, J.-M. Supramolecular Chemistry: Concepts and Perspectives, 1995, VCH, Weinheim, Germany.

(21) Tiekink, E. R. T.; Vittal, J. J. Frontiers in Crystal Engineering, 2005, Wiley.

(22) Desiraju, G. R.; Vittal, J. J.; Ramanan, A. Crystal Engineering, 2011, World Scientific. 
(23) Steed, J. W.; Gale, P. A. Supramolecular Chemistry: from Molecules to Nanomaterials, 2012, 1-8, Wiley, Hoboken, New Jersey, USA.

(24) Bürgi, H.-B.; Dunitz, J. D. Structure Correlation, 2008, Volume 1, John Wiley and Sons Inc, Wiley Online Library. DOI: 10.1002/9783527616091

(25) Desiraju, G. R.; Steiner, T. The weak hydrogen bond in structural chemistry and biology, 2001, Oxford University Press, UK.

(26) Domenicano, A.; Hargittai, I. Strength from Weakness: Structural Consequences of Weak Interactions in Molecules, Supermolecules and Crystals, 2002, 68, NATO Science series II, Springer Netherlands.

(27) Nishio, M. CH/ $\pi$ hydrogen bonds in crystals. CrystEngComm. 2004, 6, 130-158.

(28) Dance, I.; Scudder, M. Molecules embracing in Crystals. CrystEngComm. 2009, 11, 2233-2247.

(29) Alvarez, S. A cartography of the van der Waals territories. Dalton Trans. 2013, 42, 8617-8636.

(30) Martinez, C. R.; Iverson, B. L. Rethinking the term "pi-stacking". Chem. Sci. 2012, 3, 2191-2201.

(31) Metrangolo, P.; Resnati, G. Eds., Halogen Bonding: Fundamentals and Applications; Structure and Bonding, Springer, Berlin, 2008, 126.

(32) Raatikainen, K.; Rissanen, K. Breathing molecular crystals: halogen- and hydrogenbonded porous molecular crystals with solvent induced adaptation of the nanosized channels. Chem. Sci. 2012, 3, 1235-1239.

(33) Desiraju, G. R.; Ho, P. S.; Kloo, L.; Legon, A. C.; Marquardt, R.; Metrangolo, P.; Politzer, P.; Resnati, G.; Rissanen, K. Definition of the halogen bond (IUPAC Recommendations 2013). Pure Appl. Chem. 2013, 85, 1711-1713.

(34) Mukherjee, A.; Desiraju, G. R. Halogen bonds in some dihalogenated phenols: applications to crystal engineering. IUCrJ 2014, 1, 49-60.

(35) Makhothkina, O.; Lieffrig, J.; Jeannin, O.; Fourmigué, M.; Aubert, E.; Espinosa, E. Cocrystal or Salt: Solid State-Controlled lodine Shift in Crystalline Halogen-Bonded Systems. Cryst. Growth Des. 2015, 15, 3464-3473.

(36) Bauza, A.; Mooibroek, T. J.; Frontera, A. The Bright Future of Unconventional $\sigma / \pi$ Hole Interactions. ChemPhysChem 2015, 16, 2496-2517.

(37) Cavallo, G.; Metrangolo, P.; Milani, R.; Pilati, T.; Priimagi, A.; Resnati, G.; Terraneo, G. A. F. Chem. Rev. 2016, 116, 2476-2601.

(38) Kolar, M. H.; Hobza, P. Computer Modeling of Halogen Bonds and Other sigma-Hole Interactions. Chem. Rev. 2016, 116, 5155-5187.

(39) Tepper, R.; Schubert, U. S. Halogen Bonding in Solution: Anion Recognition, Templated Self-Assembly, and Organocatalysis Angew. Chem. Int. Ed. Engl. 2018, 57, 6004-6016.

(40) Allen, F. H. The Cambridge Structural Database: a quarter of a million crystal structures and rising. Acta Crystallogr. 2002, B58, 380-388.

(41) Thomas, I. R.; Bruno, I. J.; Cole, J. C.; Macrae, C. F.; Pidcock, E.; Wood, P. A. WebCSD: the online portal to the Cambridge Structural Database. J. Appl. Cryst. 2010, 43, 362-366.

(42) Groom, C. R.; Bruno, I. J.; Lightfoot, M. P.; Ward, S. C. The Cambridge Structural Database. Acta Crystallogr. 2016, B72, 171-179.

(43) Mocilac, P.; Donnelly, K.; Gallagher, J. F. Structural systematics and conformational analyses of a $3 \times 3$ isomer grid of fluoro- $\mathrm{N}$-(pyridyl)benzamides: physicochemical 
correlations, polymorphism and isomorphous relationships. Acta Crystallogr. 2012, B68, 189-203.

(44) Mocilac, P.; Lough, A. J.; Gallagher, J. F. Structures and conformational analysis of a $3 \times 3$ isomer grid of nine $\mathrm{N}$-(fluorophenyl)pyridinecarboxamides. CrystEngComm 2011, 13, 1899-1909.

(45) Mocilac, P.; Tallon, M.; Lough, A. J.; Gallagher, J. F. Synthesis, structural and conformational analysis of a $3 \times 3$ isomer grid based on nine methyl- $\mathrm{N}$ (pyridyl)benzamides. CrystEngComm 2010, 12, 3080-3090.

(46) Mocilac, P.; Gallagher, J. F. Structural systematics and conformational analyses of a $3 \times 3$ isomer grid of nine $\mathrm{N}$-(tolyl)pyridinecarboxamides and three chlorinated relatives. CrystEngComm 2011, 13, 5354-5366.

(47) Mocilac, P.; Gallagher, J. F. Trezimides and Tennimides: New Imide-Based Macrocycles. J. Org. Chem. 2013, 78, 2355-2361.

(48) Mocilac, P.; Gallagher, J. F. Halogen bonding directed supramolecular assembly in bromo-substituted trezimides and tennimides. CrystEngComm 2014, 16, 1893-1903.

(49) Mocilac, P.; Gallagher, J. F. Halogenated tennimides and trezimides: impact of halogen bonding and solvent role on porous network formation and inclusion. CrystEngComm 2016, 18, 2375-2384.

(50) Oxford Diffraction Ltd ABSFAC and CrysAlisPro CCD/RED Version 1.171.33.55 Oxford Diffraction, Abingdon, Oxon, UK.

(51) Sheldrick, G. M. A short history of SHELX. Acta Crystallogr. 2008, A64, 112-122.

(52) McArdle, P. SORTX - a program for on-screen stick-model editing and autosorting of SHELX files for use on a PC. J. Appl. Cryst. 1995, 28, 65-65.

(53) Spek, A. L. Single-crystal structure validation with the program PLATON. J. Appl. Cryst. 2003, 36, 7-13.

(54) Macrae, C. F.; Edgington, P. R.; McCabe, P.; Pidcock, E.; Shields, G. R.; Taylor, R.; Towler, M.; van de Streek, J. Mercury: visualization and analysis of crystal structures. J. Appl. Cryst. 2006, 39, 453-457.

(55) Frisch, M. J. et al., Gaussian 09 Revision B.01, 2010, Gaussian Inc. Wallingford CT USA.

(56) Becke, A. D. Density-Functional Thermochemistry. 3. The Role of Exact Exchange. J. Chem. Phys. 1993, 98, 5648-5652.

(57) Krishnan, R.; Binkley, J. S.; Seeger, R.; Pople, J. A. Self-Consistent Molecular-Orbital Methods. 20. Basis Set For Correlated Wave-Functions. J. Chem. Phys. 1980, 72, 650-654.

(58) Jelsch, C.; Guillot, B.; Lagoutte, A.; Lecomte, C. Advances in protein and smallmolecule charge-density refinement methods using MoPro. J. Appl. Cryst. 2005, 38, 38-54.

(59) Domagała, S.; Fournier, B.; Liebschner, D.; Guillot, B.; Jelsch, C. An improved experimental databank of transferable multipolar atom models-ELMAM2. Construction details and applications. Acta Crystallogr. 2012, A68, 337-351.

(60) Allen, F. H.; Bruno, I. J. Bond lengths in organic and metal-organic compounds revisited: $\mathrm{X}-\mathrm{H}$ bond lengths from neutron diffraction data. Acta Crystallogr. 2010, B66, 380-386.

(61) Guillot, B.; Espinosa, E.; Huder, L.; Jelsch, C. MoProViewer: a tool to study proteins from a charge density science perspective. Acta Crystallogr. 2014, A70, C279. 
(62) Jelsch, C.; Bisseyou, Y. B. M. Atom interaction propensities of oxygenated chemical functions in crystal packings. IUCrJ 2017, 4, 158-174.

(63) Mocilac, P.; Gallagher, J. F. The First Phenyl-N-pyridinylcarbamate Structures: Structural and Conformational Analysis of Nine Methoxyphenyl-Npyridinylcarbamates. Cryst. Growth Des. 2013, 13, 5295-5304.

(64) Mocilac, P.; Gallagher, J. F. Structural systematics and conformational analyses of an isomer grid of nine tolyl-N-pyridinylcarbamates. Structural Chemistry, 2017, 28, 697-708.

(65) Noveron, J. C.; Lah, M. S.; Del Sesto, R. E.; Arif, A. M.; Miller, J. S.; Stang, P. J. Engineering the structure and magnetic properties of crystalline solids via the metaldirected self-assembly of a versatile molecular building unit. J. Am. Chem. Soc. 2002, 124, 6613-6625.

(66) Donnelly, K.; Gallagher, J. F.; Lough, A. J. Assembling an isomer grid: the isomorphous 4-, 3- and 2-fluoro-N'-(4-pyridyl)benzamides. Acta Crystallogr. 2008, C64, 0335-0340.

(67) McMahon, J.; Anderson, F. P.; Gallagher, J. F.; Lough, A. J. A structural systematic study of three isomers of difluoro- $N$-(4-pyridyl)-benzamide. Acta Crystallogr. 2008, C64, $0493-0497$.

(68) Hehir, N. Structural systematics of halogenated benzamides. Dublin City University, Ireland. PhD thesis, 2017.

(69) Bombicz, P. The way from isostructurality to polymorphism. Where are the borders? The role of supramolecular interactions and crystal symmetries. Crystallography Reviews 2017, 23, 118-151.

(70) Palma, A. Gallagher, J. F.; Muller-Bunz, H.; Wolowska, J.; McInnes, E. J. L.; O'Shea, D. F. Co(II), Ni(II), CU(II) and Zn(II) complexes of tetraphenylazadipyrromethene. Dalton Trans. 2009, 273-279.

(71) Gelbrich, T.; Hursthouse, M. B.; Threlfall, T. L. Structural systematics of 4,4'disubstituted benzenesulfonamidobenzenes. 1. Overview and dimer based isostructures. Acta Crystallogr. 2008, B63, 621-632.

(72) Gelbrich T.; Threlfall, T. L. The crystal structure of methyl paraben at $118 \mathrm{~K}$ does not represent a new polymorph. Cryst. Growth Des. 2007, 7, 2297-2297.

(73) Brock, C. P. High-Z' structures of organic molecules: their diversity and organizing principles. Acta Crystallogr. 2016, B72, 807-821.

(74) Das, U.; Chattopadhyay, B.; Hazra, D. K.; Sureshbabu, V. V.; Mukherjee, A. K. Two carbamate derivatives with $Z^{\prime}=2$ and 3: An interplay of strong and weak hydrogen bonds. J. Mol. Struct. 2016, 1122, 290-298.

(75) Steed, K. M.; Steed, J. W. Packing Problems: High Z' Crystal Structures and Their Relationship to Cocrystals, Inclusion Compounds, and Polymorphism. Chem. Rev. 2015, 115, 2895-2933.

(76) Brittain, H. G. Ed. Polymorphism in Pharmaceutical Solids, 1999, 1st Ed. New York: Marcel Dekker Inc.

(77) Bernstein, J. Polymorphism in Molecular Crystals, 2002, Oxford: Clarendon Press.

(78) Yu, L. Polymorphism in Molecular Solids: An Extraordinary System of Red, Orange, and Yellow Crystals. Acc. Chem. Res. 2010, 43, 1257-1266.

(79) Brittain, H. G. Polymorphism and solvatomorphism 2010. J. Pharm. Sci. 2012, 101, 464-484. 
(80) Steed, J. W. Understanding exceptional polymorphs. Acta Crystallogr. 2016, B72, 805-806.

(81) Abramowitz, R.; Yalkowsky, S. H. MELTING-POINT, BOILING-POINT, AND SYMMETRY, Pharm. Res. 1990, 7, 942-947.

(82) Brown, R. J. C.; Brown, R. F. C. Melting point and molecular symmetry. J. Chem. Ed. 2000, 77, 724-731.

(83) Vishweshwar, P.; Nangia, A.; Lynch, V. M. Molecular complexes of homologous alkanedicarboxylic acids with isonicotinamide: X-ray crystal structures, hydrogen bond synthons, and melting point alternation. Cryst. Growth Des. 2003, 3, 783-790.

(84) Slovokhotov, Y. L.; Neretin, I. S.; Howard, J. A. K. Symmetry of van der Waals molecular shape and melting points of organic compounds. New J. Chem. 2004, 28, 967-979.

(85) Podsiadło, M.; Bujak, M.; Katrusiak, A. Chemistry of density: extension and structural origin of Carnelley's rule in chloroethanes. CrystEngComm 2012, 14, 4496-4500.

(86) Yalkowsky, S. H. Carnelley's Rule and the Prediction of Melting Point. J. Pharm. Sci. 2014, 103, 2629-2634.

(87) Gamidi, R. K.; Rasmuson, A. Estimation of Melting Temperature of Molecular Cocrystals Using Artificial Neural Network Model. Cryst. Growth Des. 2017, 17, 175-182.

(88) Bujak, M. Melting point, molecular symmetry and aggregation of tetrachlorobenzene isomers: the role at halogen bonding. Acta Crystallogr. 2018, B74, 458-466.

(89) Mishra, M. K.; Kelley, S. P.; Shamshina, J. L.; Choudhary, H.; Rogers, R. D. Can Melting Point Trends Help Us Develop New Tools To Control the Crystal Packing of Weakly Interacting lons? Cryst. Growth Des. 2018, 18, 597-601.

(90) Abad, A.; Agullo, C.; Cunat, A. C.; Vilanova, C.; de Arellano, M. C. R. X-ray structure of fluorinated $\mathrm{N}$-(2-chloropyridin-4-yl)-N'-phenylureas. Role of $\mathrm{F}$ substitution in the crystal packing. Cryst. Growth Des. 2006, 6, 46-57.

(91) Tuchalski, G.; Emmerling, F.; Groger, K.; Hansicke, A.; Nagel, T.; Reck, G. X-ray investigations of nebivolol and its isomers. J. Mol. Struct. 2006, 800, 28-44.

(92) Capacci-Daniel, C.; Dehghan, S.; Wurster, V. M.; Basile, J. A.; Hiremath, R.; Sarjeant, A. A.; Swift, J. A. Halogen/methyl exchange in a series of isostructural 1,3-bis(mdihalophenyl) ureas. CrystEngComm 2008, 10, 1875-1880.

(93) Dumitru, F.; Legrand, Y. -M.; Barboiu, M.; van der Lee, A. Weak intermolecular hydrogen and halogen interactions in an isomorphous halogen series of pseudoterpyridine Zn-II complexes. Acta Crystallogr. 2013, B69, 43-54.

(94) Gomes, L. R.; Low, J. N.; Cagide, F.; Borges, F. The crystal structures of four N-(4halophenyl)-4-oxo-4H-chromene-3-carboxamides. Acta Crystallogr. 2015, E71, 88-93.

(95) Jelsch, C.; Ejsmont, C.; Huder, L. The enrichment ratio of atomic contacts in crystals, an indicator derived from the Hirshfeld surface analysis. IUCrJ 2014, 1, 119-128.

(96) Jelsch, C.; Soudani, S.; Ben Nasr, C. Likelihood of atom-atom contacts in crystal structures of halogenated organic compounds. IUCrJ 2015, 2, 327-340.

(97) Salonen, L. M.; Ellermann, M.; Diederich, F. Aromatic Rings in Chemical and Biological Recognition: Energetics and Structure. Angew Chem. Int. Ed. Engl. 2011, $50,4808-4842$. 
(98) Kofoed, P. M.; Hoser, A. A.; Diness, F.; Capelli, S. C.; Madsen, A. Ф. X-ray diffraction data as a source of the vibrational free-energy contribution in polymorphic systems. IUCrJ 2019, 6, 558-571. 


\section{Graphical Abstract}

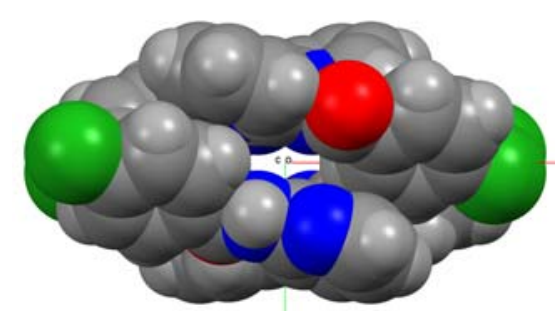

Physicochemical properties of a $3 \times 3$ isomer grid of mono-chlorobenzamides $(\mathbf{C l x x})(\mathbf{x}=p$ $/ \mathrm{m}$-/o-) are reported. Clpo forms two polymorphs as Clpo_N (N-H...N interactions with void formation as depicted in the graphic) and Clpo_O (O-H...O interactions). Weak $\mathrm{C}-\mathrm{H} . . . \mathrm{Cl}$ hydrogen bonds are the only favoured interaction partner of $\mathrm{Cl}$ with halogen bonding mostly absent. The melting temperatures $T_{\mathrm{m}}$ have been correlated to both molecular symmetry and electrostatic energies. 


\title{
ELECTRONIC SUPPLEMENTARY INFORMATION
}

\section{At the interface of isomorphous behaviour in a $3 \times 3$ isomer grid of mono-chlorobenzamides: Analyses of the interaction landscapes via contact enrichment studies.}

John F. Gallagher ${ }^{* \#, ~ M a r k ~ F a r r e l l, ~ P a v l e ~ M o c i l a c, ~ N i a l l ~ H e h i r ~}$

School of Chemical Sciences, Dublin City University, Dublin 9, Ireland

with

Emmanuel Aubert, Enrique Espinosa, Benoît Guillot, Christian Jelsch*

CRM $^{2}$, CNRS UMR 7036, Faculté des Sciences et Technologies, Université de Lorraine, BP 70239, Boulevard des Aiguillettes, 54506 Vandoeuvre-lès-Nancy, France

\author{
Corresponding author:" \\ Dr. John F. Gallagher, \\ School of Chemical Sciences, \\ Dublin City University, Dublin 9, Ireland \\ e-mail: john.gallagher@dcu.ie
}




\section{TABLE OF CONTENTS:}

\section{PAge No.}

Crystallography and ab initio calculations.

3. Scheme S1: Clxx with the four general Clxx ring conformations; nomenclature.

4. Diagrams of Figures referenced in the text (as Fpp, Mpp, NppF, NppM and 25p).

5. Table S1. Crystal Structure Data: Experimental details.

7. Table S2a. Selected hydrogen-bond parameters $\left(\AA{ }^{\circ},\right)^{\circ}$.

9. Table S2b: Interactions and contacts (plus halogen bonding) $\left(\AA \AA^{\circ}\right)$.

10. Table S2c: Selected Intermolecular interactions for the main paper.

11. Figures: Enlarged format for ease of comparisons (from Figure 10 in paper). $\boldsymbol{A} \boldsymbol{b}$ Initio calculations [Enlarged PES diagrams from main paper].

14. Melting point Table 3 and comparisons of Mxx, NxxM, Fxx, NxxF; Clxx and Brxx.

\section{Computational Structural Analysis (MoPro) Figures.}

15. Figure Sup_ $\mathbf{T}_{\mathbf{f}} \mathbf{E}_{\text {elec. }}$ Scatterplot of $\mathrm{mp}$ and computed lattice electrostatic energy.

16. Figure Sup_t $\mathbf{T}_{\mathbf{m}} \mathbf{f} \_\mathbf{E}_{\text {lat. }}$. Plot of experimental $T_{\mathrm{m}}$ and fitted $T_{\text {fit }}$ fusion temperatures.

17. Figure Sup_ $\mathbf{T}_{\mathrm{f}}\left(\mathbf{E}_{\mathrm{lat}}-\mathrm{E}_{\mathrm{hb}}\right)$. Fitting of fusion temperature and $E_{\mathrm{lat}}-E_{\mathrm{hb}}$.

18. Figure Sup Elec_D. Scatterplot of lattice $E_{\text {elec }}$ and density.

Figure for info $E_{\text {lat }}$ vs $E_{h b}$.

19. Figure Sup_Elat_Ehb. Contribution of strong HBs to the lattice electrostatic energy.

20. Table Sup_CONT. Proportion of contact types (\%) in the 10 Clxx crystal structures.

22. Table Sup_E. Contact enrichment ratios in the Clxx crystals.

24. Table Sup_C. The \% contacts between hydrophobic and hydrophilic atom types.

25. Table Sup_EC. Correlation coefficient $c$ between the different enrichment ratios.

26. Figure Sup_Eelec_dist. Scatterplot of $H_{N} \ldots N$ distance $v$ s. lattice electrostatic energy.

27. Figure Sup_CICl. Deformation of the transferred electron density in the Clom dimer. 
<smiles>[X]c1ccc(NC(=O)c2ccc(Cl)cc2)cc1</smiles>

and

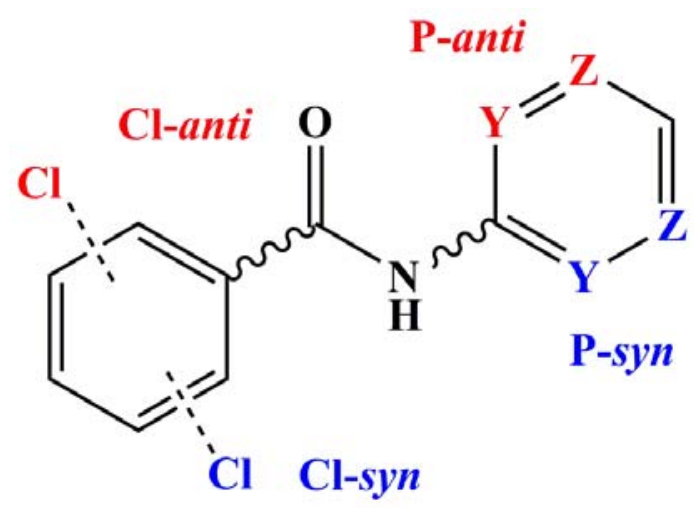

Figure S1. Clxx with the four general Clxx ring conformations.

Explanation of the Clxx nomenclature and relationship with $\mathrm{NxxCl}$ :

The $3 \times 3$ isomer grid of mono-chlorobenzamides (as Clxx) derive from the components with $\mathrm{Cl} \mathbf{x}=$ chlorobenzoyl or para-/meta-/ortho-ClC6H4C=O combined with $\mathbf{x}=$ para- or meta- or ortho-aminopyridine $\left(\mathrm{HNC}_{5} \mathrm{H}_{4} \mathrm{~N}\right)$ substitutions. The related $\mathbf{N x x C l}$ series (next paper) is a series of 9 isomers related to $\mathbf{C l x x}$ but with a reversed amide bridge.

The Fxx, ${ }^{43} \mathbf{N x x F},{ }^{44} \mathbf{M x x}{ }^{45}$ or $\mathbf{N} \mathbf{x x M}{ }^{46}$ analogues of $\mathbf{C l x x}{ }^{\text {present study }}$ and $\mathbf{B r x x}{ }^{68}$

The Fxx series is just a simple replacement of chlorine by fluorine and the $\mathbf{M x x}$ series is likewise a replacement of chlorine by the methyl group. The $\mathbf{N} \mathbf{x} \mathbf{F}^{44}$ and $\mathbf{N} \mathbf{x} \mathbf{x M}^{\mathbf{4 6}}$ series are the amide bridged reversed isomers of $\mathbf{F x x} \mathbf{x}^{43}$ and $\mathbf{M} \mathbf{x x}^{45}$ (although synthesised from different acyl chloride and amine starting materials).

$\mathbf{H p p}^{65}$ can be regarded as similar to Fxx and Clxx and as the parent compound for reference (and without any halide atom attached) 
Figure S2. Diagrams OF FIGURES REFERENCED IN THE TEXT. ${ }^{43-46}$

Representative examples of Fxx (with Fpp depicted below), ${ }^{43} \mathbf{M x x}$ (Mpp depicted below), ${ }^{45}$ NxxF (NppF depicted below) ${ }^{44}$ and $\mathbf{N x x M}$ (NppM depicted below). ${ }^{46}$

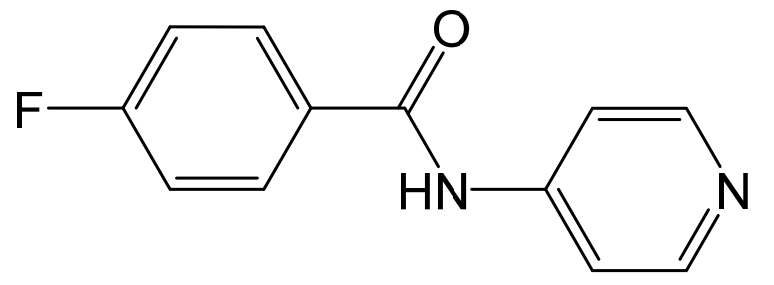

\section{Fpp}

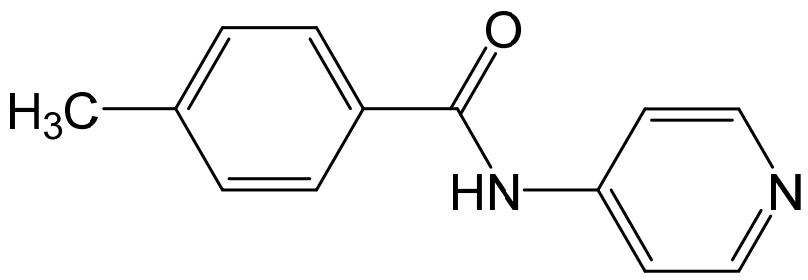

Mpp
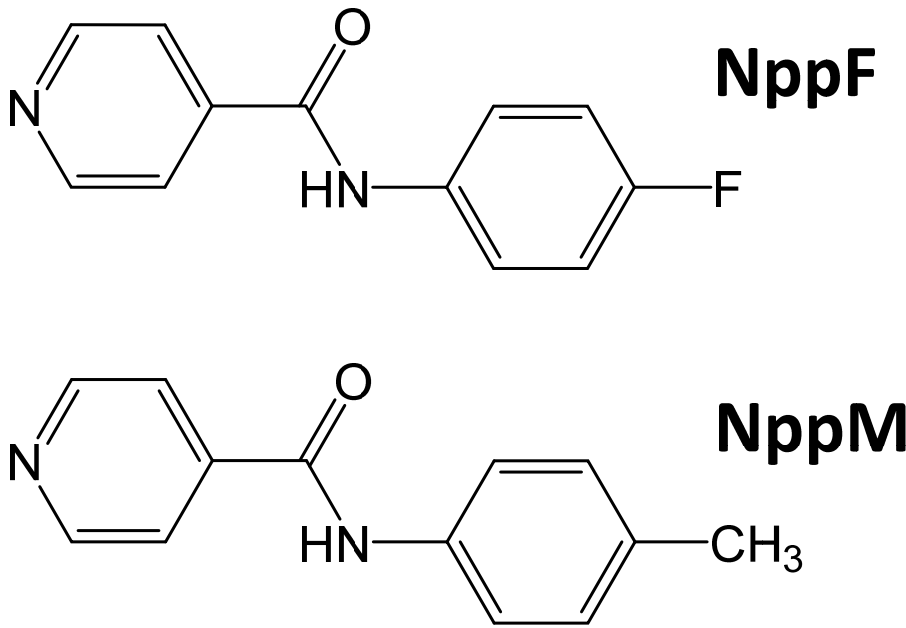

and

The difluorinated $25 p$ from reference 67.

A structural systematic study of three isomers of difluoro-N-(4-pyridyl)-benzamide. Acta Crystallogr. 2008, C64, 0493-0497.

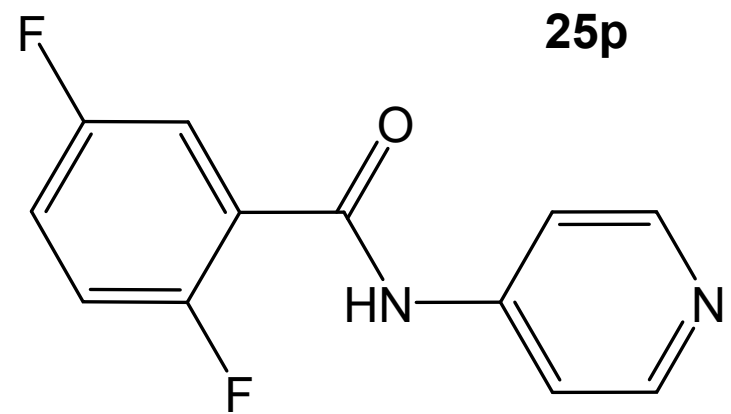




\section{Table S1. Crystal Structure Data: Experimental detalls}

Experiments were carried out at $294 \mathrm{~K}$ using a Xcalibur, Sapphire3, Gemini Ultra. H atoms were treated by a mixture of independent and constrained refinement as CSD codes 1878555 to 1878564.

\begin{tabular}{|c|c|c|c|c|c|}
\hline Clxx isomers & Clpp & Clmp & Clop & Clpm & Clmm_H ${ }_{2} \mathrm{O}$ \\
\hline \multicolumn{6}{|l|}{ Crystal data } \\
\hline Chemical formula & $\mathrm{C}_{12} \mathrm{H}_{9} \mathrm{ClN}{ }_{2} \mathrm{O}$ & $\mathrm{C}_{12} \mathrm{H}_{9} \mathrm{ClN}_{2} \mathrm{O}$ & $\mathrm{C}_{12} \mathrm{H}_{9} \mathrm{ClN}{ }_{2} \mathrm{O}$ & $\mathrm{C}_{12} \mathrm{H}_{9} \mathrm{ClN} \mathrm{N}_{2} \mathrm{O}$ & $\mathrm{C}_{12} \mathrm{H}_{9} \mathrm{ClN}{ }_{2} \mathrm{O} \cdot \mathrm{H}_{2} \mathrm{O}$ \\
\hline$M_{\mathrm{r}}$ & 232.66 & 232.66 & 232.66 & 232.66 & 250.68 \\
\hline $\begin{array}{l}\text { Crystal system, space } \\
\text { group }\end{array}$ & $\begin{array}{l}\text { Monoclinic, } \\
P 2_{1} / c\end{array}$ & Triclinic, $P^{-} 1$ & $\begin{array}{l}\text { Orthorhombic, } \\
\text { Pbca }\end{array}$ & Triclinic, $P^{-} 1$ & $\begin{array}{l}\text { Monoclinic, } \\
P 2_{1} / c\end{array}$ \\
\hline$a, b, c(\AA)$ & $\begin{array}{l}5.6453(5) \\
11.7673(8) \\
16.2271(12)\end{array}$ & $\begin{array}{l}11.4395(2) \\
12.9293(2) \\
14.8943(4)\end{array}$ & $\begin{array}{l}9.3966(18) \\
12.0918(19), \\
19.295(4)\end{array}$ & $\begin{array}{l}4.0095(4) \\
21.385(2) \\
27.378(3)\end{array}$ & $\begin{array}{l}7.4273(5), \\
18.0819(10), \\
8.9461(6)\end{array}$ \\
\hline$\alpha, \beta, \gamma\left({ }^{\circ}\right)$ & $\begin{array}{l}90,96.791(7), \\
90\end{array}$ & $\begin{array}{l}89.979(2) \\
76.924(2) \\
88.507(1)\end{array}$ & $90,90,90$ & $\begin{array}{l}112.717(9) \\
93.377(8) \\
92.305(8)\end{array}$ & $\begin{array}{l}90,107.948(7), \\
90\end{array}$ \\
\hline$V\left(\AA^{3}\right)$ & $1070.40(14)$ & $2145.05(8)$ & $2192.4(7)$ & $2156.6(4)$ & $1142.99(13)$ \\
\hline$Z$ & 4 & 8 & 8 & 8 & 4 \\
\hline Radiation type & Mo $K \alpha$ & Mo $K \alpha$ & Mo $K \alpha$ & Mo $K \alpha$ & Mo $K \alpha$ \\
\hline$\mu\left(\mathrm{mm}^{-1}\right)$ & 0.33 & 0.33 & 0.33 & 0.33 & 0.32 \\
\hline Crystal shape & Block & Block & Block & Needle & Block \\
\hline Crystal size (mm) & $\begin{array}{l}0.48 \times 0.24 \times \\
0.18\end{array}$ & $\begin{array}{l}0.46 \times 0.28 \times \\
0.22\end{array}$ & $\begin{array}{l}0.56 \times 0.08 \times \\
0.04\end{array}$ & $\begin{array}{l}0.55 \times 0.10 \times \\
0.06\end{array}$ & $\begin{array}{l}0.17 \times 0.10 \times \\
0.05\end{array}$ \\
\hline \multicolumn{6}{|l|}{ Data collection } \\
\hline Absorption correction & $\begin{array}{l}\text { Multi-scan } \\
\text { (Empirical } \\
\text { SCALE3 } \\
\text { ABSPACK) }\end{array}$ & $\begin{array}{l}\text { Multi-scan } \\
\text { (Empirical } \\
\text { SCALE3 } \\
\text { ABSPACK) }\end{array}$ & $\begin{array}{l}\text { Multi-scan } \\
\text { (Empirical } \\
\text { SCALE3 } \\
\text { ABSPACK) }\end{array}$ & $\begin{array}{l}\text { Analytical } \\
\text { (ABSFAC, Clark } \\
\text { \& Reid, 1998) }\end{array}$ & $\begin{array}{l}\text { Analytical } \\
\text { (ABSFAC, Clark } \\
\text { \& Reid, 1998) }\end{array}$ \\
\hline$T_{\min }, T_{\max }$ & $0.859,1.000$ & $0.922,1.000$ & $0.85,1.00$ & $0.919,0.983$ & $0.947,0.984$ \\
\hline $\begin{array}{l}\text { Measured, independent, } \\
\text { observed }[I>2 \sigma(I)] \\
\text { reflections }\end{array}$ & $\begin{array}{l}7681,2325 \\
1594\end{array}$ & $\begin{array}{l}21867,11150 \\
7857\end{array}$ & $\begin{array}{l}16862,2412 \\
1308\end{array}$ & $\begin{array}{l}15313,8956, \\
4067\end{array}$ & $\begin{array}{l}8847,2480, \\
917\end{array}$ \\
\hline$R_{\text {int }}$ & 0.027 & 0.015 & 0.066 & 0.035 & 0.097 \\
\hline$(\sin \theta / \lambda)_{\max }\left(\AA^{-1}\right)$ & 0.648 & 0.693 & 0.647 & 0.640 & 0.651 \\
\hline \multicolumn{6}{|l|}{ Refinement } \\
\hline$R\left[F^{2}>2 \sigma\left(F^{2}\right)\right], w R\left(F^{2}\right), S$ & $\begin{array}{l}0.038,0.098 \\
1.03\end{array}$ & $\begin{array}{l}0.039,0.113 \\
1.07\end{array}$ & $\begin{array}{l}0.041,0.089 \\
0.86\end{array}$ & $\begin{array}{l}0.043,0.084 \\
0.76\end{array}$ & $\begin{array}{l}0.050,0.097 \\
0.76\end{array}$ \\
\hline No. of reflections & 2325 & 11150 & 2412 & 8956 & 2480 \\
\hline No. of parameters & 150 & 593 & 149 & 594 & 166 \\
\hline No. of restraints & 0 & 0 & 0 & 0 & 3 \\
\hline$\left.\Delta\rangle_{\max }, \Delta\right\rangle_{\min }\left(\mathrm{e} . \AA^{-3}\right)$ & $0.36,-0.40$ & $0.41,-0.56$ & $0.18,-0.15$ & $0.16,-0.20$ & $0.29,-0.19$ \\
\hline
\end{tabular}




\begin{tabular}{|c|c|c|c|c|c|}
\hline Clxx isomers & Clom & $\begin{array}{l}\text { Clpo_0 } \\
\text { (polymorph) }\end{array}$ & $\begin{array}{l}\text { Clpo_N } \\
\text { (polymorph) }\end{array}$ & Clmo & Cloo \\
\hline \multicolumn{6}{|l|}{ Crystal data } \\
\hline Chemical formula & $\mathrm{C}_{12} \mathrm{H}_{9} \mathrm{ClN}_{2} \mathrm{O}$ & $\mathrm{C}_{12} \mathrm{H}_{9} \mathrm{ClN}_{2} \mathrm{O}$ & $\mathrm{C}_{12} \mathrm{H}_{9} \mathrm{ClN}_{2} \mathrm{O}$ & $\mathrm{C}_{12} \mathrm{H}_{9} \mathrm{ClN} \mathrm{N}_{2} \mathrm{O}$ & $\mathrm{C}_{12} \mathrm{H}_{9} \mathrm{ClN}_{2} \mathrm{O}$ \\
\hline$M_{\mathrm{r}}$ & 232.66 & 232.66 & 232.66 & 232.66 & 232.66 \\
\hline $\begin{array}{l}\text { Crystal system, space } \\
\text { group }\end{array}$ & $\begin{array}{l}\text { Monoclinic, } \\
C 2 / c\end{array}$ & $\begin{array}{l}\text { Monoclinic, } \\
C 2 / c\end{array}$ & $\begin{array}{l}\text { Monoclinic, } \\
C 2 / c\end{array}$ & Triclinic, $P^{-} 1$ & $\begin{array}{l}\text { Monoclinic, } \\
C 2 / c\end{array}$ \\
\hline$a, b, c(\AA)$ & $\begin{array}{l}\text { 18.1011(4), } \\
10.8717(2), \\
11.4678(3)\end{array}$ & \begin{tabular}{|l|}
$26.611(2)$ \\
$5.2075(4)$ \\
$15.4341(13)$
\end{tabular} & $\begin{array}{l}27.0371(3) \\
8.2490(1) \\
10.7506(1)\end{array}$ & $\begin{array}{l}5.8841(3) \\
7.3302(5) \\
12.6907(8)\end{array}$ & $\begin{array}{l}21.8178(9) \\
6.6955(3) \\
14.8776(6)\end{array}$ \\
\hline$\alpha, \beta, \gamma\left({ }^{\circ}\right)$ & $\begin{array}{l}90,91.302(2) \\
90\end{array}$ & $\begin{array}{l}90,93.485(7) \\
90\end{array}$ & $\begin{array}{l}90,112.0204 \\
(14), 90\end{array}$ & $\begin{array}{l}77.717(6) \\
82.504(5) \\
88.442(5)\end{array}$ & $\begin{array}{l}90,94.541(4) \\
90\end{array}$ \\
\hline$V\left(\AA^{3}\right)$ & $2256.16(9)$ & $2134.8(3)$ & $2222.78(5)$ & $530.27(6)$ & $2166.51(16)$ \\
\hline$Z$ & 8 & 8 & 8 & 2 & 8 \\
\hline Radiation type & Mo $K \alpha$ & Mo $K \alpha$ & $\mathrm{Cu} K \alpha$ & Mo $K \alpha$ & Mo $K \alpha$ \\
\hline$\mu\left(\mathrm{mm}^{-1}\right)$ & 0.32 & 0.34 & 2.87 & 0.34 & 0.33 \\
\hline Crystal shape & Block & Block & Block & Block & Block \\
\hline Crystal size (mm) & $\begin{array}{l}0.22 \times 0.20 \times \\
0.15\end{array}$ & $\begin{array}{l}0.35 \times 0.23 \times \\
0.14\end{array}$ & $\begin{array}{l}0.36 \times 0.18 \times \\
0.11\end{array}$ & $0.37 \times 0.29 \times$ & $\begin{array}{l}0.52 \times 0.35 \times \\
0.29\end{array}$ \\
\hline \multicolumn{6}{|l|}{ Data collection } \\
\hline Absorption correction & $\begin{array}{l}\text { Analytical } \\
\text { (ABSFAC, Clark } \\
\text { \& Reid, 1998) }\end{array}$ & $\begin{array}{l}\text { Multi-scan } \\
\text { (Empirical } \\
\text { SCALE3 } \\
\text { ABSPACK) }\end{array}$ & $\begin{array}{l}\text { Analytical } \\
\text { (ABSFAC, Clark } \\
\text { \& Reid, 1998) }\end{array}$ & $\begin{array}{l}\text { Multi-scan } \\
\text { (Empirical } \\
\text { SCALE3 } \\
\text { ABSPACK) }\end{array}$ & $\begin{array}{l}\text { Analytical } \\
\text { (ABSFAC, Clark } \\
\text { \& Reid, 1998) }\end{array}$ \\
\hline$T_{\min }, T_{\max }$ & $0.957,0.976$ & $0.98,1.00$ & $0.481,0.747$ & $0.90,1.00$ & $0.877,0.920$ \\
\hline $\begin{array}{l}\text { Measured, independent } \\
\text { and observed }[I>2 \sigma(I)] \\
\text { reflections }\end{array}$ & $\begin{array}{l}8589,2476 \\
1702\end{array}$ & $\begin{array}{l}7164,2280 \\
1841\end{array}$ & $\begin{array}{l}5698,1751 \\
1658\end{array}$ & $\begin{array}{l}4063,2303 \\
1890\end{array}$ & $\begin{array}{l}9415,2816 \\
2212\end{array}$ \\
\hline$R_{\text {int }}$ & 0.025 & 0.018 & 0.013 & 0.014 & 0.015 \\
\hline$(\sin \theta / \lambda)_{\max }\left(\AA^{-1}\right)$ & 0.650 & 0.642 & 0.575 & 0.655 & 0.686 \\
\hline \multicolumn{6}{|l|}{ Refinement } \\
\hline$R\left[F^{2}>2 \sigma\left(F^{2}\right)\right], w R\left(F^{2}\right), S$ & $\begin{array}{l}0.034,0.089 \\
1.00\end{array}$ & $\begin{array}{l}0.031,0.089 \\
1.08\end{array}$ & $\begin{array}{l}0.032,0.093 \\
1.06\end{array}$ & $\begin{array}{l}0.034,0.100 \\
1.09\end{array}$ & $\begin{array}{l}0.036,0.110 \\
1.09\end{array}$ \\
\hline No. of reflections & 2476 & 2280 & 1751 & 2303 & 2816 \\
\hline No. of parameters & 149 & 150 & 150 & 150 & 149 \\
\hline No. of restraints & 0 & 0 & 0 & 0 & 0 \\
\hline$\left.\Delta\rangle_{\max }, \Delta\right\rangle_{\min }\left(\mathrm{e} . \AA^{-3}\right)$ & $0.22,-0.28$ & $0.17,-0.18$ & $0.16,-0.25$ & $0.18,-0.20$ & $0.25,-0.26$ \\
\hline
\end{tabular}


TABle S2A: Selected hydRogen-Bond parameters $\left(\AA^{\circ},{ }^{\circ}\right)$

\begin{tabular}{|c|c|c|c|c|}
\hline$D-\mathrm{H} \cdots A$ & $D-\mathrm{H}(\AA ̊)$ & $H \cdots A(\AA ̊)$ & $D \cdots A(\AA ̊)$ & $D-\mathrm{H} \cdots A\left(\left(^{\circ}\right)\right.$ \\
\hline \multicolumn{5}{|l|}{ Clpp } \\
\hline $\mathrm{N} 1-\mathrm{H} 1 \cdots \mathrm{N} 24^{i}$ & $0.827(19)$ & 2.441 (19) & $3.114(2)$ & $139.2(17)$ \\
\hline $\mathrm{C} 26-\mathrm{H} 26 \cdots \mathrm{O} 1$ & 0.93 & 2.35 & $2.891(2)$ & 117 \\
\hline \multicolumn{5}{|l|}{ Clmp } \\
\hline $\mathrm{N} 1 \mathrm{~A}-\mathrm{H} 1 \mathrm{~A} \cdots \mathrm{N} 24 \mathrm{D}$ & $0.836(15)$ & $2.132(15)$ & $2.9431(16)$ & $163.4(14)$ \\
\hline $\mathrm{N} 1 \mathrm{~B}-\mathrm{H} 1 \mathrm{~B} \cdots \mathrm{N} 24 \mathrm{C}$ & $0.848(15)$ & $2.210(16)$ & $3.0120(16)$ & $157.7(14)$ \\
\hline $\mathrm{N} 1 \mathrm{C}-\mathrm{H} 1 \mathrm{C} \cdots \mathrm{N} 24 \mathrm{~B}^{i i}$ & $0.853(15)$ & $2.316(15)$ & $3.1576(16)$ & $169.1(13)$ \\
\hline N1D-H1D $\cdots N 24 A^{i i i}$ & $0.812(15)$ & $2.388(15)$ & $3.1913(16)$ & $170.4(14)$ \\
\hline$C 22 A-H 22 A \cdots O 1 A$ & 0.93 & 2.35 & $2.8709(16)$ & 115 \\
\hline $\mathrm{C} 22 \mathrm{~B}-\mathrm{H} 22 \mathrm{~B} \cdots \mathrm{O} 1 \mathrm{~B}$ & 0.93 & 2.35 & $2.8698(17)$ & 115 \\
\hline $\mathrm{C} 22 \mathrm{C}-\mathrm{H} 22 \mathrm{C} \cdots \mathrm{O} 1 \mathrm{C}$ & 0.93 & 2.22 & $2.8073(17)$ & 120 \\
\hline$C 22 D-H 22 D \cdots O 1 D$ & 0.93 & 2.23 & $2.8155(18)$ & 121 \\
\hline $\mathrm{C} 12 \mathrm{C}-\mathrm{H} 12 \mathrm{C} \cdots \mathrm{N} 24 \mathrm{~B}^{i i}$ & 0.93 & 2.37 & $3.2961(18)$ & 173 \\
\hline 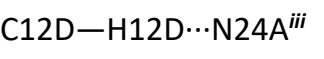 & 0.93 & 2.38 & $3.2761(18)$ & 161 \\
\hline $\mathrm{C} 14 \mathrm{~B}-\mathrm{H} 14 \mathrm{~B} \cdots \mathrm{O} 1 \mathrm{C}^{\mathrm{iv}}$ & 0.93 & 2.59 & $3.2416(17)$ & 127 \\
\hline 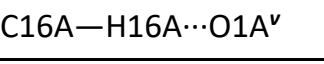 & 0.93 & 2.47 & $3.3516(17)$ & 160 \\
\hline \multicolumn{5}{|l|}{ Clop } \\
\hline $\mathrm{N} 1-\mathrm{H} 1 \cdots \mathrm{N} 24^{v i}$ & $0.846(19)$ & $2.17(2)$ & $3.010(3)$ & $175.9(18)$ \\
\hline $\mathrm{C} 15-\mathrm{H} 15 \cdots \mathrm{O} 1^{\mathrm{vii}}$ & 0.93 & 2.50 & $3.266(3)$ & 139 \\
\hline $\mathrm{C} 26-\mathrm{H} 26 \cdots \mathrm{O} 1$ & 0.93 & 2.28 & $2.860(3)$ & 120 \\
\hline \multicolumn{5}{|l|}{ Clpm } \\
\hline $\mathrm{N} 1 \mathrm{~A}-\mathrm{H} 1 \mathrm{~A} \cdots \mathrm{N} 23 \mathrm{~B}$ & $0.97(4)$ & $2.24(4)$ & $3.184(4)$ & $165(3)$ \\
\hline $\mathrm{N} 1 \mathrm{~B}-\mathrm{H} 1 \mathrm{~B} \cdots \mathrm{N} 23 \mathrm{C}$ & $0.80(4)$ & $2.43(4)$ & $3.203(4)$ & $164(4)$ \\
\hline $\mathrm{N} 1 \mathrm{C}-\mathrm{H} 1 \mathrm{C} \cdots \mathrm{N} 23 \mathrm{D}$ & $0.74(3)$ & $2.43(3)$ & $3.151(4)$ & $166(3)$ \\
\hline N1D-H1D $\cdots N 23 A^{\text {viii }}$ & $0.79(3)$ & $2.37(4)$ & $3.150(4)$ & $168(3)$ \\
\hline 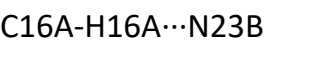 & 0.93 & 2.48 & $3.386(4)$ & 164 \\
\hline 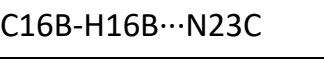 & 0.93 & 2.46 & $3.356(4)$ & 162 \\
\hline \multicolumn{5}{|l|}{ Clmm_ $\mathrm{H}_{2} \mathrm{O}$} \\
\hline $\mathrm{N} 1-\mathrm{H} 1 \cdots \mathrm{O} 1 \mathrm{~W}^{i x}$ & $0.817(18)$ & $2.11(2)$ & $2.892(4)$ & $161(3)$ \\
\hline $\mathrm{O} 1 \mathrm{~W}-\mathrm{H} 1 \mathrm{~W} \cdots \mathrm{N} 23$ & $0.905(18)$ & $1.96(2)$ & $2.858(4)$ & $169(3)$ \\
\hline $\mathrm{O} 1 \mathrm{~W}-\mathrm{H} 2 \mathrm{~W} \cdots \mathrm{O}^{i}$ & $0.876(19)$ & $2.07(3)$ & $2.890(4)$ & $156(5)$ \\
\hline $\mathrm{C} 26-\mathrm{H} 26 \cdots \mathrm{O} 1$ & 0.93 & 2.38 & $2.871(4)$ & 113 \\
\hline \multicolumn{5}{|l|}{ Clom } \\
\hline $\mathrm{N} 1-\mathrm{H} 1 \cdots \mathrm{N} 23^{x}$ & $0.835(16)$ & $2.073(17)$ & $2.9058(17)$ & $175.3(15)$ \\
\hline
\end{tabular}




\begin{tabular}{|c|c|c|c|c|}
\hline $\mathrm{C} 22-\mathrm{H} 22 \cdots \mathrm{O} 1$ & 0.93 & 2.31 & $2.8844(18)$ & 120 \\
\hline \multicolumn{5}{|l|}{ Clpo_O polymorph } \\
\hline $\mathrm{N} 1-\mathrm{H} 1 \cdots \mathrm{O} 1^{x i}$ & $0.807(17)$ & $2.368(17)$ & $3.1296(14)$ & $157.7(15)$ \\
\hline $\mathrm{C} 15-\mathrm{H} 15 \cdots \mathrm{N} 22^{x i i}$ & 0.93 & 2.60 & 3.5199 (18) & 168 \\
\hline $\mathrm{C} 26-\mathrm{H} 26 \cdots \mathrm{O} 1$ & 0.93 & 2.37 & 2.8954 (17) & 116 \\
\hline \multicolumn{5}{|l|}{ Clpo_N polymorph } \\
\hline $\mathrm{N} 1-\mathrm{H} 1 \cdots \mathrm{N} 22^{x i i i}$ & $0.762(18)$ & $2.337(18)$ & 3.0715 (19) & $162.4(17)$ \\
\hline $\mathrm{C} 15-\mathrm{H} 15 \cdots \mathrm{O} 1^{x i v}$ & 0.93 & 2.66 & $3.329(2)$ & 129 \\
\hline $\mathrm{C} 26-\mathrm{H} 26 \cdots \mathrm{O} 1$ & 0.93 & 2.24 & $2.840(2)$ & 121 \\
\hline \multicolumn{5}{|l|}{ Clmo } \\
\hline $\mathrm{N} 1-\mathrm{H} 1 \cdots \mathrm{N} 22^{x v}$ & $0.84(2)$ & $2.45(2)$ & 3.1990 (17) & $148.9(17)$ \\
\hline $\mathrm{C} 26-\mathrm{H} 26 \cdots \mathrm{O} 1$ & 0.93 & 2.31 & 2.8906 (17) & 120 \\
\hline \multicolumn{5}{|l|}{ Cloo } \\
\hline $\mathrm{N} 1-\mathrm{H} 1 \cdots \mathrm{N} 22^{x v i}$ & $0.835(16)$ & $2.219(16)$ & 3.0485 (14) & $171.9(14)$ \\
\hline $\mathrm{C} 26-\mathrm{H} 26 \cdots \mathrm{O} 1$ & 0.93 & 2.28 & $2.8700(16)$ & 121 \\
\hline $\mathrm{C} 16-\mathrm{H} 16 \cdots \mathrm{Cg} 1^{x v i i}$ & 0.93 & 2.73 & $3.5414(15)$ & 146 \\
\hline $\mathrm{C} 23-\mathrm{H} 23 \cdots \mathrm{Cg} 1^{x v i}$ & 0.93 & 2.70 & $3.4233(15)$ & 135 \\
\hline
\end{tabular}

$\mathrm{Cg} 1$ is the ring centroid of the benzene ring $\{\mathrm{C} 11, \ldots, \mathrm{C} 16\}$.

Symmetry code(s): (i) $-x+1, y+1 / 2,-z+1 / 2$; (ii) $x-1, y, z$; (iii) $x+1, y, z ;$ (iv) $x, y-1, z ;(v)-x,-y+3,-z+1 ;(v i)-x+1 / 2$, $y+1 / 2, z$; (vii) $-x-1 / 2, y+1 / 2, z$; (viii) $x-1, y+1, z$; (ix) $x,-y+1 / 2, z-1 / 2 ;(x) x,-y+1, z-1 / 2 ;(x i) x, y+1, z ;(x i i)-x+1 / 2,-$ $y+3 / 2,-z ;$ ( $x$ iii) $-x, y,-z-1 / 2$; (xiv) $x,-y, z+1 / 2$; (xv) $-x+2,-y+1,-z ;(x v i)-x, y,-z+1 / 2 ;(x v i i) 1 / 2-x, 1 / 2+y, 1 / 2-z$ and additional interactions in Table $2 b$ (xviii) 2-x, -y, 1-z; (xix) x, 1/2-y, 1/2+z; (xx) 1-x, 2-y, -z; (xxi) 1/2+x, y, 1/2-z; (xxii) 1-x, 1-y, 1-z; (xxiii) -x, -y, -1-z; (xxiv) -x, -y, 2-z; (xxv) =1/2-x, 1/2-y, -z; (xxvii) 1-x, 1-y, -z; (xxvii) -x, 2-y, -z.

In the manuscript the symmetry codes quoted correspond to those in the Table 2a (above) although given the crystal structure discussion and its discussion then they may not actually be in order in the text. 
TABLE S2B: INTERACTIONS AND CONTACTS $\left(\AA \AA^{\circ}\right)^{\circ}{ }^{25-30,40-42}$ (PLUS HALOGEN BONDING) ${ }^{31-39}$ :

\begin{tabular}{|c|c|c|c|c|c|}
\hline Clxx & Interaction type & $D-\mathrm{H}$ or $\mathrm{D}-\mathrm{X}$ & $H \cdots A$ & $D \cdots A$ or $X \cdots A$ & $D-\mathrm{H} \cdots A$ or $C-\mathrm{X} \cdots A$ \\
\hline \multirow[t]{2}{*}{ Clpp $^{*}$} & $\mathrm{C} 26-\mathrm{H} 26 \cdots \mathrm{Cg} 1^{\text {xviii }}$ & 0.93 & 2.84 & $3.5145(19)$ & 130 \\
\hline & $\mathrm{C} 14-\mathrm{Cl} 14 \cdots \mathrm{C} 21^{\mathrm{xix}}$ & 1.7351(18) for $\mathrm{C}-\mathrm{Cl}$ & / & $3.3269(18)$ & $150.10(7)^{\circ}$ \\
\hline \multirow[t]{2}{*}{ Clmp } & $\mathrm{C} 1 \mathrm{C} \cdots \mathrm{C} 12 \mathrm{C}^{\mathrm{xx}}$ & Ring stacking type & / & $3.360(2)$ for $C \cdots C$ & / \\
\hline & C14C $\cdots C 21 C^{x x}$ & Ring stacking type & / & $3.323(2)$ for $C \cdots C$ & / \\
\hline Clop & $\mathrm{C} 12-\mathrm{Cl} 12 \cdots \mathrm{O} 1=\mathrm{C} 1^{x x i}$ & $\mathrm{Cl} \cdots \mathrm{O}$ halogen bond & / & $3.1104(18)$ & $161.08(8) / 111.27(13)$ \\
\hline Clpm & $\mathrm{C} 15 \mathrm{~A}-\mathrm{H} 15 \mathrm{~A} \cdots \mathrm{Cl} 4 \mathrm{~A}^{x x i i}$ & $\mathrm{C}-\mathrm{H} \cdots \mathrm{Cl}$ contact & 2.94 & $3.807(4)$ & 156 \\
\hline $\mathrm{Clmm} \bullet \mathrm{H}_{2} \mathrm{O}$ & $\mathrm{C} 15-\mathrm{H} 15 \cdots \mathrm{C} 15^{\text {xxiii }}$ & $(\mathrm{C} 15-\mathrm{H} 15 \cdots \mathrm{C} 15)^{x x i i i}$ & 2.85 & $3.402(5)$ & $119(\mathrm{C} 15-\mathrm{H} 15 \cdots \mathrm{C} 15)^{\mathrm{xxiii}}$ \\
\hline \multirow[t]{2}{*}{ Clom } & $\mathrm{Cl} 12 \cdots \mathrm{O} 1$ & Intramolecular & / & $3.1811(13)$ & / \\
\hline & $\mathrm{C}-\mathrm{Cl} \cdots \mathrm{Cl}-\mathrm{C}^{x x i v}$ & Repulsive - type I Cl...Cl & / & $3.3699(10)$ & $167.66(6)$ \\
\hline Clpo_o & $\mathrm{C} 16 \ldots \mathrm{C} 1=\mathrm{O} 1^{x \times v}$ & $\pi \cdots(\mathrm{C}=\mathrm{O})^{x \times v}$ type & / & $3.3488(19)$ & / \\
\hline Clpo_N & $\mathrm{C} 15-\mathrm{H} 15 \cdots \mathrm{C} 12^{x i v}$ & $\mathrm{C}-\mathrm{H} \cdots \mathrm{C}$ type & 2.85 & $3.691(2)$ & 151 \\
\hline Clmo & $\mathrm{C} 12-\mathrm{H} 12 \cdots \mathrm{C} 24^{x x v i}$ & $\mathrm{C}-\mathrm{H} \cdots \mathrm{C}$ type & 2.84 & $3.504(2)$ & 130 \\
\hline Cloo & $C 24 \ldots C 26^{x x v i i}$ & $\pi \cdots \pi$ stacking type & / & $3.3049(18)$ & / \\
\hline
\end{tabular}

$*=$ The $\mathrm{C} 14-\mathrm{Cl} 14 \ldots \pi$ (pyridine) contact has angle dimensions of $\mathrm{C} 14-\mathrm{Cl} 14 \ldots \pi($ centroid $)=163.34(7)^{\circ}$ in Clpp.

The value quoted in Table $\mathbf{S} 2 \mathbf{b}$ refers to the closest $\mathrm{Cl} \cdots \mathrm{C}$ contact as $\mathrm{C} 14-\mathrm{Cl} 14 \cdots \mathrm{C} 21^{x i x}$ 
TABLE S2C: SELECTED INTERMOLECULAR INTERACTIONS FOR THE MAIN PAPER.

\begin{tabular}{|c|c|c|c|c|c|}
\hline Clxx & $D-\mathrm{H} \cdots A$ & $D-\mathrm{H}(\AA)$ & $H \cdots A(\AA)$ & $D \cdots A(\AA)$ & $D-\mathrm{H} \cdots A\left(\left(^{\circ}\right)\right.$ \\
\hline Clpp & $\mathrm{N} 1-\mathrm{H} 1 \cdots \mathrm{N} 24^{i}$ & 0.827 (19) & $2.441(19)$ & $3.114(2)$ & $139.2(17)$ \\
\hline \multirow[t]{6}{*}{ Clmp } & $\mathrm{N} 1 \mathrm{~A}-\mathrm{H} 1 \mathrm{~A} \cdots \mathrm{N} 24 \mathrm{D}$ & $0.836(15)$ & $2.132(15)$ & $2.9431(16)$ & $163.4(14)$ \\
\hline & $\mathrm{N} 1 \mathrm{~B}-\mathrm{H} 1 \mathrm{~B} \cdots \mathrm{N} 24 \mathrm{C}$ & $0.848(15)$ & $2.210(16)$ & $3.0120(16)$ & $157.7(14)$ \\
\hline & $\mathrm{N} 1 \mathrm{C}-\mathrm{H} 1 \mathrm{C} \cdots \mathrm{N} 24 \mathrm{~B}^{i i}$ & $0.853(15)$ & $2.316(15)$ & $3.1576(16)$ & $169.1(13)$ \\
\hline & N1D-H1D $\cdots N 24 A^{i i i}$ & $0.812(15)$ & $2.388(15)$ & $3.1913(16)$ & $170.4(14)$ \\
\hline & $\mathrm{C} 12 \mathrm{C}-\mathrm{H} 12 \mathrm{C} \cdots \mathrm{N} 24 \mathrm{~B}^{i i}$ & 0.93 & 2.37 & $3.2961(18)$ & 173 \\
\hline & C12D-H12D $\cdots N 24 A^{i i i}$ & 0.93 & 2.38 & $3.2761(18)$ & 161 \\
\hline \multirow[t]{2}{*}{ Clop } & $\mathrm{N} 1-\mathrm{H} 1 \cdots \mathrm{N} 24^{\mathrm{vi}}$ & $0.846(19)$ & $2.17(2)$ & $3.010(3)$ & $175.9(18)$ \\
\hline & $\mathrm{C} 15-\mathrm{H} 15 \cdots \mathrm{O} 1^{\text {vii }}$ & 0.93 & 2.50 & 3.266 (3) & 139 \\
\hline \multirow[t]{4}{*}{ Clpm } & $\mathrm{N} 1 \mathrm{~A}-\mathrm{H} 1 \mathrm{~A} \cdots \mathrm{N} 23 \mathrm{~B}$ & $0.97(4)$ & $2.24(4)$ & $3.184(4)$ & $165(3)$ \\
\hline & $\mathrm{N} 1 \mathrm{~B}-\mathrm{H} 1 \mathrm{~B} \cdots \mathrm{N} 23 \mathrm{C}$ & $0.80(4)$ & $2.43(4)$ & $3.203(4)$ & $164(4)$ \\
\hline & $\mathrm{N} 1 \mathrm{C}-\mathrm{H} 1 \mathrm{C} \cdots \mathrm{N} 23 \mathrm{D}$ & $0.74(3)$ & $2.43(3)$ & $3.151(4)$ & $166(3)$ \\
\hline & N1D-H1D $\cdots N 23 A^{\text {viii }}$ & $0.79(3)$ & $2.37(4)$ & $3.150(4)$ & $168(3)$ \\
\hline \multirow[t]{3}{*}{ Clmm } & $\mathrm{N} 1-\mathrm{H} 1 \cdots \mathrm{O} 1 \mathrm{~W}^{\mathrm{ix}}$ & $0.817(18)$ & $2.11(2)$ & $2.892(4)$ & $161(3)$ \\
\hline & $\mathrm{O} 1 \mathrm{~W}-\mathrm{H} 1 \mathrm{~W} \cdots \mathrm{N} 23$ & $0.905(18)$ & $1.96(2)$ & $2.858(4)$ & $169(3)$ \\
\hline & $\mathrm{O} 1 \mathrm{~W}-\mathrm{H} 2 \mathrm{~W} \cdots \mathrm{O} 1^{i}$ & $0.876(19)$ & $2.07(3)$ & $2.890(4)$ & $156(5)$ \\
\hline Clom & $\mathrm{N} 1-\mathrm{H} 1 \cdots \mathrm{N} 23^{x}$ & $0.835(16)$ & $2.073(17)$ & 2.9058 (17) & $175.3(15)$ \\
\hline Clpo_O & $\mathrm{N} 1-\mathrm{H} 1 \cdots \mathrm{O} 1^{x i}$ & $0.807(17)$ & $2.368(17)$ & $3.1296(14)$ & $157.7(15)$ \\
\hline Clpo_N & $\mathrm{N} 1-\mathrm{H} 1 \cdots \mathrm{N} 22^{x i i i}$ & $0.762(18)$ & $2.337(18)$ & 3.0715 (19) & $162.4(17)$ \\
\hline Clmo & $\mathrm{N} 1-\mathrm{H} 1 \cdots \mathrm{N} 22^{x v}$ & $0.84(2)$ & $2.45(2)$ & 3.1990 (17) & $148.9(17)$ \\
\hline Cloo & $\mathrm{N} 1-\mathrm{H} 1 \cdots \mathrm{N} 22^{x v i}$ & $0.835(16)$ & $2.219(16)$ & 3.0485 (14) & $171.9(14)$ \\
\hline
\end{tabular}

In the manuscript the symmetry codes quoted correspond to those for the most important intermolecular interactions in the Table (above) although given the crystal structure discussion and its development they may not actually seem in order. 


\section{FIGURE S3. : ENLARGED FORMAT FOR EASE OF VIEWING/COMPARISONS}

The Potential Energy Surface conformational analysis for Clxx molecules optimized in the gas phase: the equivalent solid-state angle is shown by $(\bullet)$ with, if applicable, an assigned identifier.

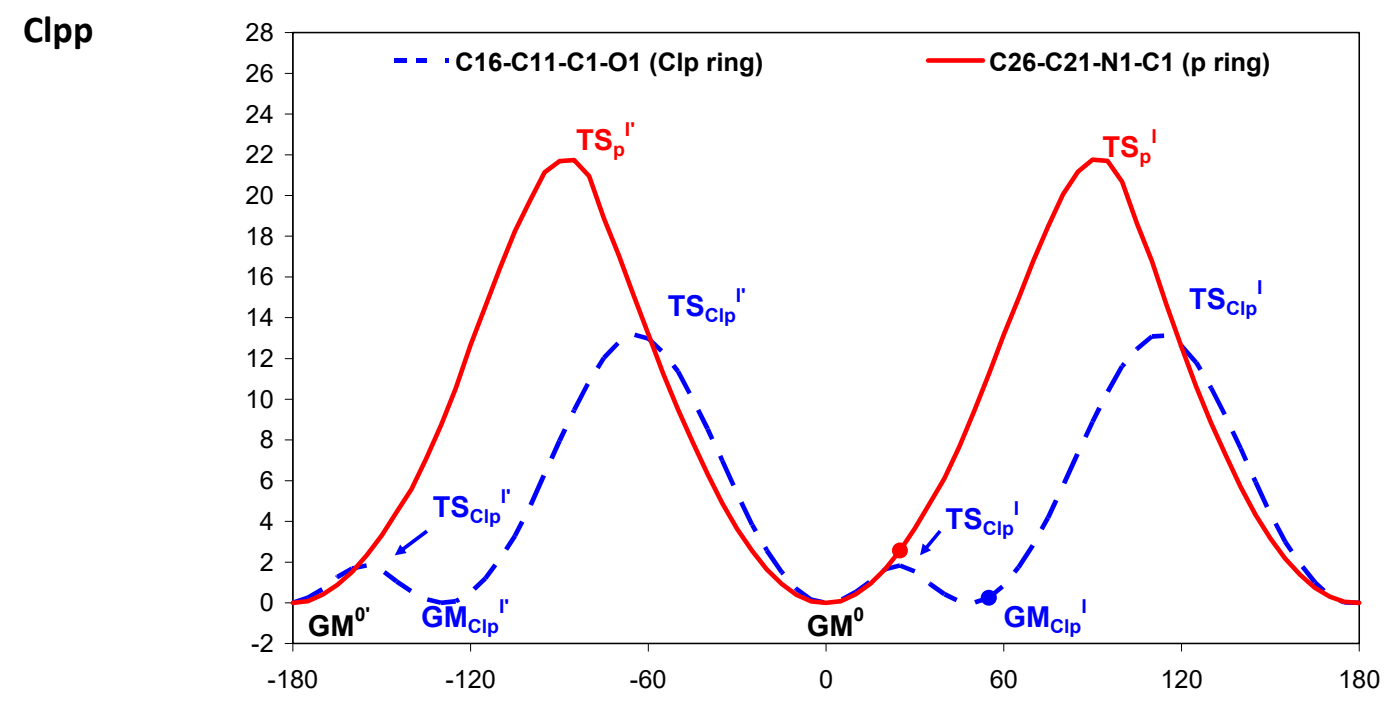

\section{Clmp}

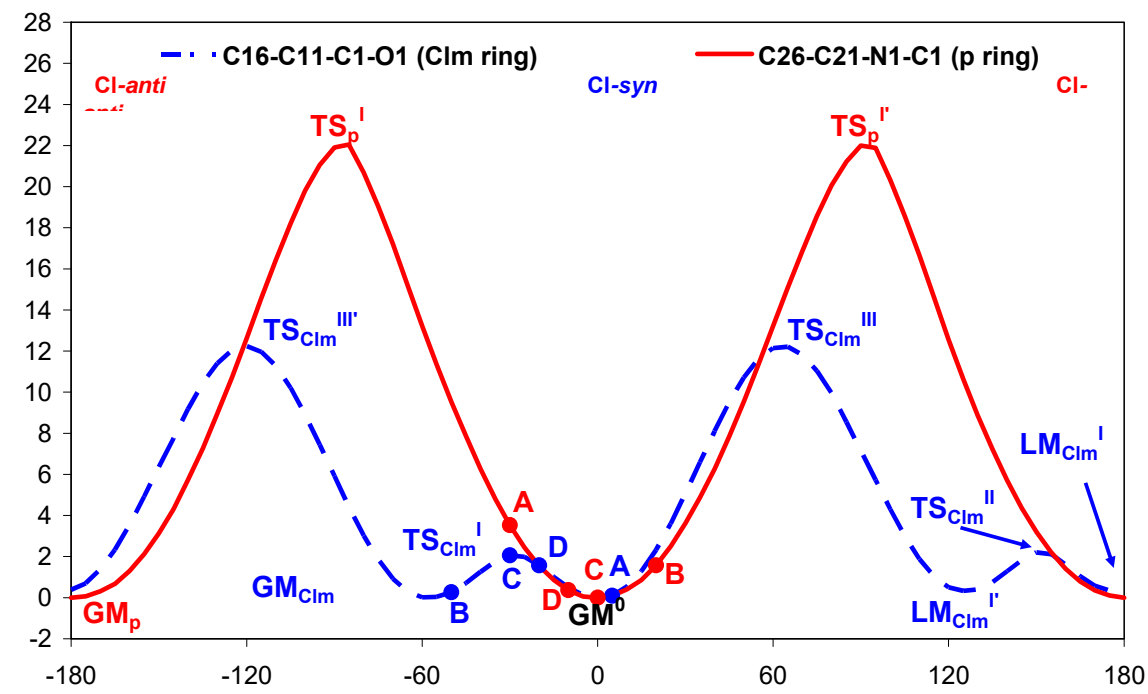




\section{Clop}

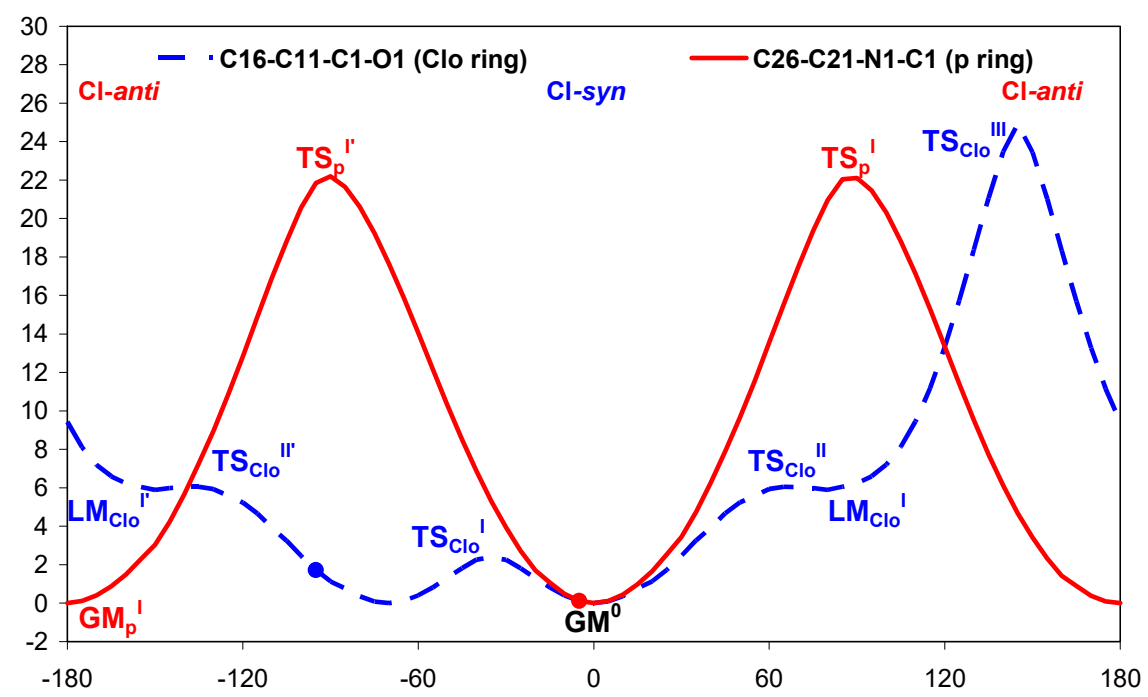

\section{Clpm}

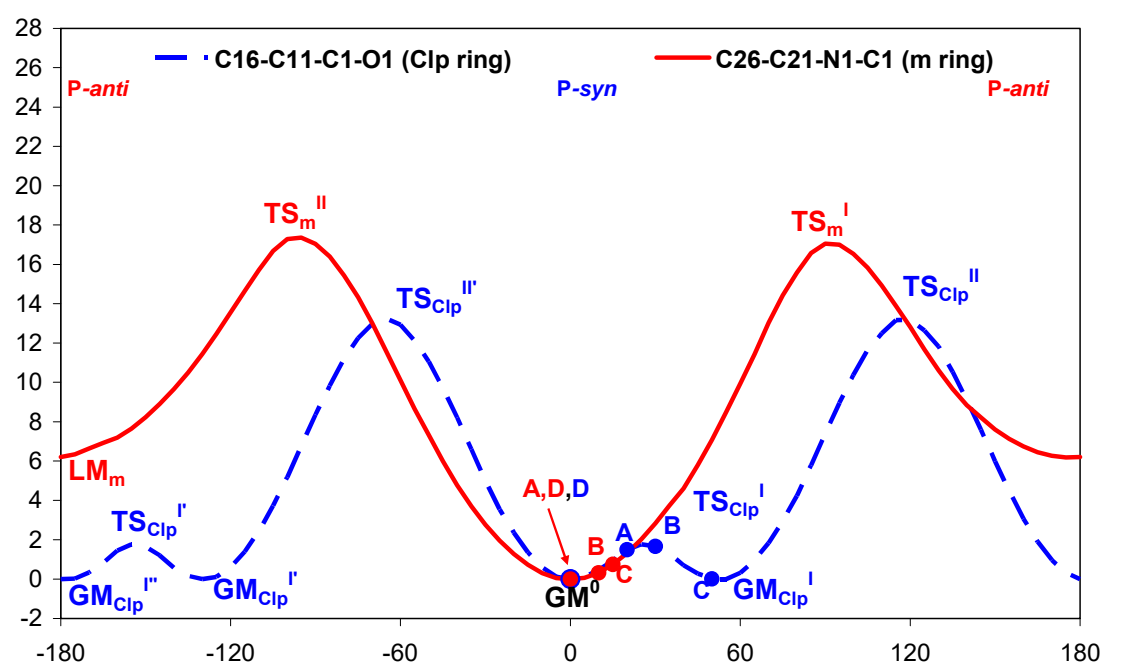

\section{Clmm}

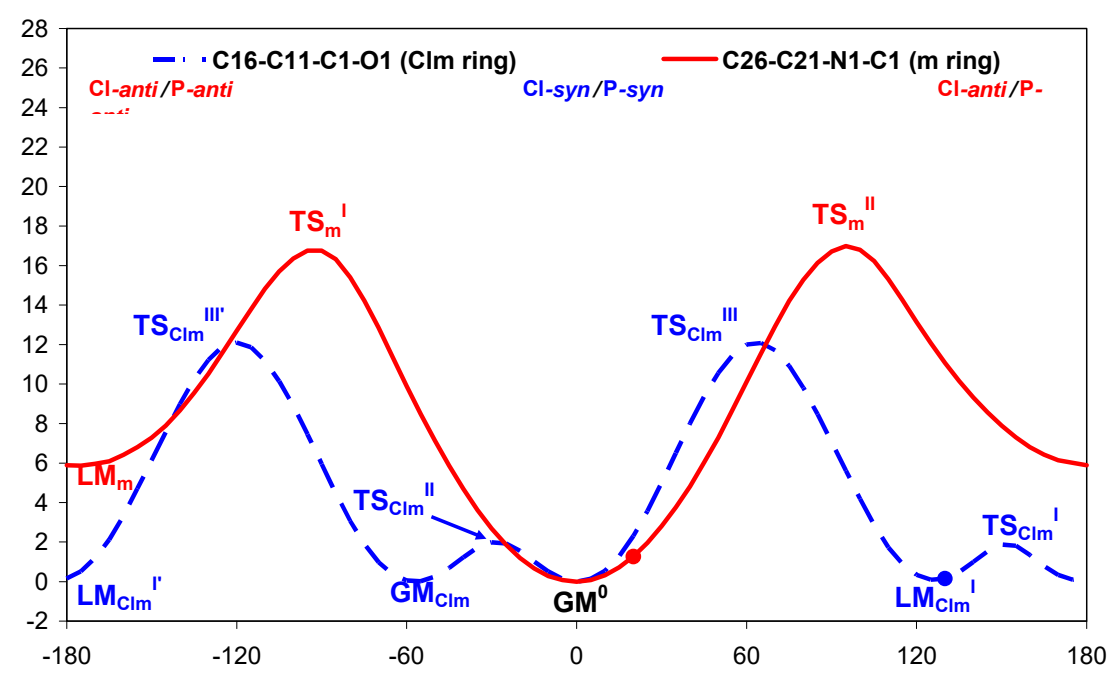

\section{Clom}



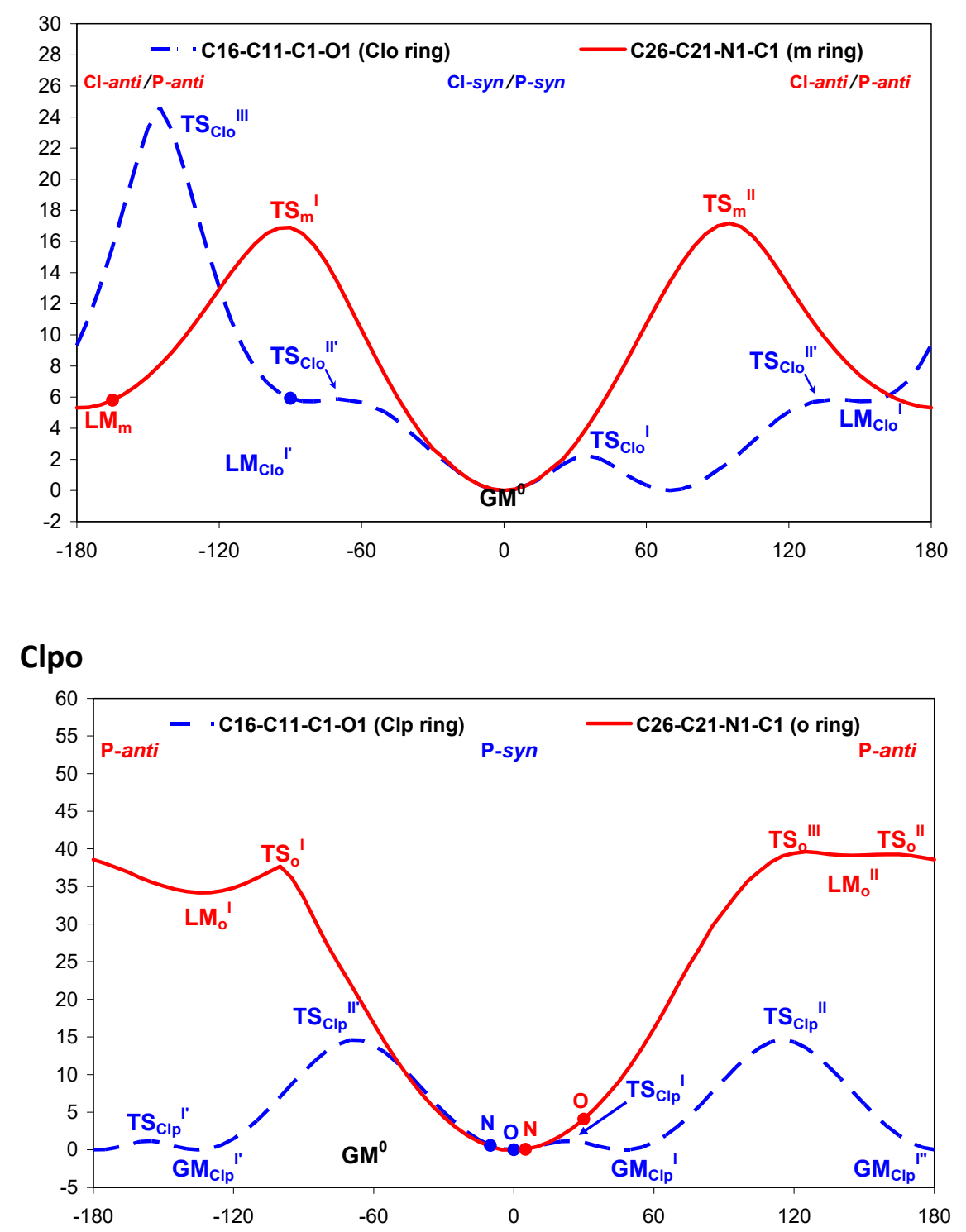

\section{Clmo}

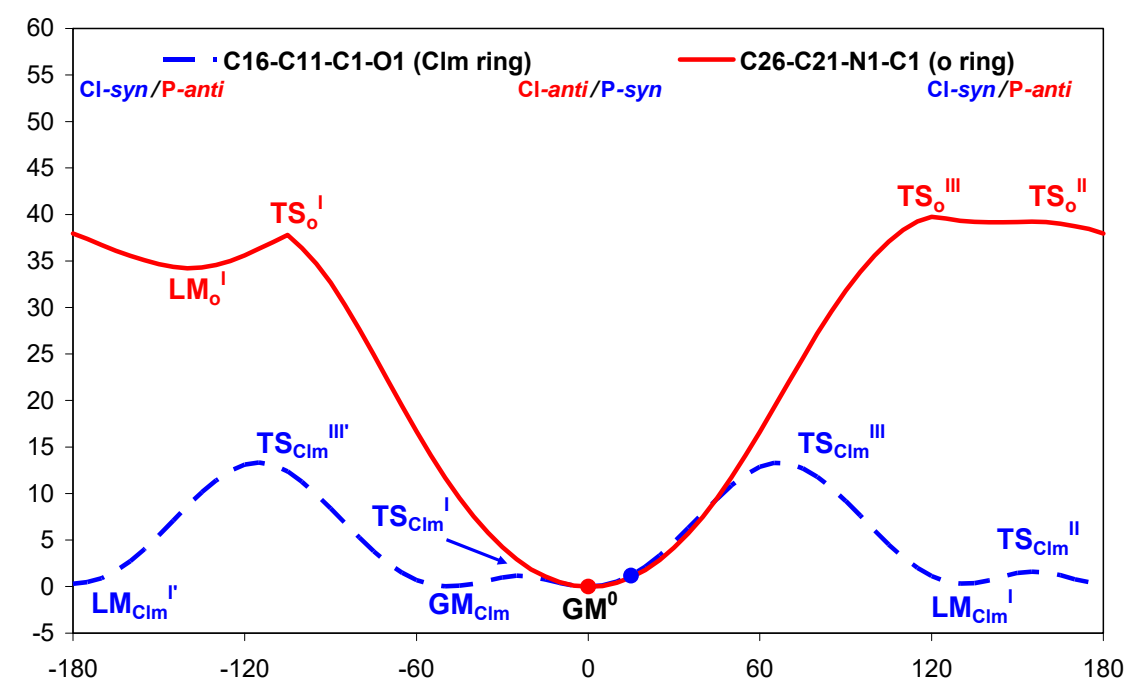


Cloo

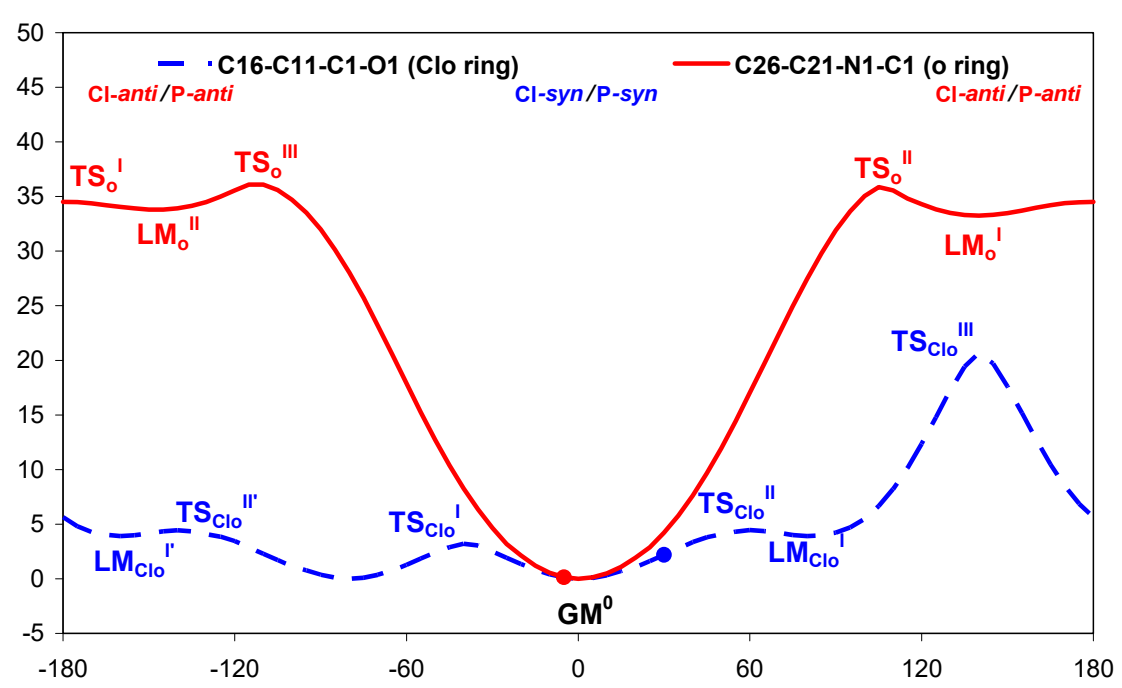




\section{TABLE S3 SUPPLEMENTARY MELTING POINT}

Melting points: Comparisons of the Mxx, NxxM, Fxx and NxxF [3 $\times 3]$ isomer grids.

benzamides

\begin{tabular}{|c|c|c|c|c|c|c|c|}
\hline $\mathbf{M x x}$ & $\mathbf{M p}$ & $\mathbf{M m}$ & Mo & No & $\mathrm{Nm}$ & $\mathbf{N p}$ & NxxM \\
\hline $\mathbf{p}$ & $181^{\circ}$ & 106 & 129 & 105 & 148 & $162^{\circ}$ & $\mathbf{p M}$ \\
\hline m & $\underline{128}$ & 91 & 108 & $50 *$ & 115 & 142 & $\mathbf{m M}$ \\
\hline O & 105 & $79 \%$ & 116 & 65 & 107 & 125 & $\mathbf{o M}$ \\
\hline о & 120 & $77 *$ & 85 & 107 & $\underline{117}$ & $140^{\circ}$ & oF \\
\hline m & 150,148 & 151 & 89 & $78 \% x$ & 122 & 132 & $\mathbf{m F}$ \\
\hline p & $187^{\bullet}$ & 186 & 135 & 94 & 133 & 135 & pF \\
\hline $\mathbf{F x x}^{\mathbf{b}}$ & $\mathbf{F p}$ & $\mathbf{F m}$ & Fo & No & $\mathrm{Nm}$ & $\mathbf{N p}$ & NxxF \\
\hline
\end{tabular}

Average melting point range for all 37 compounds with highest denoted by $\bullet$ and lowest by *

- Green labels highlight the N-H...N interaction

- Orange labels the $\mathrm{N}-\mathrm{H} . . . \mathrm{O}=\mathrm{C}$ hydrogen bonds

- Melting points for compounds in non-centrosymmetric space groups are underlined.

Graph of melting point trends in series of benzamides (Fxx, $\mathbf{M x x}$ ) and their amide-reversed

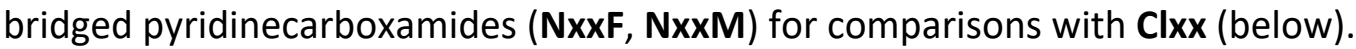

Melting point averages and ranges for Clxx

\begin{tabular}{|l|l|l|l|}
\hline Clxx isomers & Clp & Clm & Clo \\
\hline para & $207^{\star}$ & 187 & 169 \\
\hline meta & 151 & $113^{\#}$ & 136 \\
\hline ortho & 133 & $100^{*}$ & 136 \\
\hline
\end{tabular}

as taken from the following

\begin{tabular}{|l|l|l|l|}
\hline Clxx (mp range) & Clp & Clm & Clo \\
\hline para & $206.2-208.4$ & $185.4-187.2$ & $167.9-169.9$ \\
\hline meta & $150.1-151.3$ & $112.4-113.9$ & $134.5-137.8$ \\
\hline ortho & $131.5-134.5$ & $95-105$ & $134.4-138.0$ \\
\hline
\end{tabular}

From Chloe Violin results and comparisons:

Melting point averages for Brxx

\begin{tabular}{|l|l|l|l|}
\hline Brxx isomers & Brp & Brm & Bro \\
\hline para & $188^{*}$ & 162 & 177 \\
\hline meta & 159 & $122^{\#}$ & 119 \\
\hline ortho & 132 & $118^{*}$ & $\mathbf{3 0}$ \\
\hline
\end{tabular}


Figure S4

Scatterplot of the melting point temperature and computed lattice electrostatic energy.

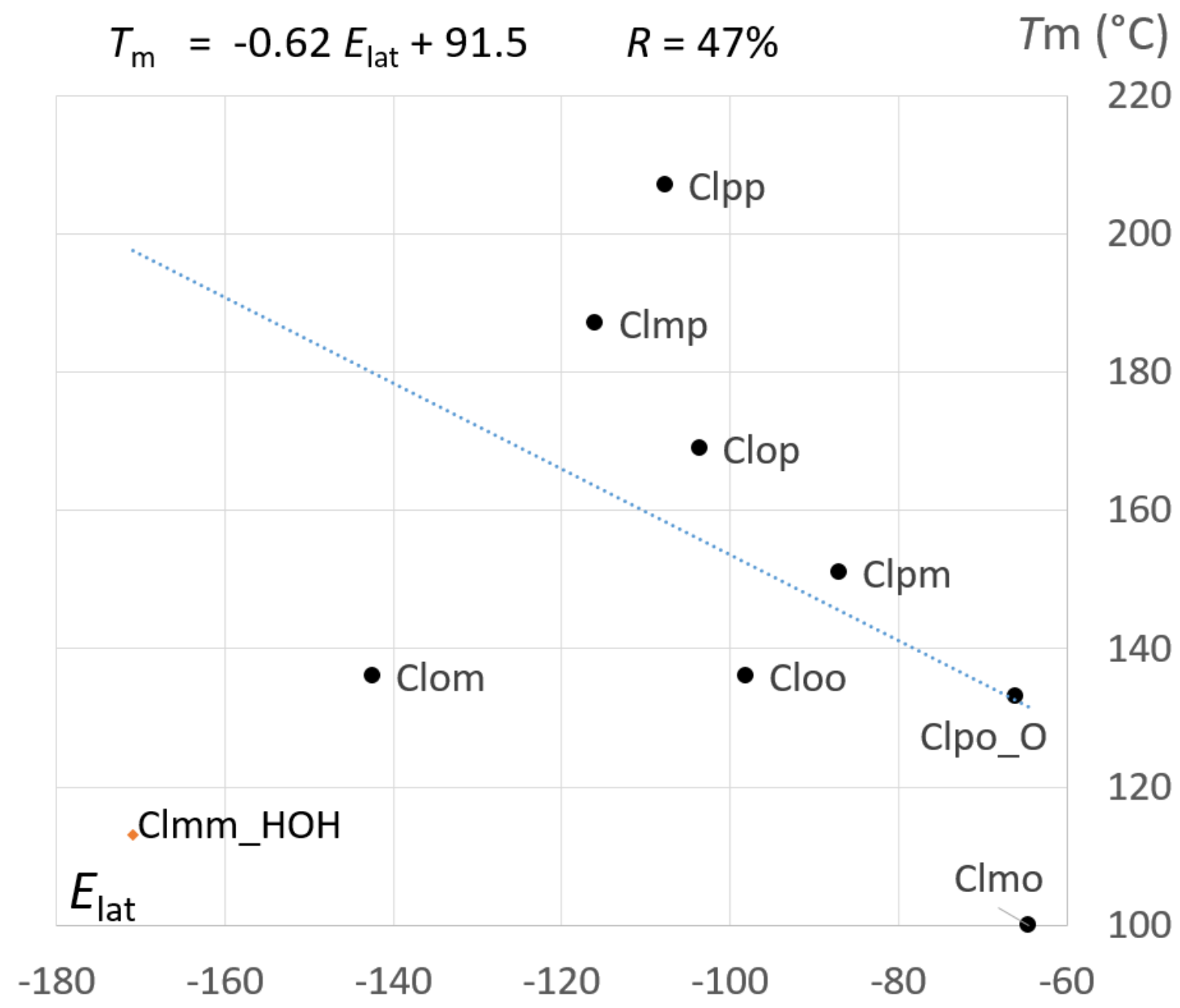




\section{Figure S5}

Scatterplot of the experimental $T_{\mathrm{m}}$ and fitted $T_{\text {fit }}$ fusion temperatures. The double linear regression was performed on the ortho-/meta-/para-positions descriptor $f(\mathrm{Clxy})$ and $E_{\text {lat. }}$.

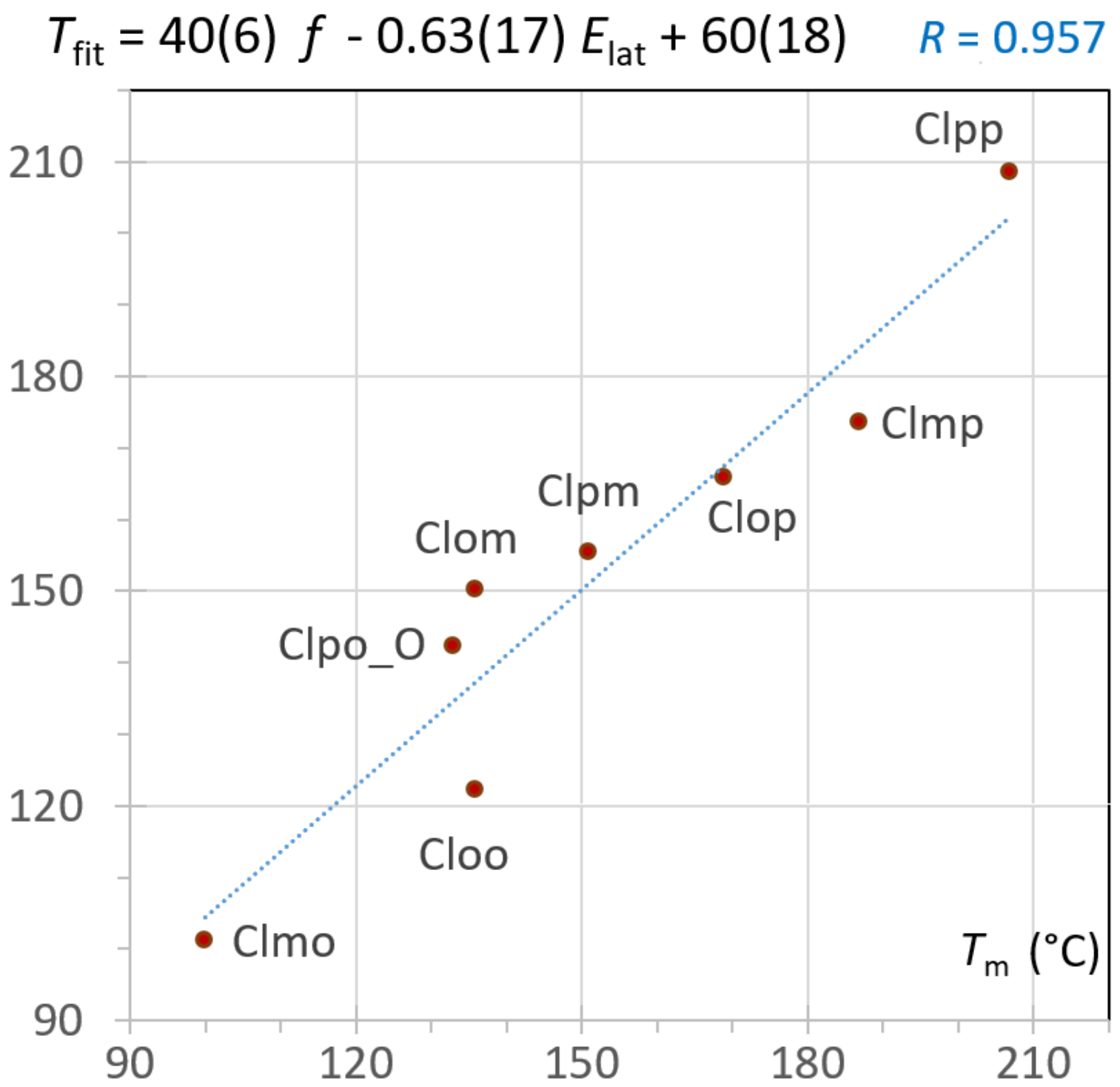


Figure S6.

Scatterplot of lattice $E_{\text {lat }}$ and density

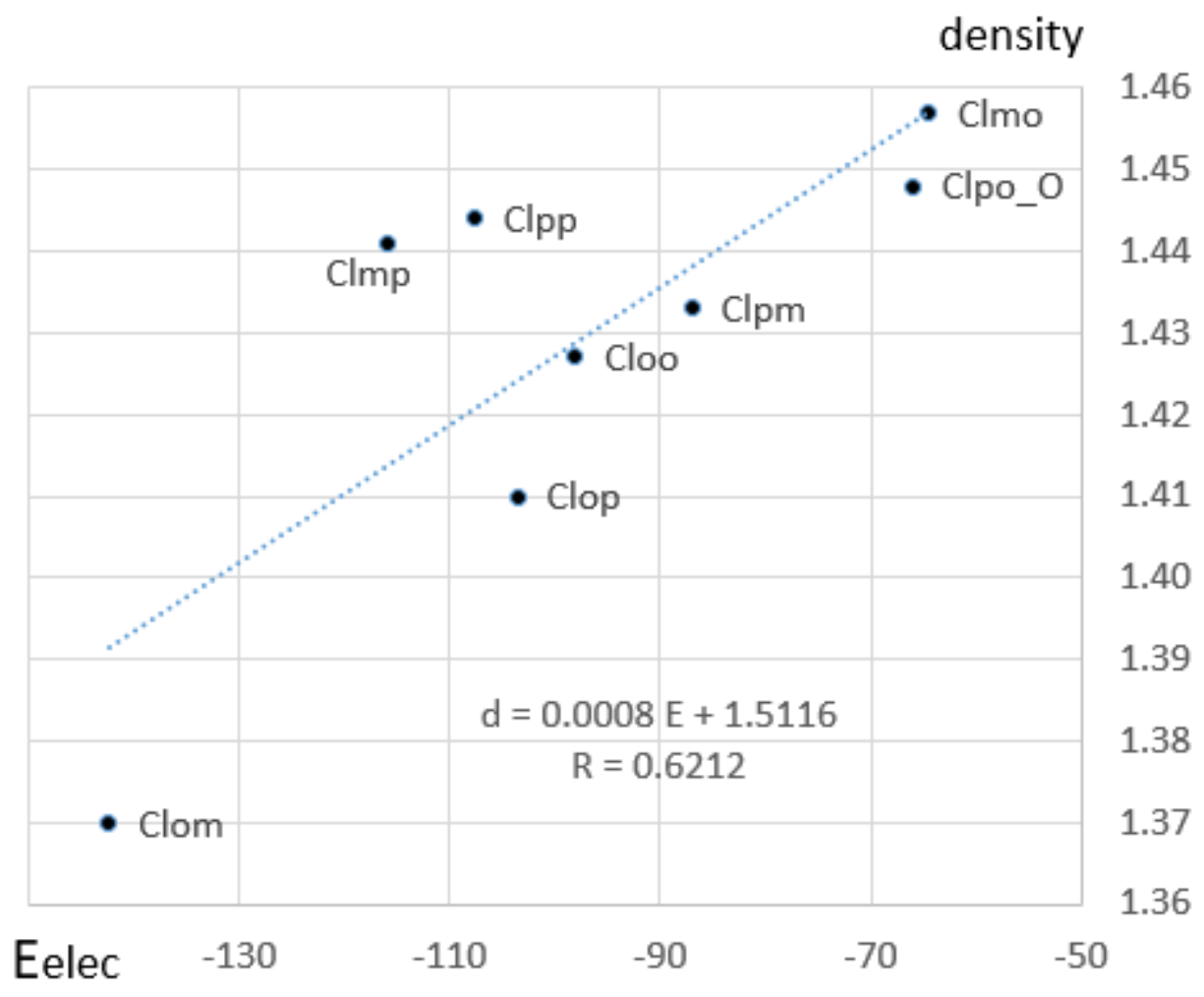

Figure S7

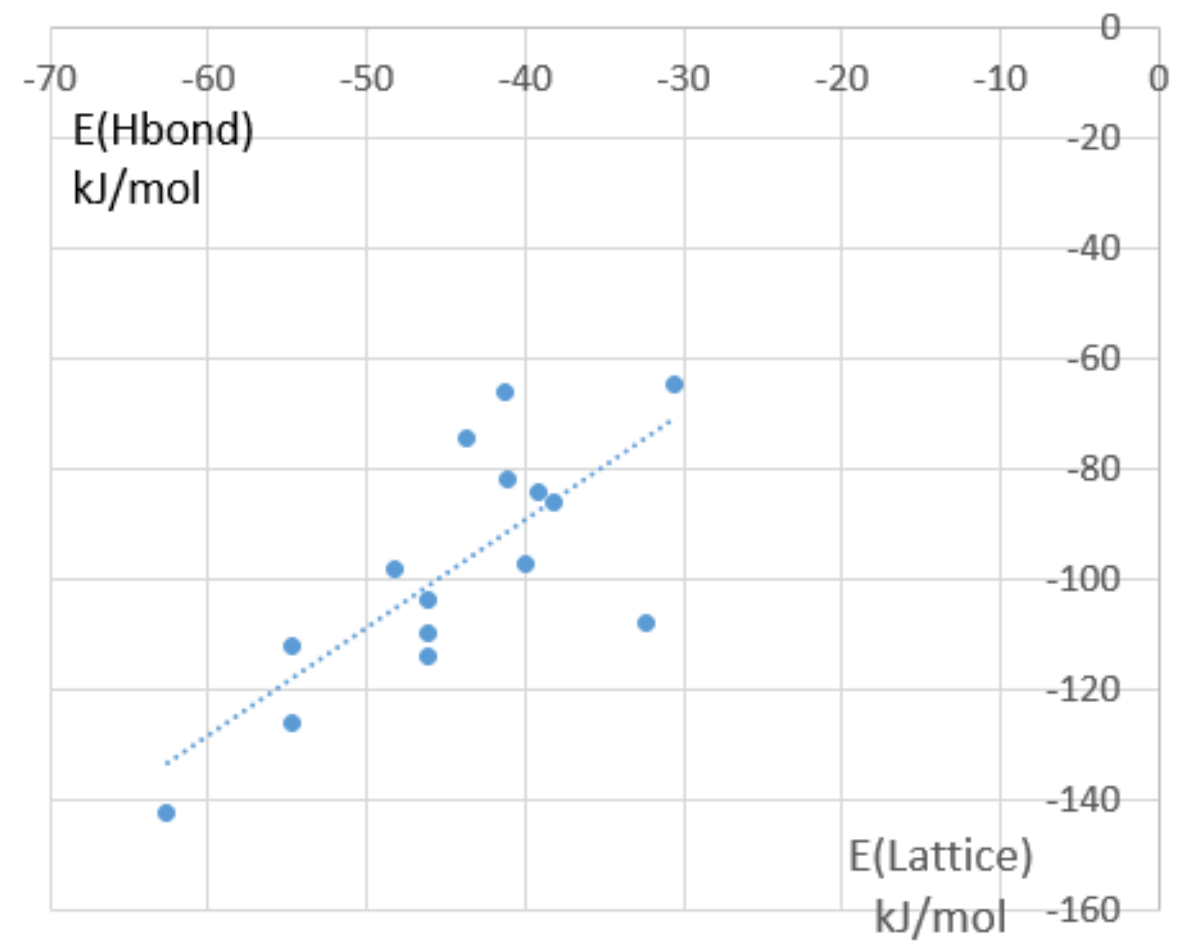




\section{Figure S8}

Contribution of the $\mathrm{N}-\mathrm{H} \ldots \mathrm{N}$ and $\mathrm{N}-\mathrm{H} \ldots \mathrm{O}$ strong hydrogen bonds to the lattice electrostatic energy.

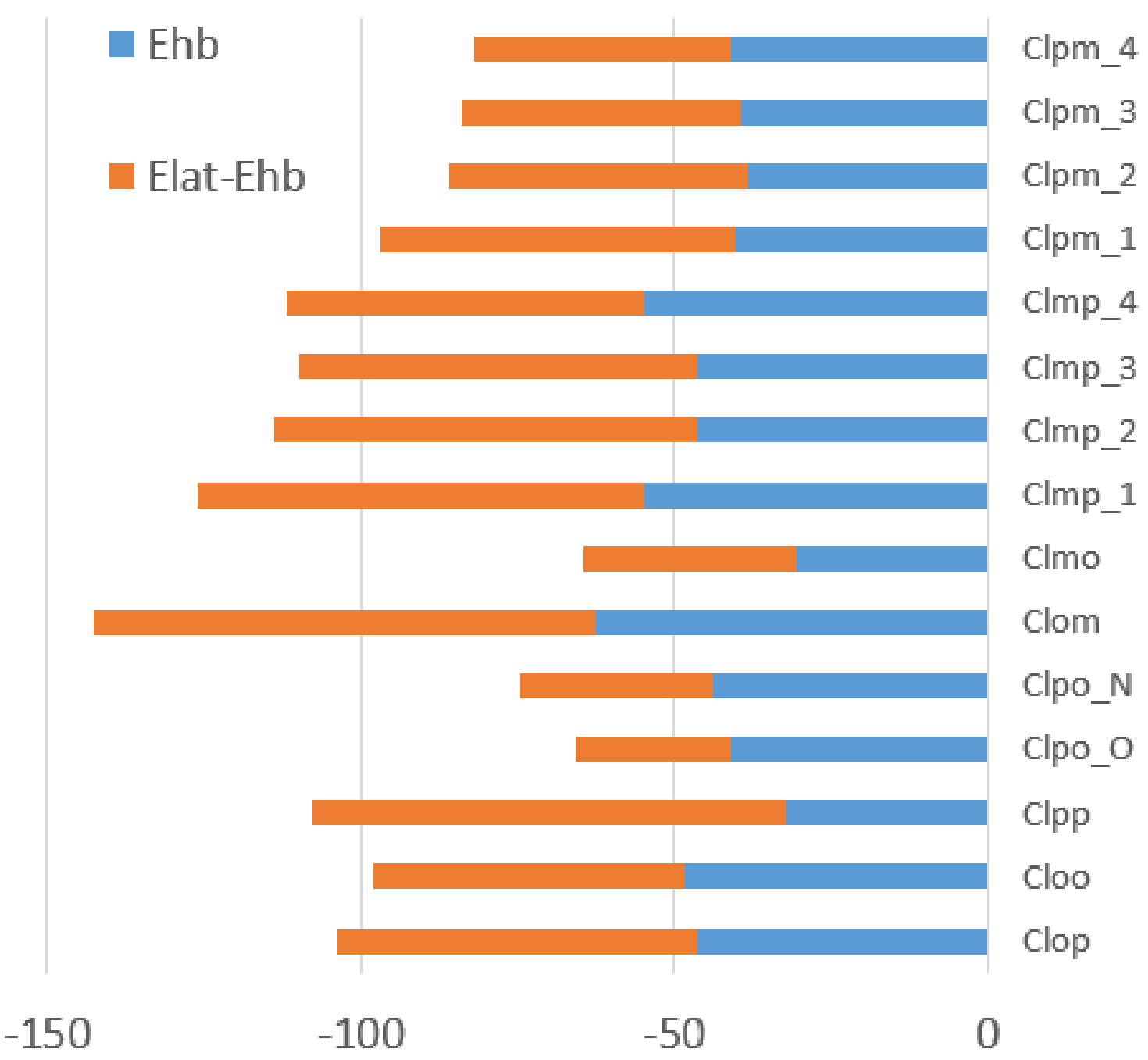


Table S9. Proportion of contact types (\%) in the 10 Clxx crystal structures.

\begin{tabular}{|c|c|c|c|c|c|c|}
\hline atom & C & $\mathbf{H}_{\mathrm{C}}$ & $\mathrm{Cl}$ & $\mathbf{N}$ & 0 & $\mathbf{H}_{\mathrm{N}}$ \\
\hline C & 12.1 & & & & & \\
\hline $\mathbf{H}_{\mathrm{C}}$ & 32.6 & 6.5 & & & & Clmo \\
\hline $\mathrm{Cl}$ & 4.8 & 23.6 & 0.1 & & & \\
\hline $\mathbf{N}$ & 1.9 & 3.5 & 0.0 & 0.0 & & \\
\hline 0 & 4.6 & 3.3 & 0.0 & 0.9 & 0.0 & \\
\hline $\mathrm{H}_{\mathrm{N}}$ & 0.2 & 0.2 & 0.0 & 3.8 & 1.4 & 0.6 \\
\hline C & 11.7 & & & & & \\
\hline $\mathbf{H}_{\mathrm{C}}$ & 32.2 & 11.9 & & & & Clom \\
\hline $\mathrm{Cl}$ & 5.0 & 13.0 & 3.6 & & & \\
\hline $\mathbf{N}$ & 3.8 & 2.6 & 0.0 & 0.0 & & \\
\hline 0 & 1.9 & 8.0 & 0.0 & 0.0 & 0.0 & \\
\hline $\mathbf{H}_{\mathrm{N}}$ & 1.3 & 0.7 & 0.0 & 4.5 & 0.0 & 0.0 \\
\hline C & 15.3 & & & & & \\
\hline $\mathbf{H}_{\mathrm{C}}$ & 26.3 & 13.6 & & & & Cloo \\
\hline $\mathrm{Cl}$ & 4.4 & 17.7 & 0.2 & & & \\
\hline $\mathbf{N}$ & 0.8 & 1.5 & 2.8 & 0.0 & & \\
\hline 0 & 4.7 & 6.3 & 0.0 & 0.0 & 0.0 & \\
\hline $\mathrm{H}_{\mathrm{N}}$ & 0.1 & 0.1 & 1.1 & 4.6 & 0.0 & 0.7 \\
\hline C & 15.9 & & & & & \\
\hline $\mathbf{H}_{\mathrm{C}}$ & 19.9 & 18.7 & & & & Clop \\
\hline $\mathrm{Cl}$ & 10.1 & 11.7 & 0.0 & & & \\
\hline $\mathbf{N}$ & 2.4 & 3.9 & 0.0 & 0.0 & & \\
\hline 0 & 1.7 & 5.9 & 3.3 & 0.0 & 0.0 & \\
\hline$H_{N}$ & 1.4 & 1.0 & 0.0 & 4.1 & 0.0 & 0.0 \\
\hline C & 18.2 & & & & & \\
\hline $\mathbf{H}_{\mathrm{C}}$ & 20.9 & 13.3 & & & & Clpo_N \\
\hline $\mathrm{Cl}$ & 7.3 & 17.3 & 1.4 & & & \\
\hline $\mathbf{N}$ & 2.7 & 2.9 & 0.0 & 0.1 & & \\
\hline 0 & 1.8 & 8.1 & 0.1 & 0.0 & 0.0 & \\
\hline $\mathbf{H}_{\mathrm{N}}$ & 0.4 & 0.7 & 0.0 & 4.3 & 0.0 & 0.7 \\
\hline C & 11.6 & & & & & \\
\hline $\mathbf{H}_{\mathrm{C}}$ & 30.9 & 8.1 & & & & Clpo_O \\
\hline $\mathrm{Cl}$ & 7.7 & 17.8 & 1.0 & & & \\
\hline $\mathbf{N}$ & 3.8 & 7.2 & 0.0 & 0.0 & & \\
\hline 0 & 3.4 & 1.9 & 0.0 & 0.2 & 0.0 & \\
\hline $\mathbf{H}_{\mathrm{N}}$ & 0.7 & 1.3 & 0.0 & 0.0 & 4.5 & 0.0 \\
\hline C & 8.2 & & & & & \\
\hline $\mathbf{H}_{\mathrm{C}}$ & 37.2 & 7.1 & & & & Clpp \\
\hline Cl & 12.6 & 13.9 & 0.0 & & & \\
\hline $\mathbf{N}$ & 1.1 & 4.5 & 0.9 & 0.3 & & \\
\hline 0 & 3.2 & 5.0 & 0.0 & 0.1 & 0.0 & \\
\hline $\mathrm{H}_{\mathrm{N}}$ & 0.0 & 0.3 & 0.0 & 3.8 & 2.0 & 0.0 \\
\hline
\end{tabular}




\begin{tabular}{|c|ccc|ccc|}
\hline $\mathbf{C}_{\mathbf{x y}}$ & $\mathbf{C}$ & $\mathbf{H}_{\mathbf{C}}$ & $\mathbf{C l}$ & $\mathbf{N}$ & $\mathbf{O}$ & $\mathbf{H}_{\mathbf{N}}$ \\
\hline $\mathbf{C}$ & 18.2 & & & & & \\
$\mathbf{H}_{\mathbf{C}}$ & 17.4 & 13.5 & & & & \\
$\mathbf{C l}$ & 9.5 & 16.2 & 2.2 & & & \\
$\mathbf{N}$ & 3.8 & 2.8 & 0.2 & 0.1 & & \\
$\mathbf{O}$ & 1.7 & 8.2 & 0.3 & 0.1 & 0.0 & 0.0 \\
$\mathbf{H}_{\mathbf{N}}$ & 1.3 & 0.3 & 0.0 & 4.2 & 0.1 & \\
\hline $\mathbf{C}$ & 20.2 & & & & & \\
$\mathbf{H}_{\mathbf{C}}$ & 16.6 & 12.6 & & & & \\
$\mathbf{C l}$ & 7.8 & 17.3 & 2.1 & & & \\
$\mathbf{N}$ & 4.0 & 4.3 & 0.0 & 0.0 & 0.0 \\
$\mathbf{0}$ & 1.7 & 6.8 & 0.4 & 0.0 & 0.0 & \\
$\mathbf{H}_{\mathbf{N}}$ & 1.4 & 1.1 & 0.0 & 3.3 & 0.0 & \\
\hline
\end{tabular}

and

\begin{tabular}{|c|ccc|ccc|}
\hline $\boldsymbol{C}_{\mathrm{xy}}$ & $\mathbf{C}$ & $\mathbf{H}_{\mathrm{C}}$ & $\mathbf{C l}$ & $\mathbf{N}$ & $\mathbf{O}$ & $\mathbf{H}_{\mathrm{N} / \mathrm{O}}$ \\
\hline $\mathbf{C}$ & 18.6 & & & & & \\
$\mathbf{H}_{\mathbf{C}}$ & 12.5 & 9.9 & & & & \\
$\mathbf{C l}$ & 3.8 & 14.0 & 0.3 & & \\
$\mathbf{N}$ & 3.3 & 1.0 & 1.3 & 0.0 & & \\
$\mathbf{O}$ & 1.2 & 8.9 & 2.6 & 0.0 & 0.0 & \\
$\mathbf{H}_{\mathrm{N} / \mathrm{O}}$ & 2.6 & 6.8 & 1.8 & 4.5 & 6.6 & 0.3 \\
\hline
\end{tabular}


Table S10. Contact enrichment ratios in the Clxx crystals.

\begin{tabular}{|c|c|c|c|c|c|c|}
\hline$E x y$ & C & $\mathrm{H}_{\mathrm{c}}$ & $\mathrm{Cl}$ & $\mathrm{N}$ & 0 & $H_{N}$ \\
\hline c & 1.0 & & & & & \\
\hline $\mathrm{H}_{\mathrm{c}}$ & 1.3 & 0.5 & & & Clmo & \\
\hline $\mathrm{Cl}$ & 0.5 & 2.2 & 0 & & & \\
\hline $\mathbf{N}$ & 0.6 & 0.9 & 0 & 0 & & \\
\hline 0 & 1.3 & 0.9 & 0 & 1.7 & 0 & \\
\hline $\mathbf{H}_{N}$ & 0.1 & 0.1 & 0 & 11.2 & 4 & 5.2 \\
\hline C & 1.0 & & & & & \\
\hline $\mathrm{H}_{\mathrm{c}}$ & 1.2 & 0.7 & & & Clom & \\
\hline $\mathrm{Cl}$ & 0.6 & 1.3 & 2.3 & & & \\
\hline $\mathbf{N}$ & 1 & 0.6 & 0 & 0 & & \\
\hline 0 & 0.6 & 2 & 0 & 0 & 0 & \\
\hline $\mathbf{H}_{\mathrm{N}}$ & 0.6 & 0.3 & 0 & 12.8 & 0 & 0 \\
\hline C & 1.4 & & & & & \\
\hline$H_{c}$ & 1.0 & 0.9 & & & Cloo & \\
\hline $\mathrm{Cl}$ & 0.5 & 1.7 & 0.1 & & & \\
\hline$N$ & 0.2 & 0.4 & 2.2 & 0 & & \\
\hline 0 & 1.3 & 1.4 & 0 & 0 & 0 & \\
\hline$H_{N}$ & 0 & 0.1 & 1.2 & 13.1 & 0 & 5.2 \\
\hline $\bar{c}$ & 1.4 & & & & & \\
\hline $\mathrm{H}_{\mathrm{c}}$ & 0.7 & 1.2 & & & Clop & \\
\hline $\mathrm{Cl}$ & 1.2 & 1.2 & 0 & & & \\
\hline $\mathbf{N}$ & 0.7 & 0.9 & 0 & 0 & & \\
\hline 0 & 0.5 & 1.4 & 2.4 & 0 & 0 & \\
\hline$H_{N}$ & 0.6 & 0.4 & 0 & 12.2 & 0 & 0 \\
\hline $\mathrm{c}$ & 1.5 & & & & & \\
\hline$H_{c}$ & 0.8 & 0.9 & & & Clpo_N & \\
\hline $\mathrm{Cl}$ & 0.8 & 1.7 & 0.7 & & & \\
\hline $\mathbf{N}$ & 0.8 & 0.8 & 0 & 0.4 & & \\
\hline 0 & 0.5 & 2.1 & 0.1 & 0 & 0 & \\
\hline$H_{N}$ & 0.2 & 0.3 & 0 & 12.8 & 0 & 6 \\
\hline $\begin{array}{l}\mathrm{c} \\
\end{array}$ & 1.0 & & & & & \\
\hline$H_{c}$ & 1.2 & 0.6 & & & Clpo_o & \\
\hline $\mathrm{Cl}$ & 0.8 & 1.7 & 0.6 & & & \\
\hline $\mathbf{N}$ & 1.0 & 1.7 & 0 & 0 & & \\
\hline 0 & 1.0 & 0.5 & 0 & 0.4 & 0 & \\
\hline$H_{N}$ & 0.3 & 0.5 & 0 & 0 & 13.9 & 0 \\
\hline
\end{tabular}




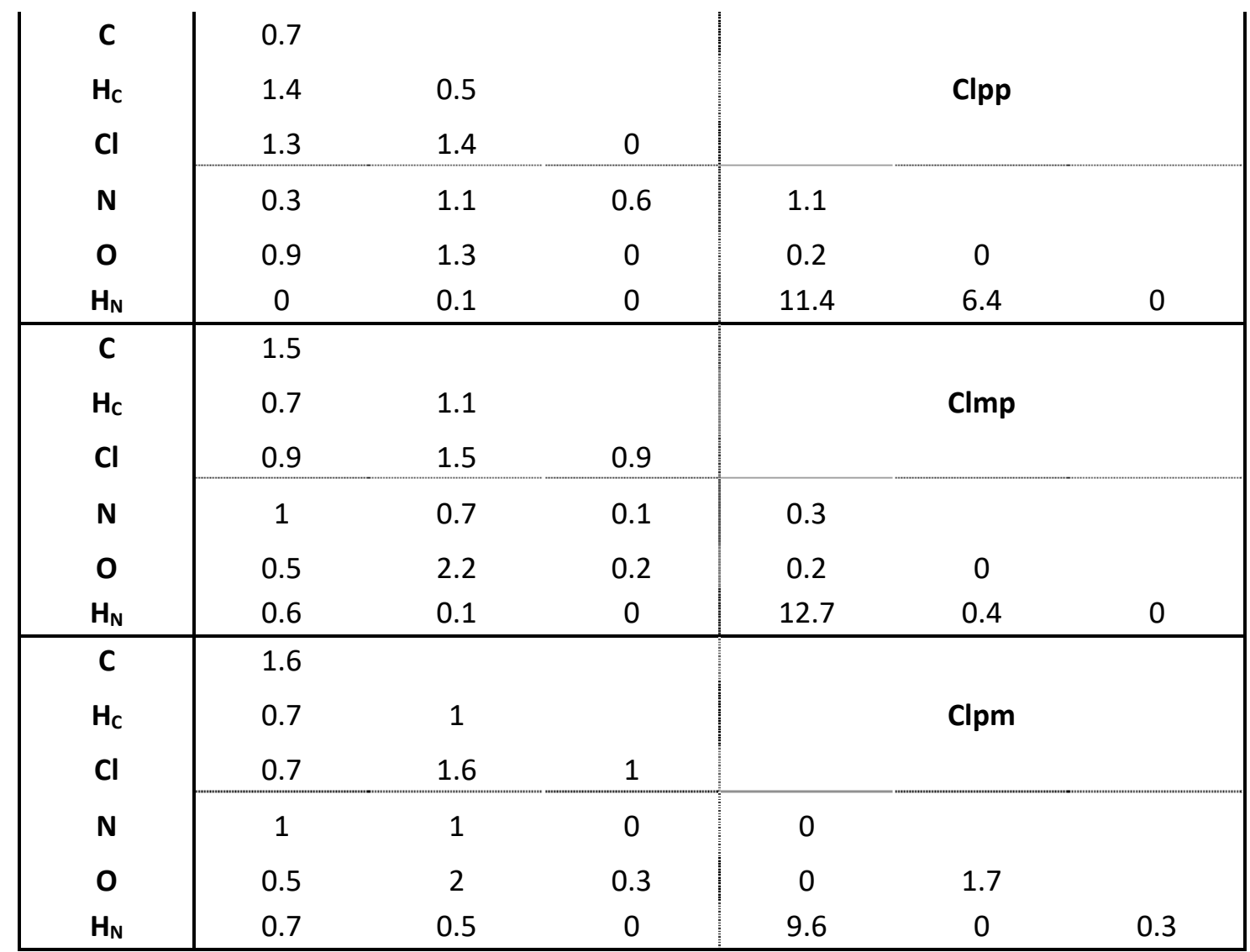

and

\begin{tabular}{|c|ccc|ccc|}
\hline Exy & $\mathbf{C}$ & $\mathbf{H}_{\mathrm{C}}$ & $\mathrm{Cl}$ & $\mathbf{N}$ & $\mathbf{0}$ & $\mathrm{H}_{\mathrm{N} / \mathrm{O}}$ \\
\hline $\mathbf{C}$ & 2.0 & & & & & \\
$\mathbf{H C}$ & 0.7 & 1.0 & & & $\mathrm{Clmm}^{\prime} \mathrm{H}_{2} \mathrm{O}$ & \\
$\mathrm{Cl}$ & 0.5 & 1.8 & 0.2 & & & \\
$\mathbf{N}$ & 1.1 & 0.3 & 1.1 & 0.0 & & \\
$\mathbf{O}$ & 0.2 & 1.5 & 1.1 & 0.0 & 0.0 & \\
$\mathrm{H}_{\mathrm{N} / \mathrm{O}}$ & 0.4 & 0.9 & 0.7 & 3.9 & 3.0 & 0.2 \\
\hline
\end{tabular}


Table S11

The \% contacts are regrouped by interactions between hydrophobic $\left(\mathrm{C}, \mathrm{H}_{\mathrm{C}}, \mathrm{Cl}\right)$ and hydrophilic $\left(\mathrm{O}, \mathrm{N}, \mathrm{H}_{\mathrm{N}}\right)$ atom types as well as cross interactions.

\begin{tabular}{|l|ccc|}
\hline \% contacts & hydrophobic & hydrophilic & cross \\
\hline Clmo & 80 & 7 & 13 \\
Clom & 77 & 5 & 18 \\
Cloo & 77.5 & 5 & 17.5 \\
Clop & 76 & 4 & 20 \\
Clpo_N & 78 & 5 & 17 \\
Clpo_0 & 77 & 5 & 18 \\
Clpp & 79 & 6 & 14 \\
Clmp & 77 & 4.5 & 18.5 \\
Clpm & 76.5 & 4 & 19.5 \\
\hline average & 78 & 5 & 17 \\
ssd & 1.4 & 1.2 & 2.1 \\
\hline
\end{tabular}


Table S12.

Correlation coefficient $c$ between the different enrichment ratios of the nine non-hydrated Clxx crystal structures. The $c$ values with the largest magnitude are in bold characters. Numbers highlighted in yellow are discussed in the manuscript.

\begin{tabular}{|c|cccccccccc|}
\hline Contact & $\mathbf{C}: \mathbf{H}_{\mathbf{N}}$ & $\mathbf{C : C}$ & $\mathbf{N}: \mathbf{H}_{\mathbf{N}}$ & $\mathbf{N}: \mathbf{C}$ & $\mathbf{N}: \mathbf{N}$ & $\mathbf{O}: \mathbf{H}_{\mathbf{N}}$ & $\mathbf{O}: \mathbf{C}$ & $\mathbf{O}: \mathbf{N}$ & $\mathbf{0 : 0}$ & $\mathbf{C l}: \mathbf{H}_{\mathbf{N}}$ \\
\hline $\mathbf{H}_{\mathbf{N}}: \mathbf{H}_{\mathbf{N}}$ & -0.65 & 0.23 & 0.31 & -0.45 & -0.14 & -0.24 & 0.51 & 0.35 & -0.23 & 0.46 \\
$\mathbf{C : H}$ & & -0.65 & 0.23 & 0.31 & -0.45 & -0.14 & -0.24 & 0.51 & 0.35 & -0.23 \\
$\mathbf{C}: \mathbf{C}$ & & & 0.49 & 0.01 & $\mathbf{0 . 7 9}$ & -0.39 & -0.34 & $-\mathbf{0 . 7 9}$ & -0.40 & 0.44 \\
$\mathbf{N}: \mathbf{H}_{\mathbf{N}}$ & & & & 0.32 & 0.31 & -0.45 & -0.66 & -0.46 & -0.36 & 0.41 \\
$\mathbf{N}: \mathbf{C}$ & & & & & -0.34 & 0.19 & -0.89 & -0.19 & -0.14 & -0.09 \\
$\mathbf{N}: \mathbf{N}$ & & & & & & -0.41 & 0.02 & -0.63 & -0.18 & 0.30 \\
$\mathbf{O}: \mathbf{H}_{\mathbf{N}}$ & & & & & & & 0.14 & -0.10 & -0.13 & -0.18 \\
$\mathbf{O}: \mathbf{C}$ & & & & & & & & 0.41 & 0.32 & -0.22 \\
$\mathbf{O}: \mathbf{N}$ & & & & & & & & & 0.62 & -0.32 \\
$\mathbf{O}: \mathbf{O}$ & & & & & & & & & & -0.19 \\
\hline
\end{tabular}

\begin{tabular}{|c|c|c|c|c|c|c|c|c|c|c|}
\hline$H_{N}: H_{N}$ & -0.56 & 0.38 & -0.30 & -0.31 & -0.47 & 0.02 & -0.42 & -0.02 & 0.66 & -0.15 \\
\hline $\mathrm{C}: \mathrm{H}_{\mathrm{N}}$ & 0.46 & -0.56 & 0.38 & -0.30 & -0.31 & -0.47 & 0.02 & -0.42 & -0.02 & 0.66 \\
\hline C:C & -0.42 & 0.11 & -0.53 & 0.46 & 0.56 & 0.56 & -0.64 & 0.02 & 0.46 & -0.50 \\
\hline $\mathrm{N}: \mathrm{H}_{\mathrm{N}}$ & 0.18 & -0.24 & 0.00 & 0.31 & 0.10 & 0.21 & -0.96 & -0.40 & 0.59 & -0.01 \\
\hline $\mathrm{N}: \mathrm{C}$ & 0.22 & -0.02 & 0.24 & 0.15 & 0.07 & -0.63 & -0.23 & -0.90 & 0.67 & -0.24 \\
\hline $\mathrm{N}: \mathrm{N}$ & -0.59 & -0.14 & -0.73 & 0.03 & 0.72 & 0.64 & -0.41 & 0.28 & 0.31 & -0.15 \\
\hline $0: H_{N}$ & -0.21 & 0.67 & 0.04 & -0.22 & -0.24 & -0.35 & 0.33 & 0.07 & 0.13 & -0.28 \\
\hline $0: C$ & -0.22 & 0.17 & -0.14 & -0.27 & -0.25 & 0.28 & 0.58 & 0.86 & -0.80 & 0.26 \\
\hline $\mathrm{O}: \mathrm{N}$ & 0.55 & -0.43 & 0.56 & -0.41 & -0.49 & -0.47 & 0.64 & 0.03 & -0.70 & 0.68 \\
\hline $0: 0$ & -0.19 & -0.32 & -0.20 & -0.22 & -0.34 & -0.32 & 0.45 & 0.20 & -0.56 & 0.77 \\
\hline $\mathrm{Cl}: \mathrm{H}_{\mathrm{N}}$ & -0.13 & -0.10 & -0.17 & -0.02 & 0.17 & 0.56 & -0.46 & 0.14 & 0.28 & 0.07 \\
\hline $\mathrm{Cl}: \mathrm{C}$ & & -0.41 & 0.96 & -0.16 & -0.26 & -0.43 & 0.01 & -0.52 & -0.05 & 0.16 \\
\hline Cl:N & & & -0.22 & 0.51 & -0.34 & 0.15 & -0.01 & 0.35 & -0.03 & -0.65 \\
\hline $\mathrm{Cl}: \mathrm{O}$ & & & & -0.19 & -0.35 & -0.51 & 0.15 & -0.47 & -0.09 & 0.07 \\
\hline $\mathrm{Cl}: \mathrm{Cl}$ & & & & & -0.29 & 0.29 & -0.43 & 0.04 & -0.04 & -0.52 \\
\hline$H_{c}: H_{N}$ & & & & & & 0.23 & -0.10 & -0.21 & 0.57 & -0.29 \\
\hline $\mathrm{H}_{\mathrm{c}}: \mathrm{C}$ & & & & & & & -0.34 & 0.65 & -0.09 & -0.19 \\
\hline$H_{c}: \mathbf{N}$ & & & & & & & & 0.24 & -0.59 & 0.19 \\
\hline $\mathrm{H}_{\mathrm{c}}: \mathrm{O}$ & & & & & & & & & -0.64 & 0.12 \\
\hline $\mathrm{H}_{\mathrm{c}}: \mathrm{Cl}$ & & & & & & & & & & -0.40 \\
\hline$c\left(\mathrm{E}, \mathrm{E}^{\prime}\right)$ & $\mathrm{Cl}: \mathrm{C}$ & $\mathrm{Cl}: \mathrm{N}$ & $\mathrm{Cl}: \mathrm{O}$ & $\mathrm{Cl}: \mathrm{Cl}$ & $\mathrm{H}_{\mathrm{c}}: \mathrm{H}_{\mathrm{N}}$ & $H_{\mathbf{c}}: \mathbf{C}$ & $H_{c}: \mathbf{N}$ & $H_{c}: O$ & $\mathrm{H}_{\mathrm{c}}: \mathrm{Cl}$ & $\mathbf{H}_{\mathrm{c}}: \mathrm{H}_{\mathrm{c}}$ \\
\hline
\end{tabular}




\section{Figure S13}

Scatterplot of $H_{N} . . . N$ distance vs. lattice electrostatic energy in the Clxx crystal structures with one molecule per asymmetric unit. Clpo_O was excluded due to absence of any $\mathrm{H}_{\mathrm{N} . . . \mathrm{N}}$ hydrogen bonding interaction.

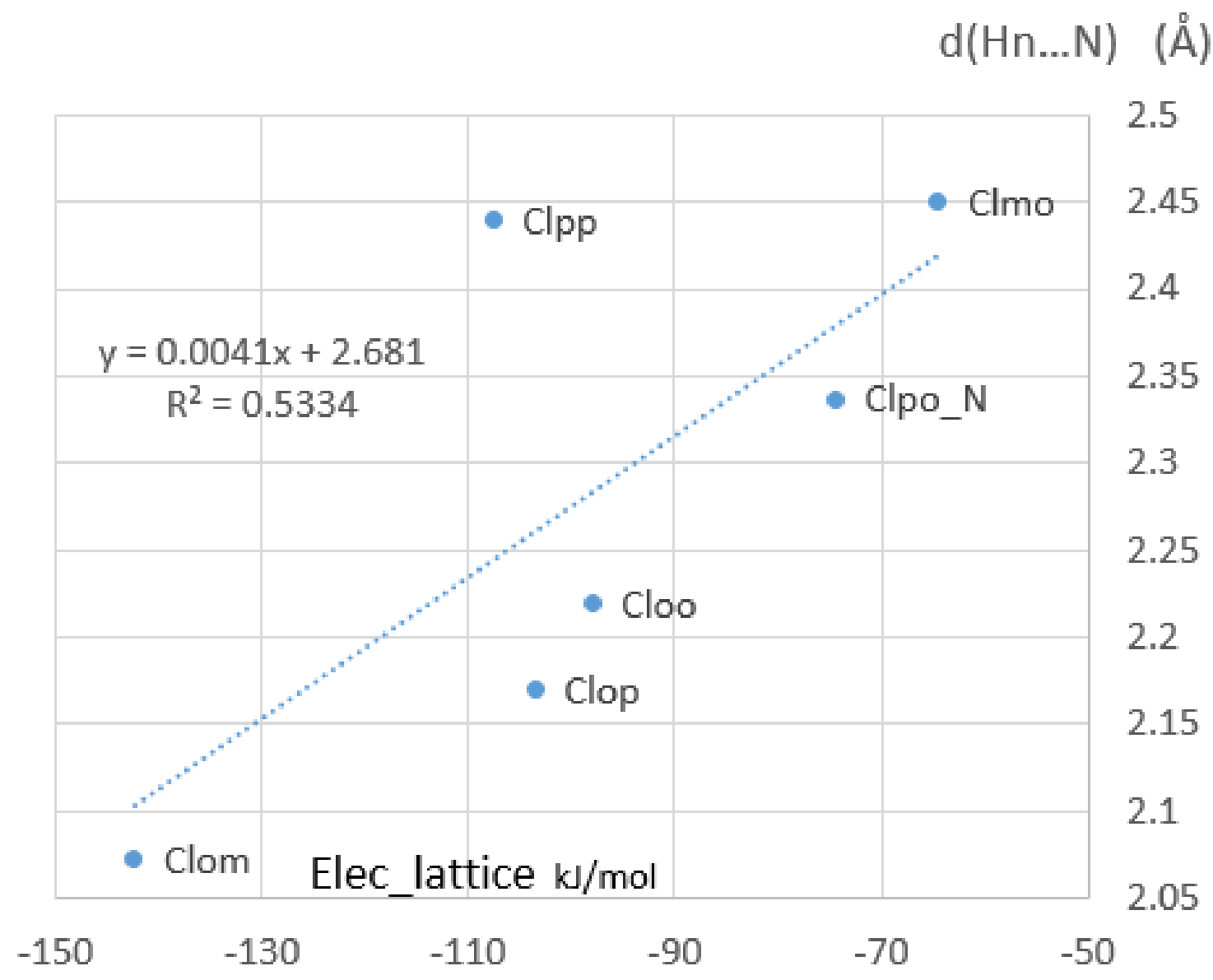




\section{Figure S14}

(a) Deformation of the transferred electron density in the Clom dimer (inversion center) in the $\mathrm{C}-\mathrm{Cl}$...Cl-C plane. Contour $+/-0.05$ e/ $\AA^{3}$.

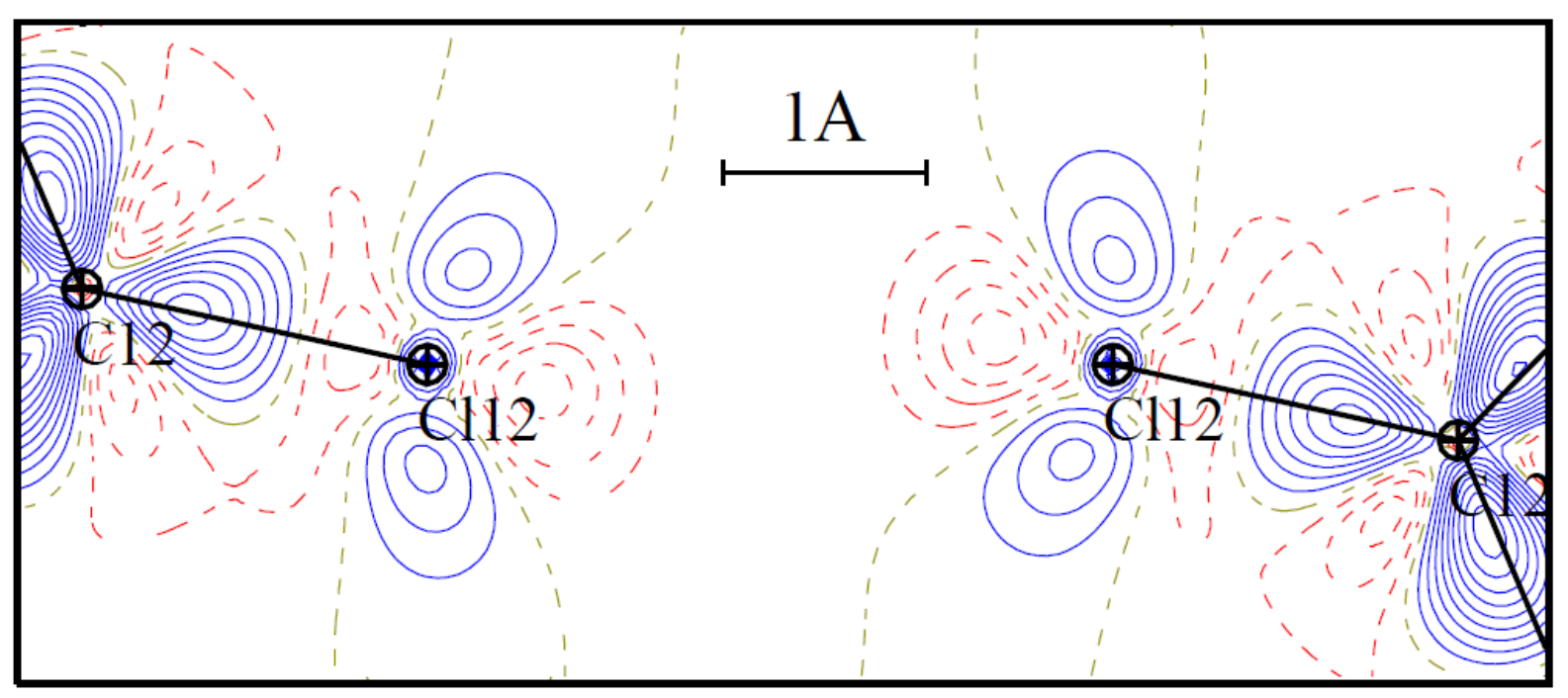

(b) Electrostatic potential generated by each chlorine atom alone.

Contours +/- 0.02 e/Å. Green and blue: positive; purple and red: negative, grey and yellow: zero contour.

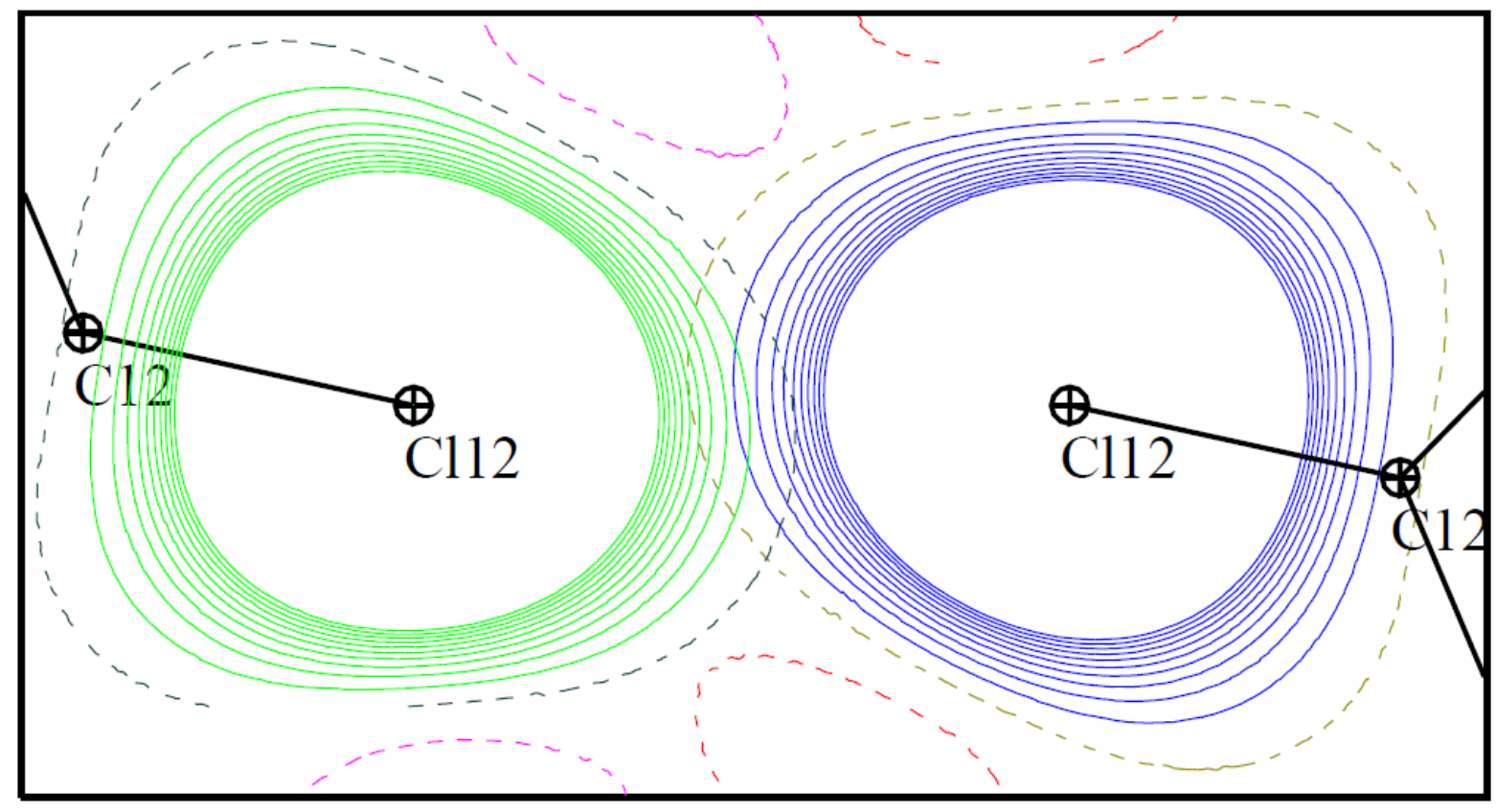

See Results and Discussion section in main manuscript:

$A b$ initio modelling and conformational analyses section (last couple of paragraphs). 